\title{
Image Guided FNAC in Deep Seated Lesions - An Epidemiological Study in and around Rajkot City
}

\section{Rajkumar P1*, Jagdish D Dalsania ${ }^{2}$ and Gauravi A Dhruva ${ }^{3}$}

${ }^{1}$ Final Year Resident Doctor Department of Pathology, Pandit Dindayal Upadhyay Medical College, India

${ }^{2}$ Associate Professor Department of Pathology, Pandit Dindayal Upadhyay Medical College, India

3Professor and Head, Department of Pathology, Pandit Dindayal Upadhyay Medical College, India

*Corresponding author: Rajkumar Pichai, Final Year Resident Doctor Department of Pathology, Pandit Dindayal Upadhyay Medical College, India, Tel: 8825725871; Email: suzell@outlook.com

\section{Abstract}

Fine needle aspiration cytology (FNAC) is the first choice of investigation and possibly the second best choice after biopsy in many lesions. The role of pathologists in both taking FNAC and interpreting the diagnosis is really challenging. If the lesion is so deep then the difficulty is increasing exponentially. In this study the deep seated lesions are biopsied and interpreted and the conclusion has been given mostly as malignant lesion in and around Rajkot city, Gujarat. The brief descriptive study and the analytical study has been done along with interpretation of results with exposure to tobacco(100\%) in a case of squamous cellcarcinoma of lung which is the most common deep seated lesion in my study. The present study has been done in IMAGE GUIDED FNAC IN DEEP SEATED LESIONS. And also to know the incidence of deep seated lesions, at P.D.U. medical college and hospital, Rajkot and knowledge about the epidemiology which mainly concentrate on incidence, prevalence among males \& females. In this study the result came as most common deep lesion is in the LUNGS, and the most common malignancy is squamous cell carcinoma of lung which predominates in males who are smokers and tobacco chewers.

Keywords: Parenchymal Disease; Pyogenic Abscess; Cytoplasm; Lymphoid Cells; Cysts; Carcinoma

Abbreviations: FNAC: Fine Needle Aspiration Cytology; CT: Computed Tomography; US: Ultrasonography; MRI: Magnetic Resonance Imaging; USG: Ultrasonogram; GISTs: Gastrointestinal Stromal Tumors; SDRPL: Splenic Red Pulp Lymphoma; IPMN: Intraductal Papillary-Mucinous Neoplasm; MCN:
Mucinous Cystic Neoplasm; NSE: Neuron-Specific Enolase; GANT: Gastrointestinal Autonomic Nerve Tumor; DSRBCT: Desmoplastic Small Cell Round Tumor; DIPNECH: Diffuse Idiopathic Neuroendocrine Cell Hyperplasia; TTF: Thyroid Transcription Factor; GCDFP: Gross Cystic Disease Protein; PSA: Prostate-Specific 
Antigen; IMFT: Inflammatory Myofibroblastic Tumor; EWS/PNET: $\quad$ Ewing's Sarcoma//Primitive Neuroectodermal Tumor; HCG: Human Chorionic Gonadotrophin.

\section{Introduction}

Fine needle aspiration cytology (FNAC) typically yields a small sample for cytological assessment, with limited or no architectural information. Fine needle aspiration biopsy and core biopsy often complement each other in facilitating and assisting in the diagnostic process. There have been continuous improvements in needles, biopsy guides and mechanical biopsy devices, together with technological advances in the major imaging methods of computed tomography (CT) and ultrasonography (US). The use of magnetic resonance imaging (MRI), and the development of stereotactic guidance. Previously inaccessible lesions can be safely sampled and many more areas of the body are now routinely biopsied under guidance.

Ultrasound guidance offers flexibility and speed, whereas CT often provides safer access for deeper tissue biopsy. Ultimately, the imaging modality which offers the best lesion visualization and safest route will dictate the biopsy pathway. Where practical, ultrasound is the preferred biopsy option, particularly given there is no ionizing radiation. In many instances, however, the nature and position of a lesion may mandate the use of CT guidance. Modern CT equipment allows for real-time assessment of the needle position using CT fluoroscopy, streamlining the biopsy process. The presence of a pathologist at the biopsy generally facilitates a more efficient process. The pathologist may direct the radiologist to a different area of the lesion, for example to the viable periphery rather than the central necrotic area of a solid lesion, and may request additional tissue for ancillary tests, such as special stains, electron microscopy or culture, or to determine the need for a core biopsy.

\section{Aims and Objectives}

To study the incidence of different deep seated lesions.

To find out the frequency of all types of inflammatory, benign and malignant lesions.

To study the cytological appearance of different lesions.

To compare and correlate the various deep seated lesions in relation to age, gender and site distribution.

To compare the present data with other similar studies.

\section{Material and Methods}

The present study was undertaken in cytology laboratory of Department of Pathology, P.D.U. medical college and hospital, Rajkot. All the patients, comes for image guided FNAC to P.D.U. hospital will be studied in the duration of July 2014 to June 2016. Most of the cases in our institute are coming from clinical department O.P.D.'s /wards mainly. A cytological study of total 130 cases of image guided FNAC was done. After getting written consent from patients FNA taken from involved (lesion) site with the help of image guidance by radiologist. After aspiration smears are made by spreading the aspirate in slides and immediately kept into methanol for fixation. Dry slides were also kept for special staining like MGG. Then, the fixed slides were stained with PAP, MGG \& hematoxylin and eosin, dried and mounted in DPX and then microscopy was done. The relevant clinical details and laboratory investigations were collected from the hospital case sheet.

\section{Observations and Results}

The present study was conducted from July 2014 to June 2016, a time period of 2 years included a total of 130 cases and the study was carried out in cytopathology section, Department of Pathology, P. D. U. Government Medical College and Hospital, Rajkot (Tables 1-7).

\begin{tabular}{|c|c|c|}
\hline Age (years) & Number of cases & Mean age (yrs) \\
\hline $0-10$ & 3 & 8 \\
\hline $11-20$ & 6 & 24.12 \\
\hline $21-30$ & 4 & 35 \\
\hline $31-40$ & 9 & 38.22 \\
\hline $41-50$ & 29 & 47.1 \\
\hline $\mathbf{5 1 - 6 0}$ & $\mathbf{3 3}$ & $\mathbf{5 8 . 3}$ \\
\hline $61-71$ & 30 & 66.76 \\
\hline $71-80$ & 15 & 75.53 \\
\hline $81-90$ & 1 & 88 \\
\hline Total & $\mathbf{1 3 0}$ & \\
\hline
\end{tabular}

Table 1: Distribution of deep seated lesions according to age.

In the present study age of the patient ranged from 0 90 years. Maximum number of cases 33 was seen in the age group 51-60 years followed by 29 in 41-50 years age group. Table 1 showed maximum number of patients (33) in the age group of (51-60 yrs) followed by 29 in 41-50 years. According to this study, it explained that the occurrence of symptoms due to deep seated lesions or coming to the clinical attention was in between 51 to 60 yrs of age (Charts 1-7). 


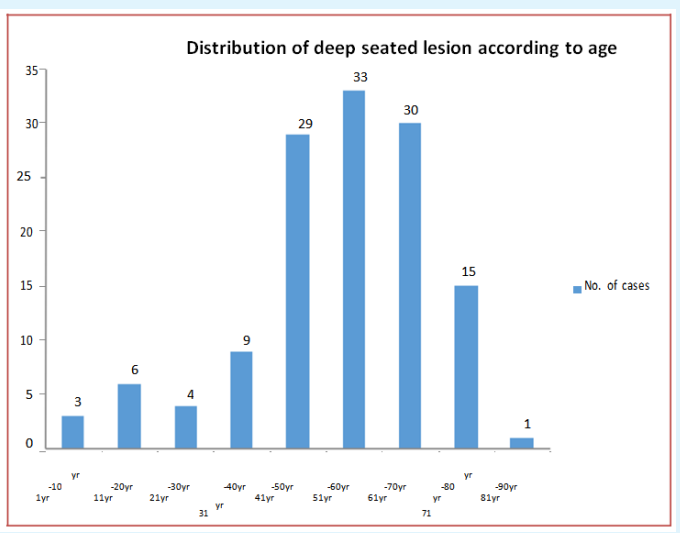

Chart 1: Distribution of deep seated lesions according to age.

Chart 1 showed graphical representation of deep seated lesions according to age.

\begin{tabular}{|c|c|c|}
\hline Gender & No. of cases & Percentage (\%) \\
\hline Male & 97 & 73.84 \\
\hline Female & 33 & 26.15 \\
\hline Total & $\mathbf{1 3 0}$ & $\mathbf{1 0 0}$ \\
\hline
\end{tabular}

Table 2: Distribution of deep seated lesions according to gender.

A male predominance was seen in the present study consisting of 130 cases, with 97 (73.84\%) being males and $33(26.15 \%)$ being females. Male to female ratio was 2.82:1.

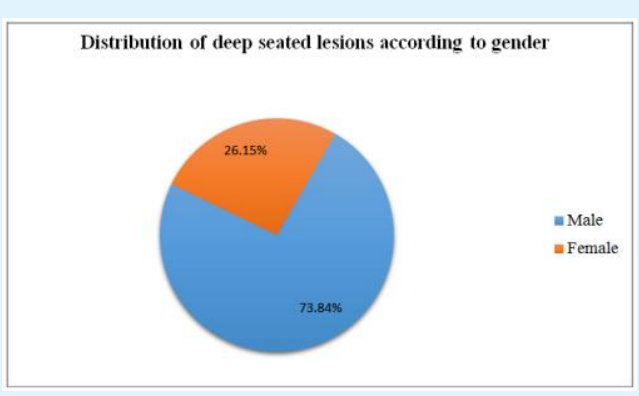

Chart 2: Distribution of deep seated lesions according to gender.

\begin{tabular}{|c|c|c|}
\hline Imaging methods & No. of cases & Percentage (\%) \\
\hline USG & 113 & 86.92 \\
\hline CT & 17 & 13.07 \\
\hline OTHERS & 0 & 0 \\
\hline Total & $\mathbf{1 3 0}$ & $\mathbf{1 0 0}$ \\
\hline
\end{tabular}

Table 3: Imaging Methods.
In the present study out of 130 cases, 113 (86.92\%) were using ultrasonogram (USG) for imaging and 17 $(13.07 \%)$ were using computed tomography for imaging.

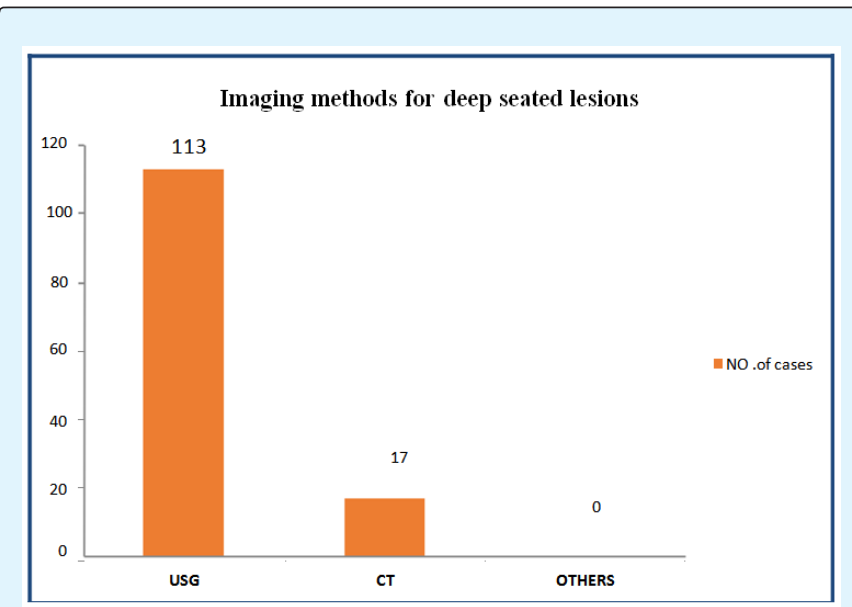

Chart 3: Imaging methods for deep seated lesions.

\begin{tabular}{|c|c|c|}
\hline Sites & $\begin{array}{c}\text { No. of } \\
\text { cases }\end{array}$ & $\begin{array}{c}\text { Percentage } \\
\text { (\%) }\end{array}$ \\
\hline Lung & 90 & 69.23 \\
\hline Abdomen & 9 & 6.92 \\
\hline Liver & 8 & 6.15 \\
\hline Kidney & 3 & 2.30 \\
\hline Medisatinum & 3 & 2.30 \\
\hline Pancrea & 2 & 1.54 \\
\hline Pleura & 2 & 1.54 \\
\hline Pelvis & 2 & 1.54 \\
\hline Hypochondrium & 2 & 1.54 \\
\hline Ascending colon & 1 & 0.77 \\
\hline Iliac fossa & 1 & 0.77 \\
\hline Right sided neck \&cheek & 1 & 0.77 \\
\hline swelling & 1 & 0.77 \\
\hline Epigastric\&iliac lump & 1 & 0.77 \\
\hline Retroperitoneum & 1 & 0.77 \\
\hline Right lumbar & 1 & 0.77 \\
\hline Liver \&kidney & 1 & 0.77 \\
\hline Lung \&renal & 1 & 0.77 \\
\hline Ear fossa & 130 & 100 \\
\hline Total &
\end{tabular}

Table 4: Sites involved in deep seated lesions.

In the present study out of 130 cases, 90 (69.23\%) were arising from lung, $9(6.92 \%)$ were from abdomen and $8(6.15 \%)$ were from liver. 


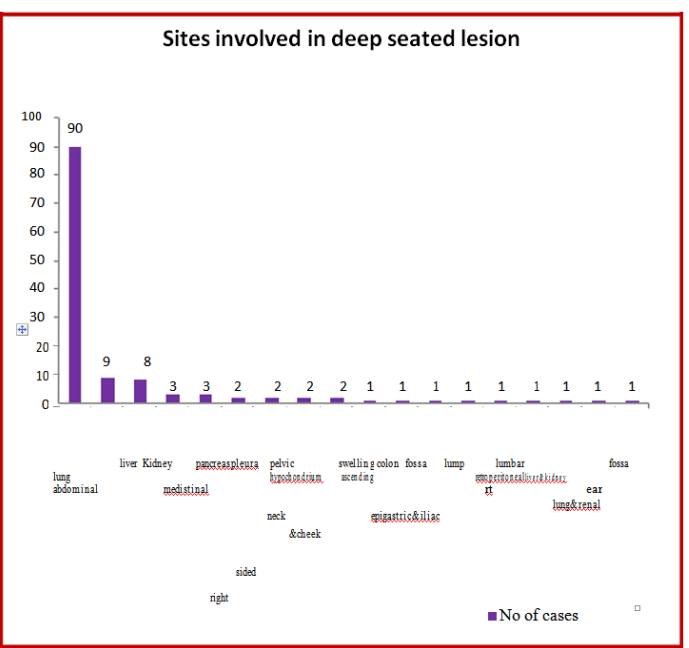

Chart 4(A): Sites involved in deep seated lesion.

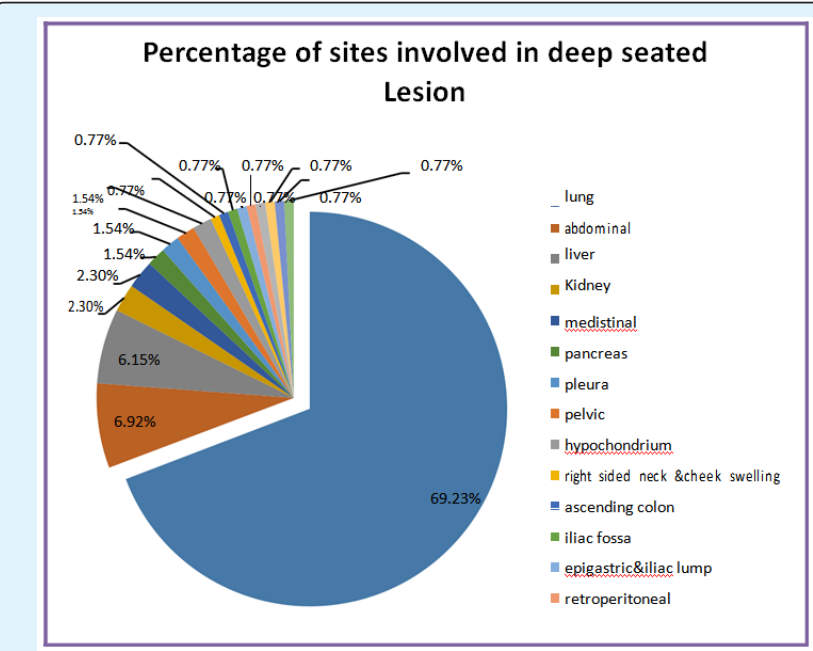

Chart 4 (B): Percentage of sites involved in deep seated lesion.

\begin{tabular}{|c|c|c|c|}
\hline \multicolumn{2}{|c|}{ Type of lesions } & Total & $\begin{array}{c}\text { Percentage } \\
\text { (\%) }\end{array}$ \\
\hline \multicolumn{2}{|c|}{ Non neoplastic lesions } & 11 & 8.46 \\
\hline \multirow{2}{*}{$\begin{array}{c}\text { Neoplastic } \\
\text { lesions }\end{array}$} & Benign lesions & 3 & 2.30 \\
\cline { 2 - 4 } & Malignant lesions & 97 & 74.62 \\
\cline { 2 - 4 } & $\begin{array}{c}\text { Benign/Malignant } \\
\text { lesions }\end{array}$ & 7 & 5.38 \\
\hline \multicolumn{2}{|c|}{ Others } & 2 & 1.54 \\
\hline \multicolumn{2}{|c|}{ No possible opinion } & 10 & 7.69 \\
\hline \multicolumn{2}{|c|}{ Total } & 130 & 100 \\
\hline
\end{tabular}

Table 5: Type of lesions.

The present study included total 130 cases of deep seated lesions. Out of these, 11 (8.46\%) were non neoplastic and $107(82.30 \%)$ were of neoplastic origin. Out of $107(82.30 \%)$ cases of neoplastic lesions, 3(2.30\%) were purely benign and $97(74.62 \%)$ were purely malignant lesions and 7 (5.38\%) cases were both benign and malignant. Neoplastic lesions were composed of the majority of cases followed by non neoplastic lesions.
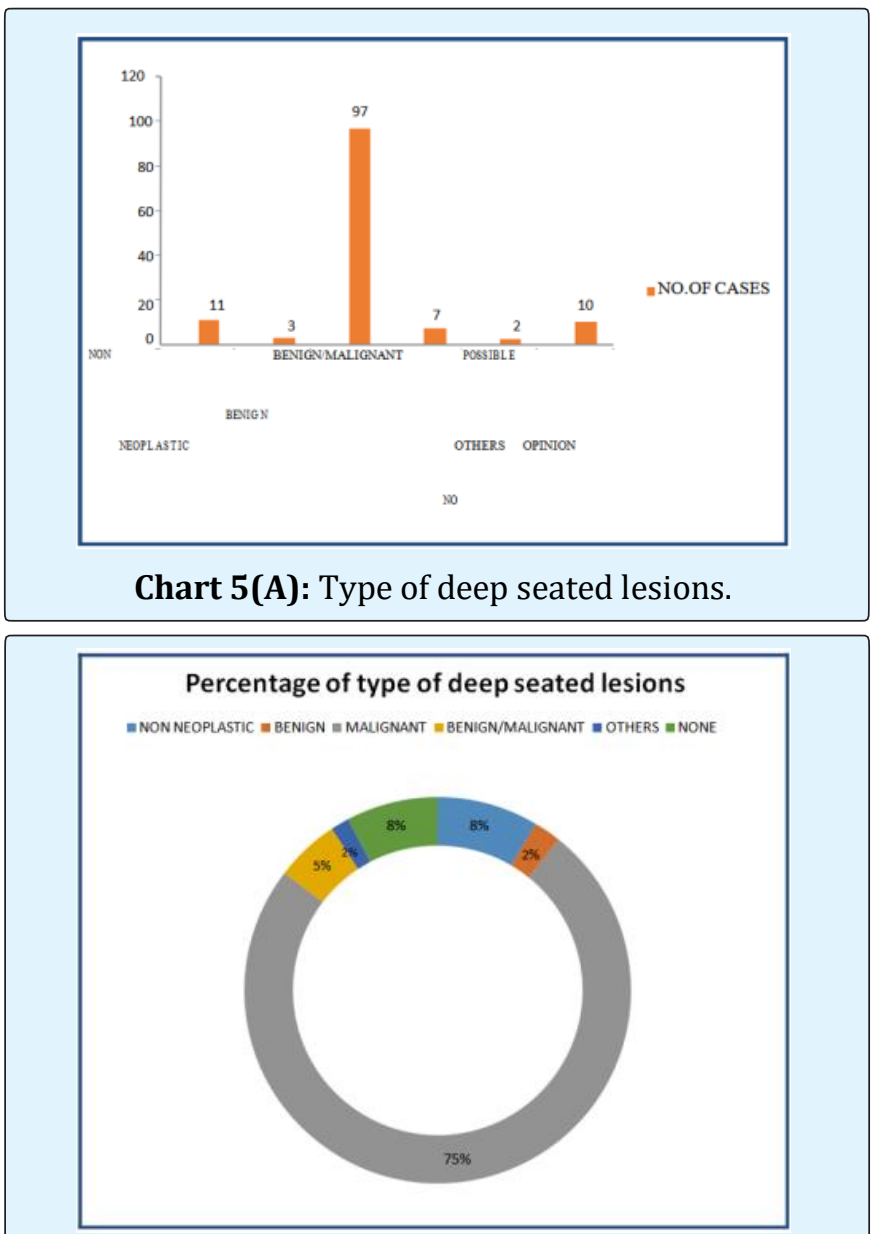

Chart 5(B): Percentage of type of deep seated lesions.

\begin{tabular}{|c|c|}
\hline Age (years) & Number of cases \\
\hline $0-10$ & 0 \\
\hline $11-20$ & 1 \\
\hline $21-30$ & 1 \\
\hline $31-40$ & 3 \\
\hline $41-50$ & 1 \\
\hline $51-60$ & 4 \\
\hline $61-70$ & 1 \\
\hline $71-80$ & 0 \\
\hline $81-90$ & 0 \\
\hline Total & $\mathbf{1 1}$ \\
\hline
\end{tabular}

Table 6: Distribution of non neoplastic lesion according to the age. 


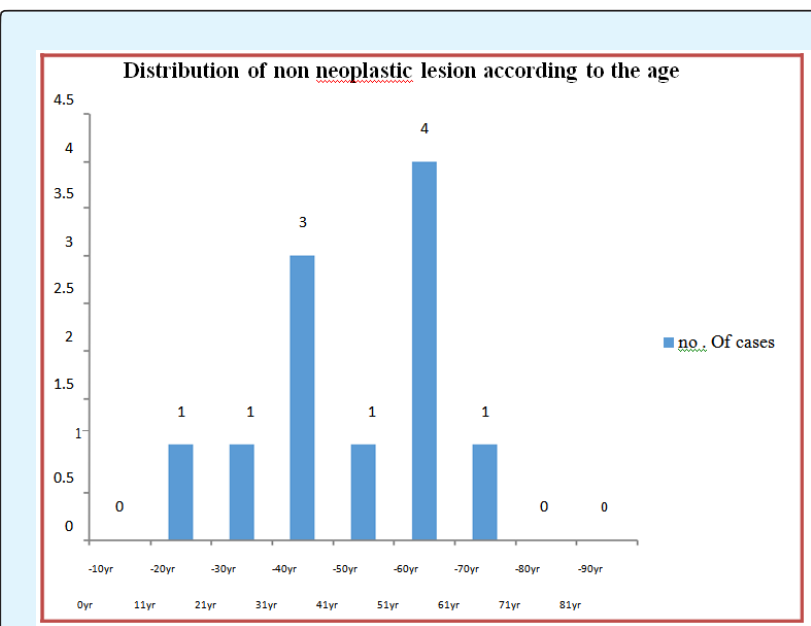

Chart 6(A): Distribution of non neoplastic lesion according to the age.

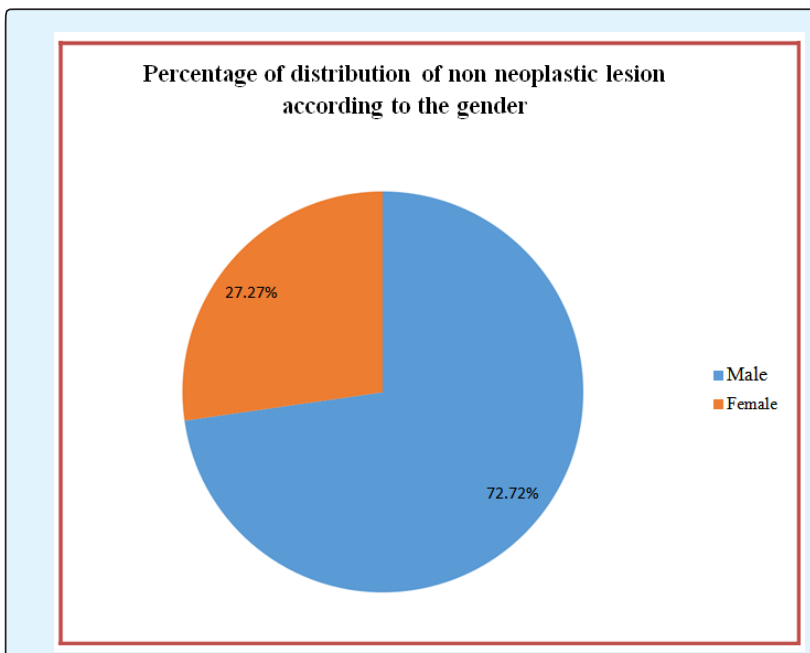

Chart 6(B): Percentage of distribution of nonneoplastic lesion according to the gender.

\begin{tabular}{|c|c|}
\hline Age (years) & Number of cases \\
\hline $0-10$ & 3 \\
\hline $11-20$ & 4 \\
\hline $21-30$ & 1 \\
\hline $31-40$ & 6 \\
\hline $41-50$ & 24 \\
\hline $51-60$ & 28 \\
\hline $61-70$ & 26 \\
\hline $71-80$ & 14 \\
\hline $81-90$ & 1 \\
\hline Total & $\mathbf{1 0 7}$ \\
\hline
\end{tabular}

Table 7: Distribution of neoplastic lesion according to the age.

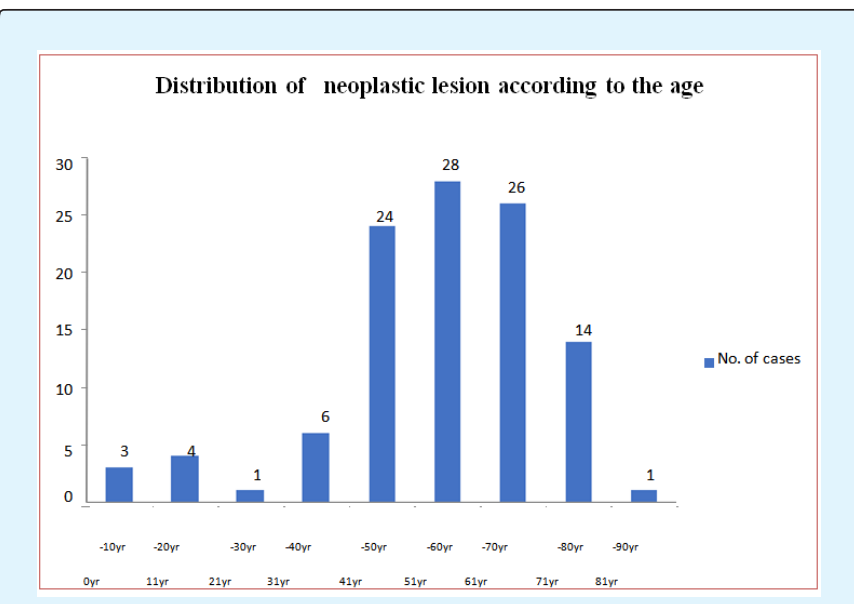

Chart 7(A): Distribution of neoplastic lesion according to the age.

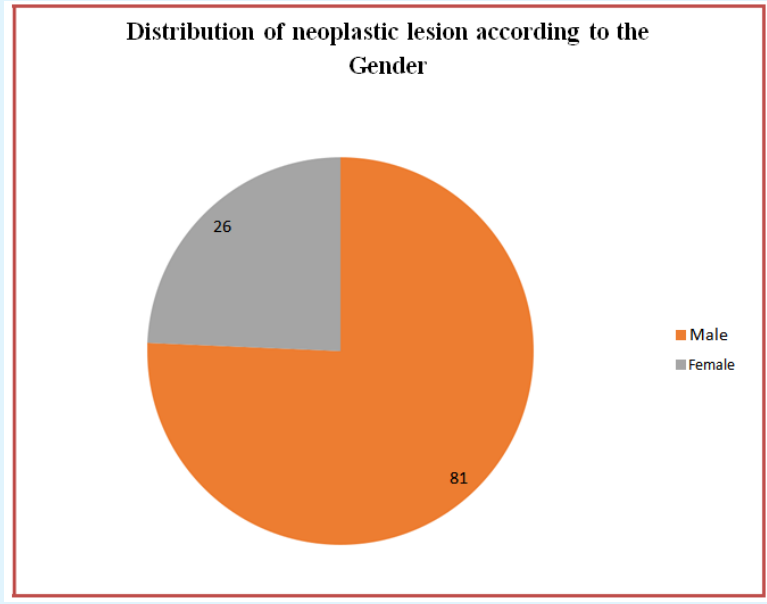

Chart 7(B): Distribution of neoplastic lesion according to the gender.

\section{Discussion}

\section{Liver}

\section{Diffuse parenchymal disease}

- Decreased cohesion of hepatocytes, Degenerative changes in hepatocytes,

- Hepatocytic regeneration-cells and nuclei vary in size, uneven chromatin pattern, large nucleoli, cytoplasmic staining is uneven, multinucleation and mitoses,

- Increased lymphocytes and Kupffer cells

- Increase of bile duct epithelial cells (cirrhosis),

- Cholestasis (variable)

Diffuse parenchymal diseases are

- cirrhosis,

- granulomatous inflammation 
- hemosiderosis and

- amyloidosis

Non neoplastic lesions:

- Congenital cyst

- Hydatid cyst

- Abscess

- Focal nodular hyperplasia

\section{Criteria for Diagnosis}

\section{Congenital cyst}

- Sparsely cellular,

- Cuboidal or columnar epithelial cells, usually bland but can be

- hyperplastic, dysplastic or rarely malignant,

- Ciliated cells (in ciliated hepatic foregut cyst) have basal nuclei without prominent nucleoli, abundant apical cytoplasm, terminal

- plates and fine delicate cilia,

- Macrophages and mucin may be present,

- Abundant bile pigment in Caroli's disease (Figure 1).

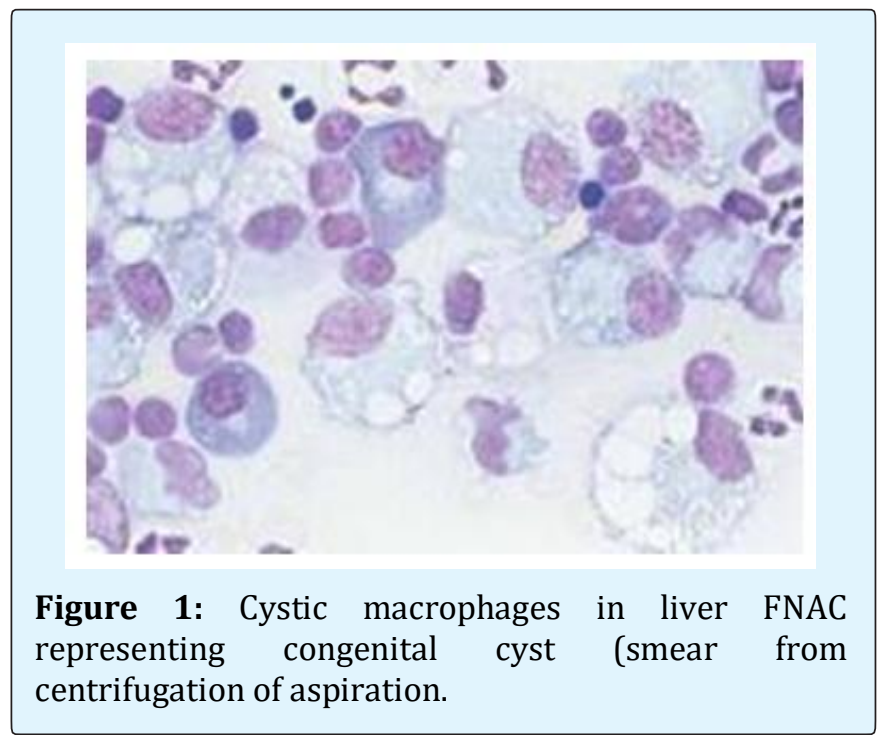

Hydatid cyst: During aspiration, fluid may spill into the abdomen and may produce anaphylaxis.

- The aspirated fluid may be clear or turbid and thick,

- Fragments of laminated membrane (stains pink in Papanicolaou smears and magenta with a PAS stain

- Detatched hooklets which are refractile and birefringent - Scolices are bulging, rounded, blunt 'heads' with attached suckers and rows of hooklets (Figures 2\&3).

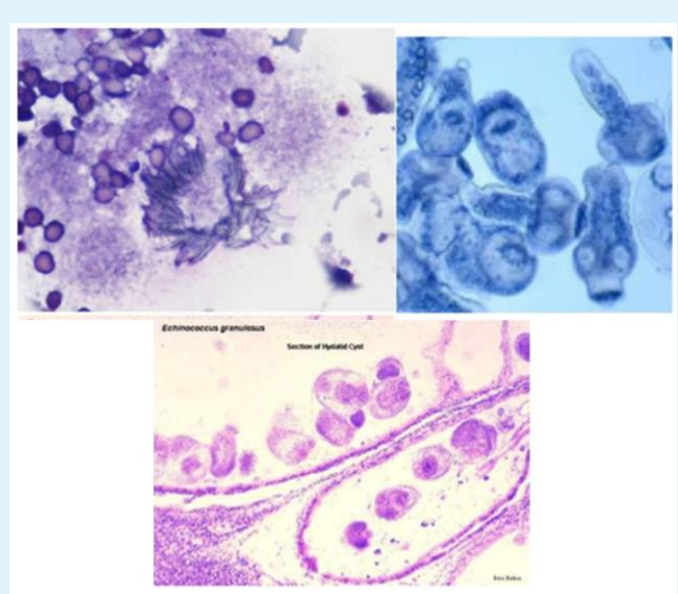

Figure 2: All the above three pictures clearly shows hooklets, full echinococci in aspirated fluid.

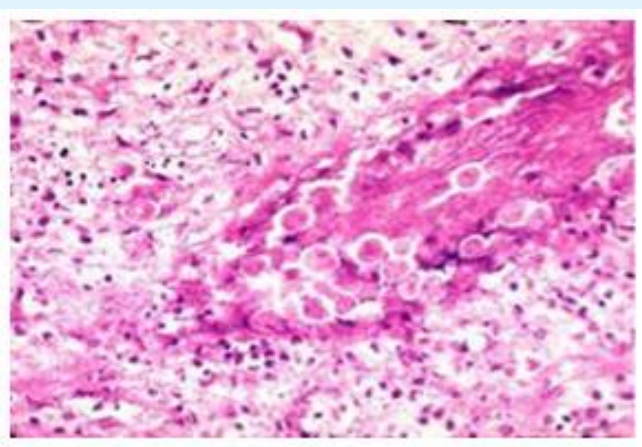

Figure 3: Trophozoites of E.histolytica in amebic liver abscess.

Abscess: Pyogenic abscess showed a marked neutrophil infiltrate, with necrotic debris. Hepatocytes from the periphery of the abscess may show considerable atypia. The predominant organism in pyogenic abscesses is Klebsiella. Amebic abscess due to Entamoeba histolytica, with contents likened to anchovy paste (thick reddishbrown semi-fluid material), shows abundant necrosis with fewer inflammatory cells. Trophozoites are not found in the central necrotic area; they should be sought in the viable periphery of the abscess. They are globular organisms, with an eccentric spherical nucleus showing a central clear zone with a dot-like karyosome and margination of chromatin. The cytoplasm is vacuolated and contains ingested red blood cells. Amoebae stain positive with PAS. They resemble foamy macrophages and may be missed if not suspected. 


\section{Focal nodular hyperplasia}

- Moderately cellular smears,

- Cohesive uniform benign hepatocytes in sheets or clusters

- Trabecular/sinusoidal architecture confirmed on a reticulin stain,

- No dispersal or stripped nuclei,

- Fragments of fibrous tissue with lymphocytes,

- Increased bile ductules (Figures 4 \& 5).
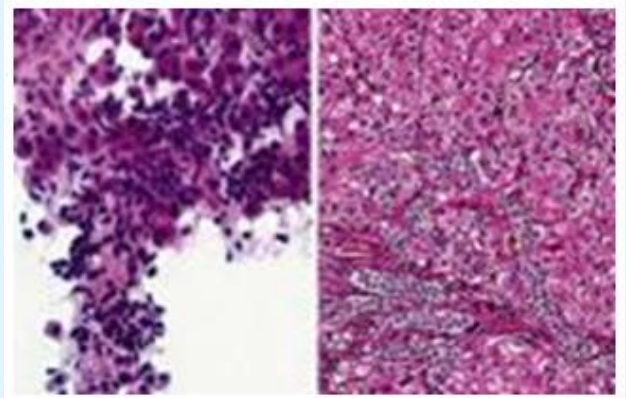

Figure 4: Focal nodular hyperplasia cyto and histo image.

Other non-neoplastic lesions: Nodular extramedullary hemopoiesis occurs typically in the setting of myeloproliferative disease and is recognized by the criteria of the triple cell lines-normoblasts, promyelocytes and megakaryocytes.

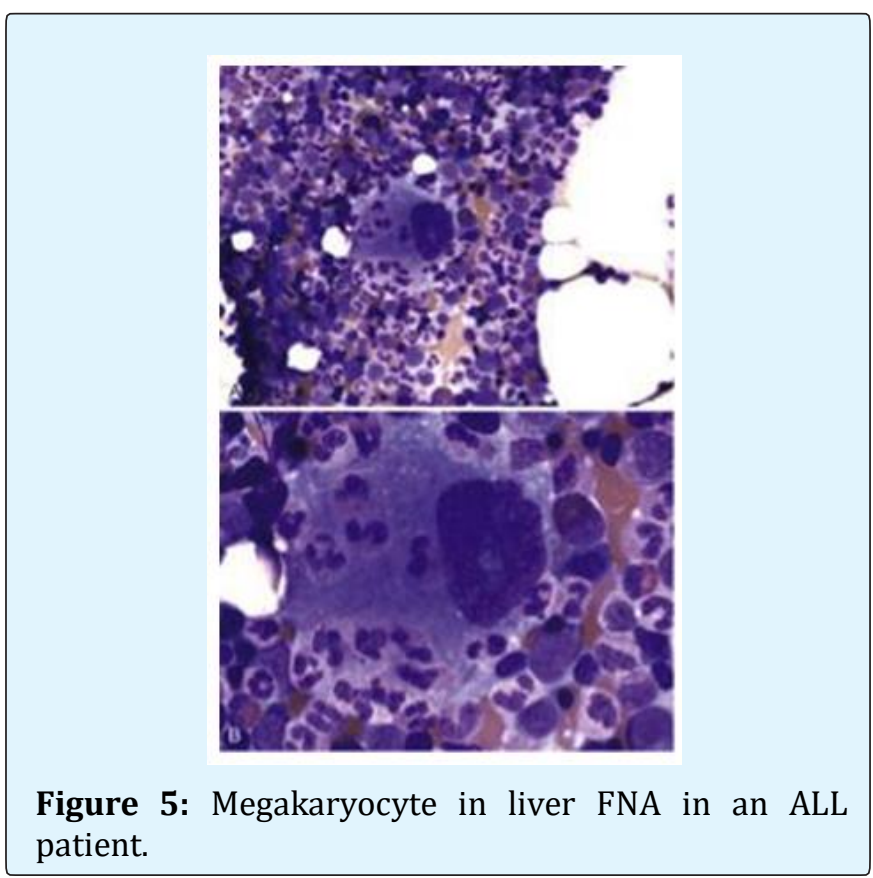

\section{Hepatobiliary cystadenoma}

- Abundant acellular or sparsely cellular fluid [1],

- Often degenerate bland cuboidal to columnar epithelial cells showing little atypia,

- Stromal fragments not usually included (Figure 6).

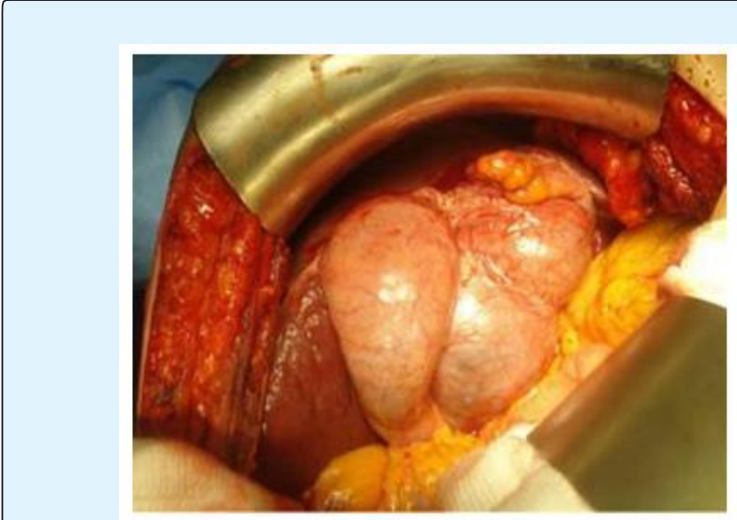

Figure 6: Large hepatobiliary cystadenoma causing obstructive jaundice.

\section{Liver Cell Adenoma}

- Moderate to markedly cellular smears arranged in clusters or tissue fragments [2],

- Monotonous cells resembling normal hepatocytes with pale or vacuolated cytoplasm,

- Absence of bile duct epithelium (Figure 7).

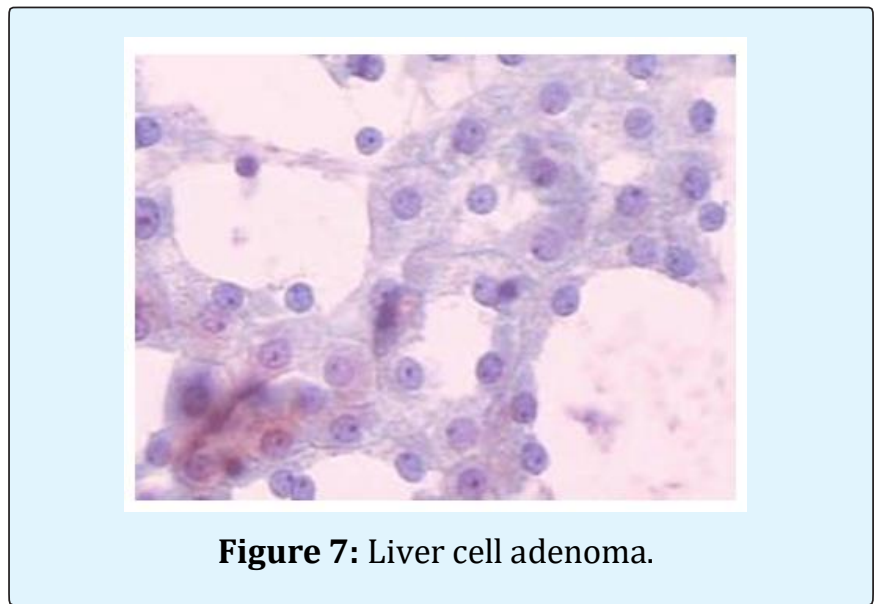

\section{Hepatocellular Carcinoma}

- Cellular smears,

- Neoplastic cells forming widened trabeculae, acini or multilayered sheets, 
- Endothelial cells lining cell groupings or small capillaries transgressing clusters of tumor cells,

- Polygonal cells with increased $\mathrm{N}$ : C ratio,

- Central round nuclei often with macronucleoli,

- Increased nuclear size and atypia with binucleation and multinucleation,

- Scant to abundant eosinophilic, granular cytoplasm; may be vacuolated,

- Dispersed cells including many atypical stripped nuclei,

- Intranuclear cytoplasmic inclusions,

- Intracytoplasmic eosinophilic fibrillary inclusions (hyaline bodies),

- Intracytoplasmic bile pigment and/or bile plugs between cells, green or yellow in Papanicolaou smears and greenish-black with MGG,

- Frequent mitoses,

- Bile duct epithelium absent,

- Loss of above characteristics with dedifferentiation (Figure 8).

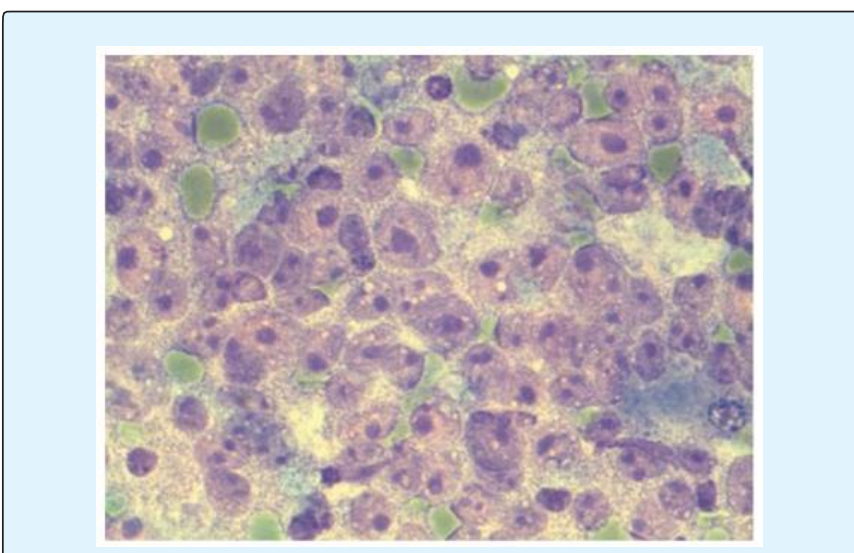

Figure 8: Malignant hepatocytes in HCC (prominent nucleoli is not a feature of HCC).

\section{Cholangiocarcinoma}

- Sheets, clusters and micro glandular arrangement showing nuclear crowding and overlapping [3],

- Decreased cell cohesion,

- Small to medium cuboidal/columnar cells resembling bile duct epithelium,

- Variable nuclear enlargement and pleomorphism,

- Prominent nucleoli in the less well-differentiated tumors,

- Delicate cytoplasm with fine vacuolization, positive for mucin,

- Occasionally fragments of stroma (Figure 9).

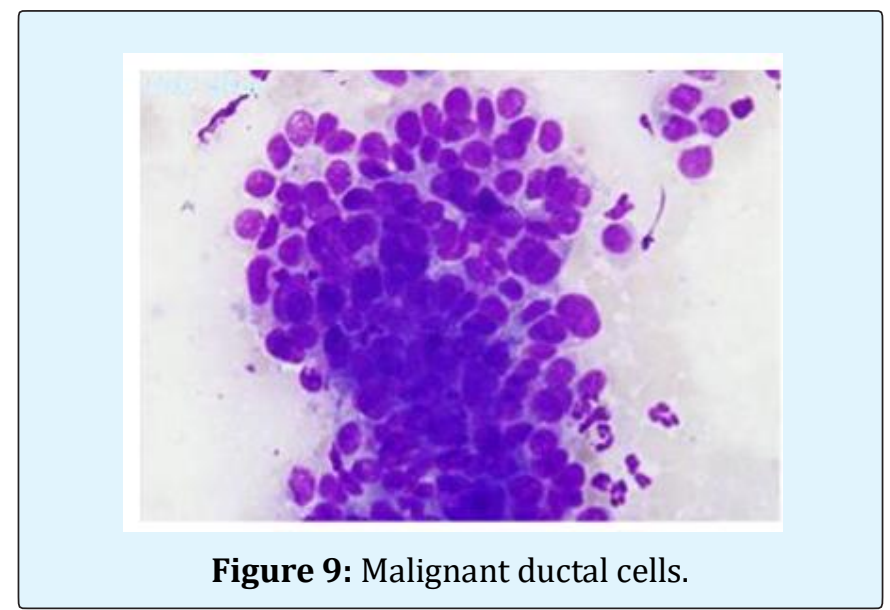

\section{Hepatoblastoma}

Hepatoblastoma is a rare, highly malignant tumor of infants and young children, the alpha fetoprotein level is significantly raised in approximately $90 \%$ of cases. The cytological appearance is that of a small round cell childhood tumor, with clusters, ribbons and rosettes of embryonal cells, which are small cells with a high $\mathrm{N}: \mathrm{C}$ ratio, oval to spindled nuclei, coarse chromatin, prominent, often multiple, nucleoli, and scant to moderate cytoplasm [4] (Figure 10).

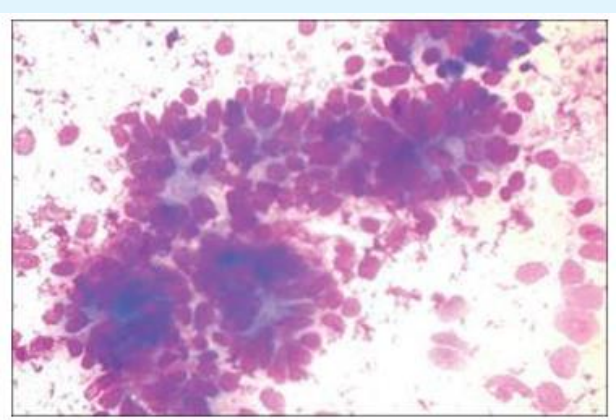

Figure 10: Hepatoblastoma showing pseudo rosettes in FNA of neonatal liver.

\section{Malignant lymphoma}

The liver tumor may be solitary, multiple or diffuse. Aspirates are usually markedly cellular with dispersed cells and scattered small aggregates without true cohesion, and lymphoglandular bodies are present in the background. Non-Hodgkin lymphoma of diffuse large B cell type (high grade) is the most common type [5] (Figure 11). 


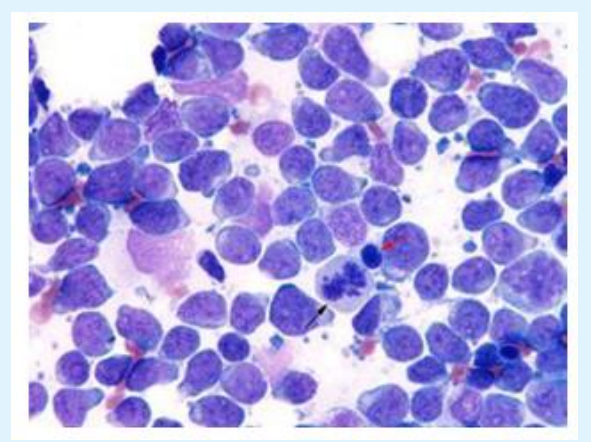

Figure 11: Mitotic spindle formation in lymphoma cells.

\section{GIST}

- Gastrointestinal stromal tumors (GISTs) are the most frequently encountered sarcoma in the liver. Most are metastatic from the stomach. Diagnosis is accomplished without difficulty with spindle morphology.

- Epithelioid variant, have small round dissociated cells with clear cytoplasm. The differential diagnosis in these cases is that of metastatic carcinoma. Immunocytochemical positivity for CD117 is diagnostic and CD34 may also be positive (Figure 12).

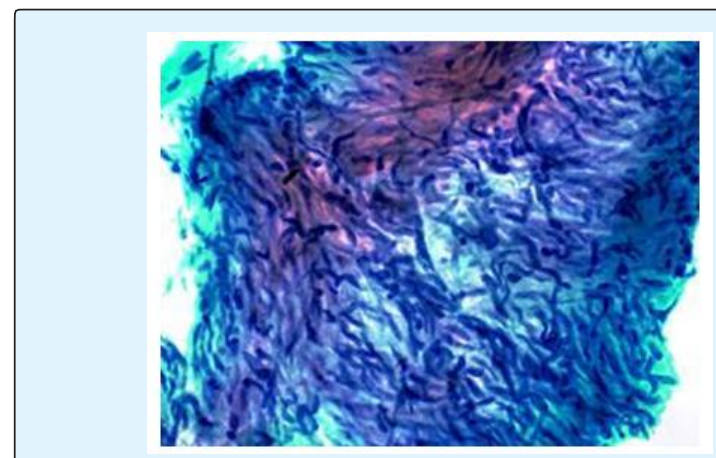

Figure 12: Classical spindle morphology of GIST.

\section{Metastatic Malignancy}

The liver is a common site of metastatic disease. Differentiation between primary and secondary tumors on imaging can be problematic (Table 8 \& Figure 13).

\begin{tabular}{|c|c|c|}
\hline Features & HCC & Metastatic Malignancy \\
\hline CD34 and factor VIII immunostaining & Present & Absent \\
\hline Cytological smears Glypican-3 & Positive & Euploive \\
\hline Flow cytometric studies & Aneuploid & Positive \\
\hline Cytokeratins 7 and 20 & Negative & Negative \\
\hline TTF-1 & cytoplasmic staining & nuclear staining (pulmonary adeno.ca) \\
\hline In situ hybridization albumin mRNA & Positive & . \\
\hline
\end{tabular}

Table 8: Metastatic Malignancy.

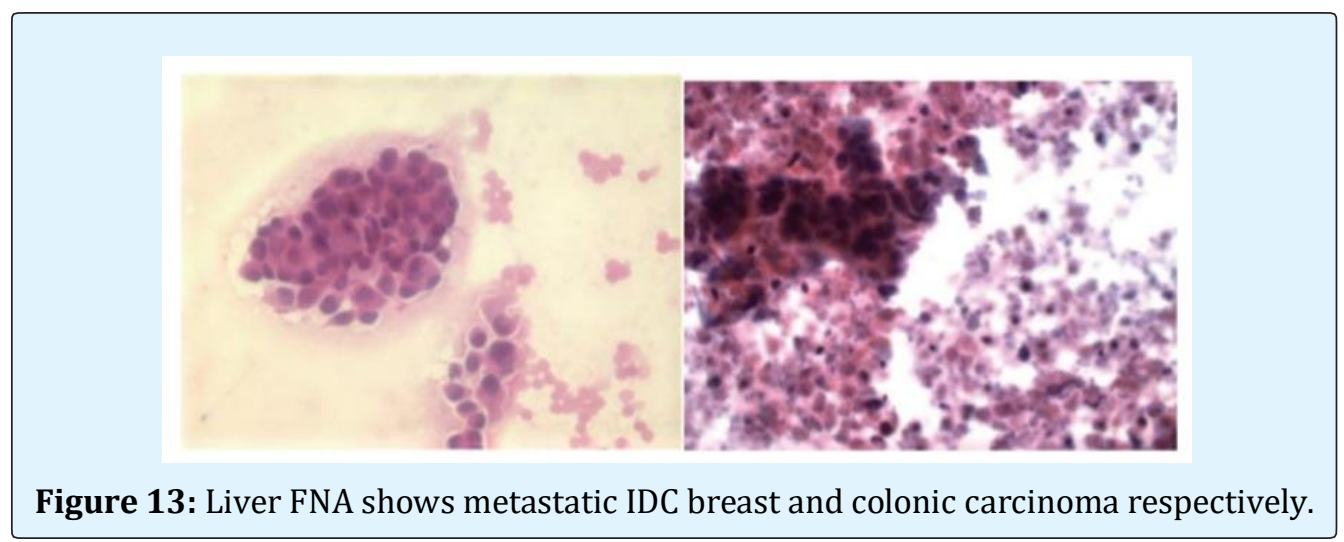

\section{Spleen}

Non-specific findings in splenomegaly:

- Abundant blood and platelet aggregates,
- Tissue fragments (lymphoid cells and endothelial cells),

- Numerous lymphoid cells,

- Endothelial cells and histiocytes. 


\section{Non-neoplastic Processes}

\section{Myeloid metaplasia:}

- The findings in myeloid metaplasia include normoblasts, myelocytes and megakaryocytes intermingled with the cells of normal splenic tissue.

- Normoblasts are easily recognized by their relatively small, round, hyperchromatic nuclei and their homogeneous, dense eosinophilic or amphophilic cytoplasm.

- Megakaryocytes may be mistaken for malignant neoplastic cells but should be recognizable by the giant, lobulated nucleus and the abundant, granular cytoplasm. Myelocytes have specific cytoplasmic granules.

- All these features are best seen in MGG-stained smears (Figure 14).

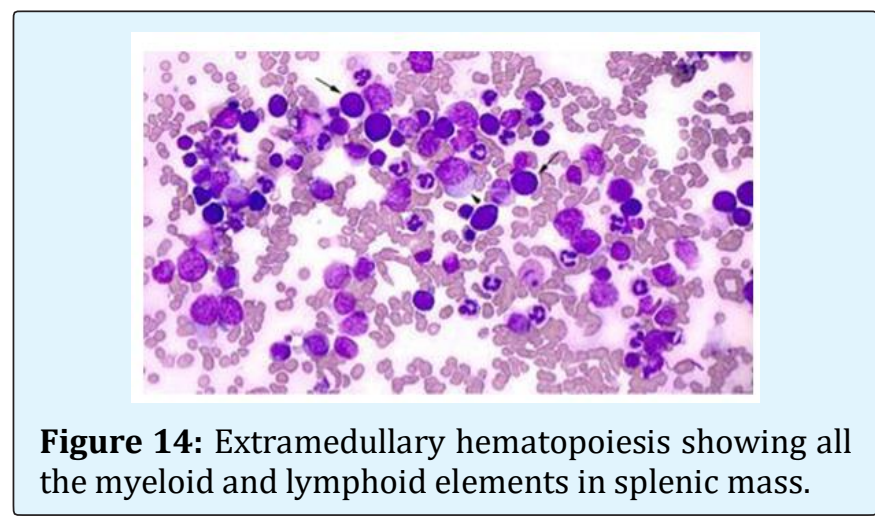

\section{Granulomatous Processes}

Histiocytes forming granulomatous clusters may be found in several unrelated conditions and do not permit a specific diagnosis when found in splenic aspirates. Wellformed granulomata of epithelioid histiocytes, with or without Langhans giant cells, suggest the main differential diagnoses of sarcoidosis and tuberculosis (Figures $15 \& 16$ ).

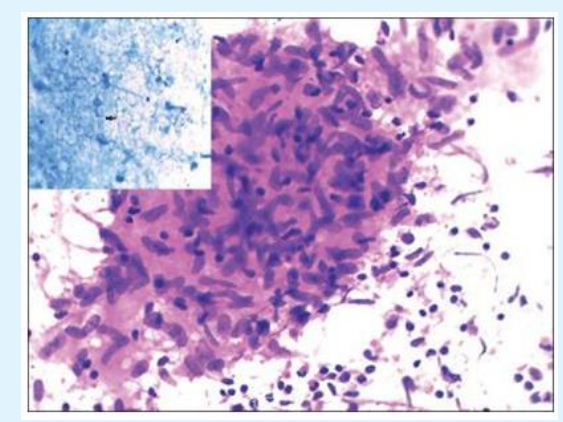

Figure 15: Epithelioid granuloma with AFB positivity in ZN stain.

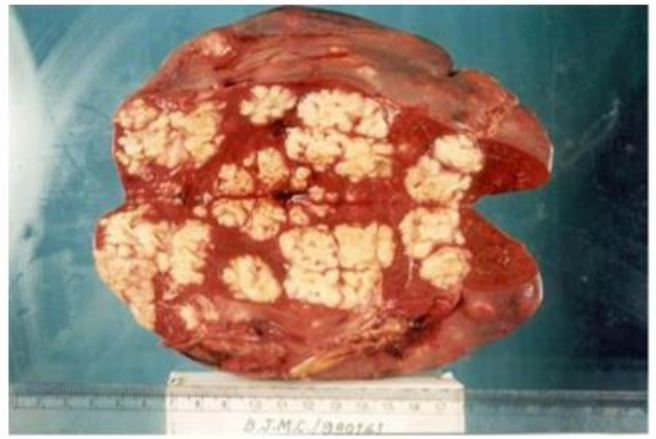

Figure 16: Extensive granulomas occupying large areas of spleen.

\section{Storage Disease}

Conspicuous large histiocytes with foamy cytoplasm indicate lipid storage disease. Histiocytes in Gaucher's disease have a characteristic striated cytoplasmic appearance (Figures 17 \& 18).

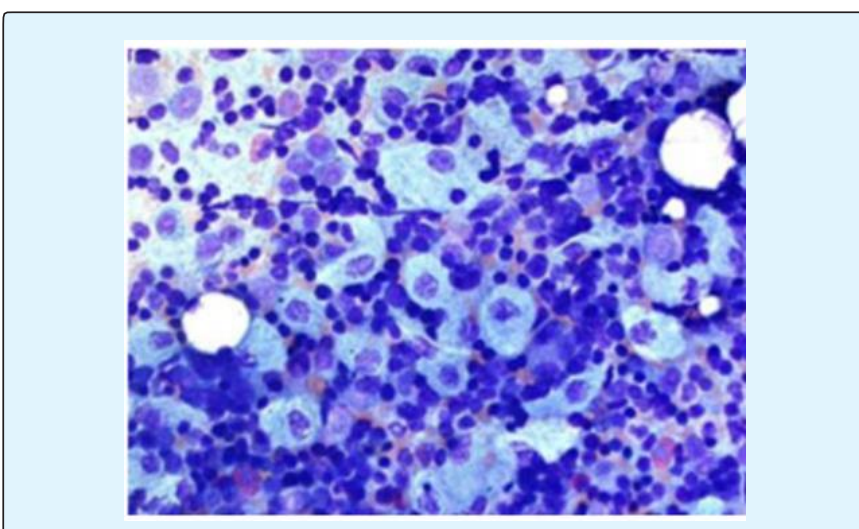

Figure 17: FNA of spleen- macrophages contain lysosomal accumulation of glucocerebroside.

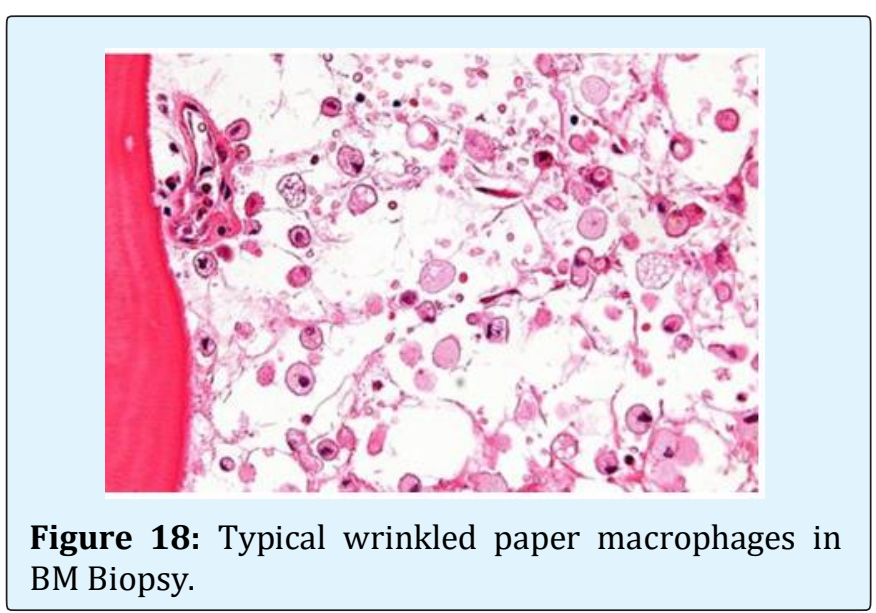


The foamy histiocytes seen in Niemann-Pick disease are less characteristic and the specific diagnosis rests on biochemical analyses. Pseudo gaucher cells in CML shouldn't be confused with gaucher cells (Figure 19).

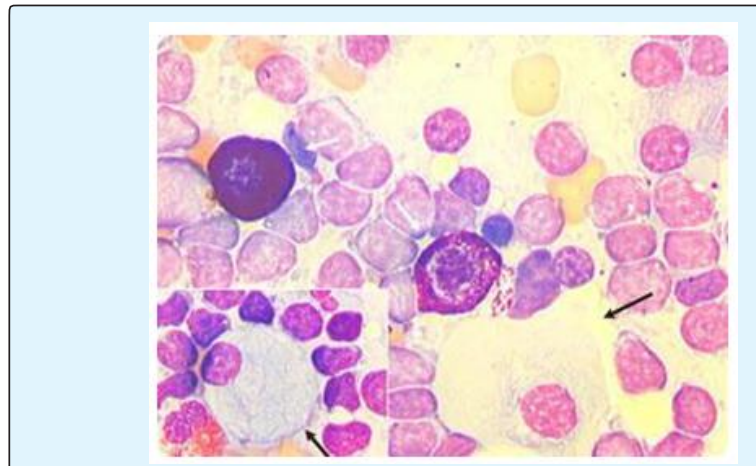

Figure 19: Pseudo gaucher cells in BMA of ALL.

\section{Neoplasms}

Malignant lymphoma: It includes, 1) Hairy cell leukemia, 2) Splenic marginal zone lymphoma,3) Splenic red pulp lymphoma(SDRPL), 4) CLL

Hairy cell leukemia: A monotonous population of abnormal lymphoid cells of B-cell immunophenotype, Nuclei ovoid or kidney shaped; larger and paler than those of normal lymphocytes, Pale basophilic cytoplasm; fine, hair-like cytoplasmic projections, Positive staining for tartrate-resistant acid phosphatase and for acid nonspecific esterase, Material sent for flow cytometry is useful in confirming the diagnosis. Immunophenotypic markers includes: CD 11a, CD 25, CD 103, and TRAP. Differential diagnosis should be considered with hairy cells in aspirate (Figure 20).

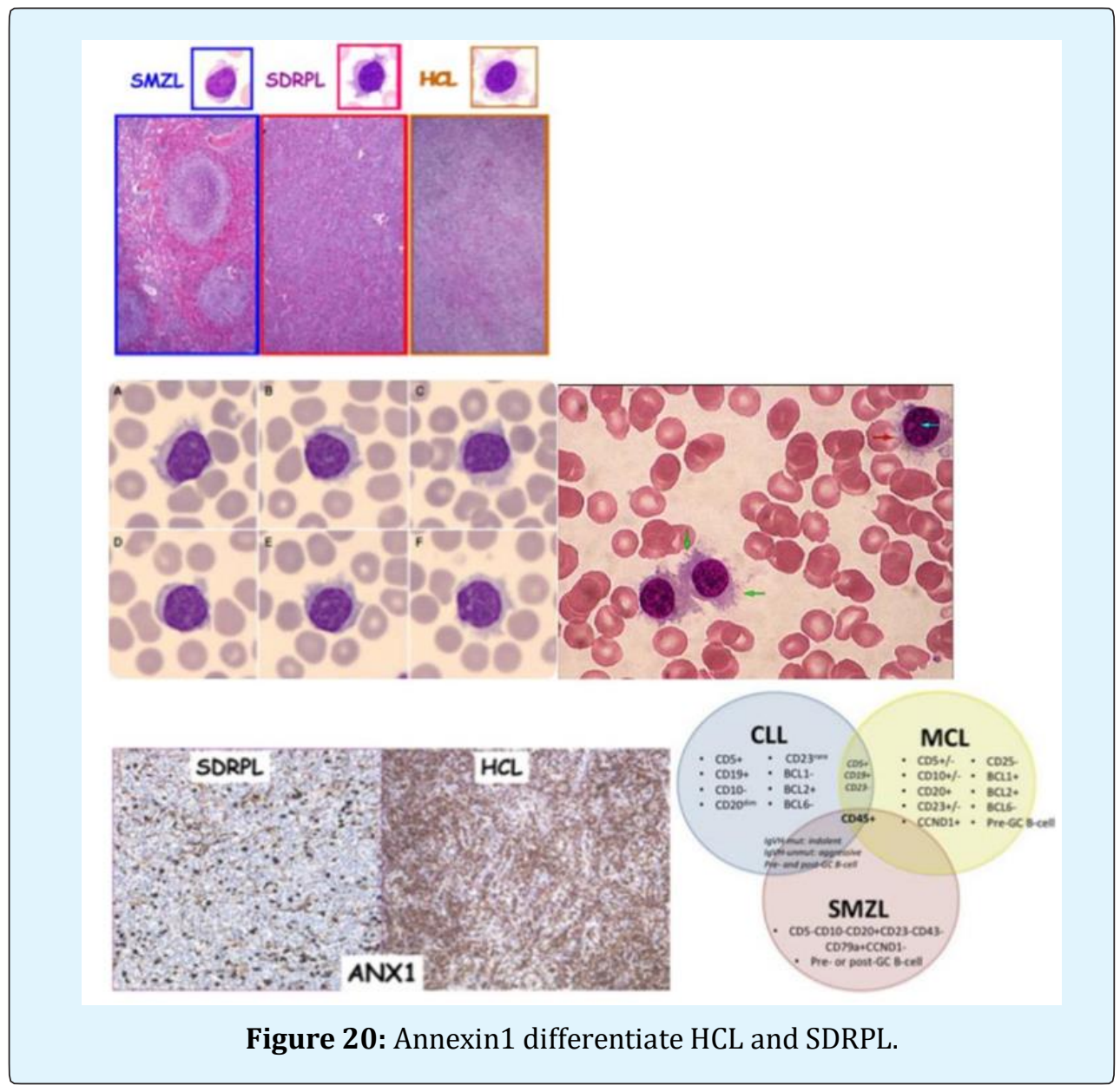

Vascular Tumors: Splenic hamartoma is consisting close differential (Figures $21 \& 22$ ). exclusively of red pulp tissue. Splenic angiosarcoma is the 

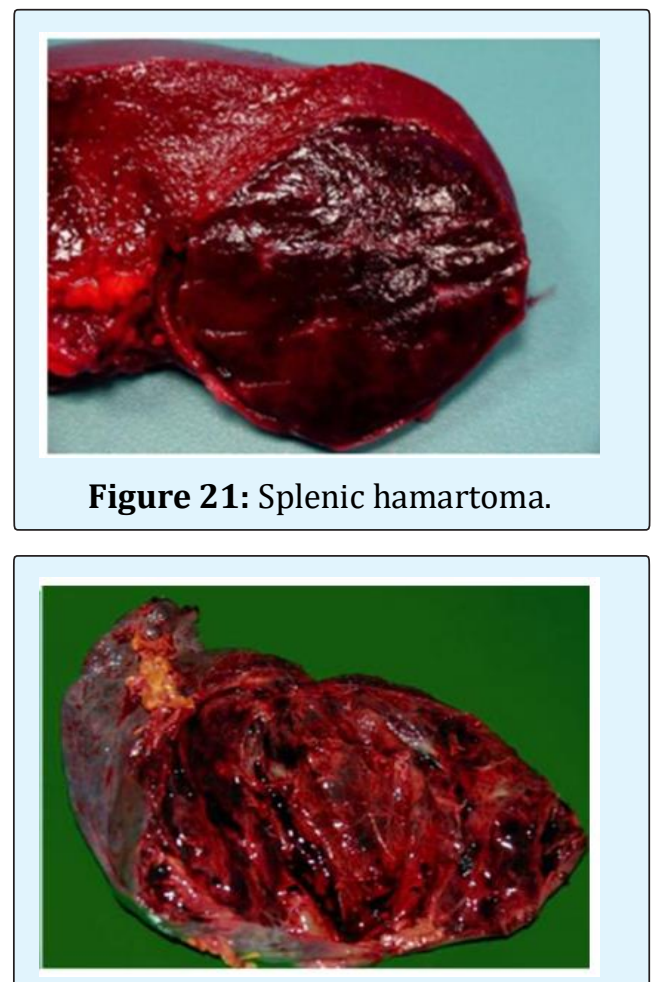

Figure 22: Splenic angiosarcoma.

Gross cut surface picture of both tumors show huge difference.

\section{Splenic Metastases}

Metastases may be solitary or multiple. Splenic FNA has value in diagnosis and staging to provide prognostic information and directing further management. The more common primary sites include breast, lung, colorectal and ovarian carcinoma and melanoma.

\section{The pancreas and Biliary Tract}

\section{Pancreatitis}

- Normal, degenerate or regenerating admixed acinar and ductal epithelial cells,

- Variable acute and chronic inflammatory cells,

- Foamy macrophages, some multinucleated,

- Abundant mucous or serous exudate and debris

- In severe chronic pancreatitis much of the exocrine parenchyma may be destroyed and be replaced by fibrous tissue. In such cases, remaining ductal, acinar and endocrine epithelium can show prominent reactive/regenerative atypia which can be difficult to distinguish from well-differentiated adenocarcinoma [6] (Figures 23 \& 24).

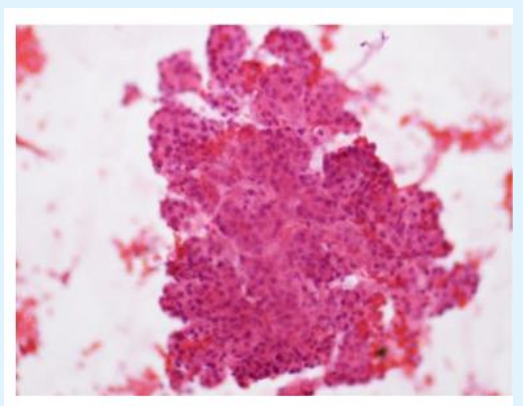

Figure 23: Normal Acinar component with few inflammatory cells.

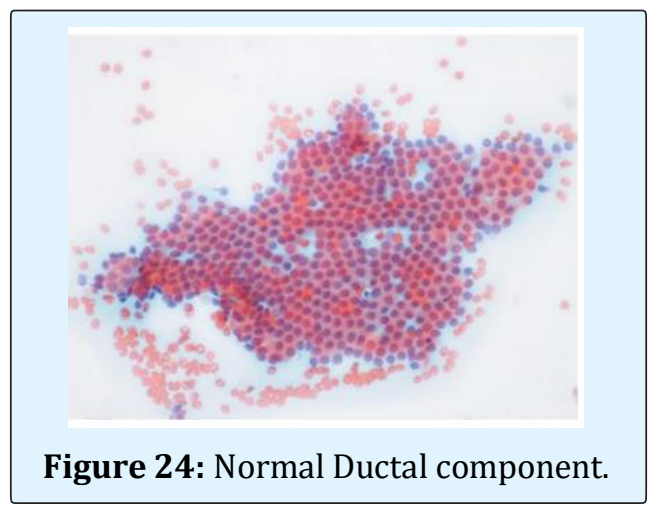

Cysts

- Cysts in the pancreas can be congenital or postpancreatiticpseudocysts.

- Some tumors are inherently and primarily cystic; in addition, any neoplasm, benign or malignant, may undergo cystic degeneration.

- Cytologic evaluation of aspirated cyst fluid is widely used method.

- Sensitivity of cytodiagnosis of pancreatic cystic lesions was considerably lower than that of solid lesions.

- Biochemical analysis of fluid from cystic lesions improves the sensitivity and specificity overcytologic assessment alone [7].

\section{Pseudocyst}

- These non-neoplastic cysts are the most common pancreatic cysts. Being fluid collections occurring in post-pancreatitic states, they are not true cysts .These cysts are lined by granulation tissue, not by epithelium.

- Aspiration yields copious turbid watery fluid which contains debris, occasional inflammatory cells including histiocytes, possible fibroblasts and bile, and perhaps rare fragments of epithelial tissue from the surrounding gland. 
- Raised enzyme levels, e.g. amylase and lipase, and low or absent tumor marker levels are found in the aspirated cyst fluid.

- The fluid is nonmucinous, but may demonstrate background fibrinous strands. Should the aspirate appear purulent, it should be submitted for culture to confirm secondary infection (Figure 25).

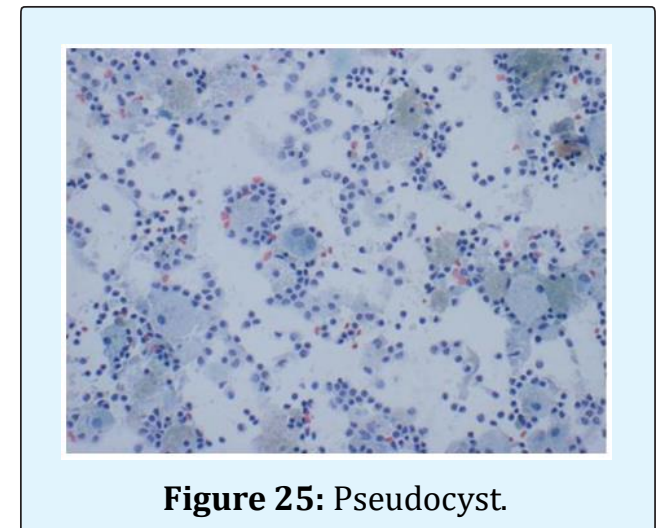

Figure 25: Pseudocyst.

\section{Serous Cystadenoma (Microcystic/ Glycogen- Rich Adenoma)}

These are uncommon benign lesions, often incidental findings in older individuals. Histopathologically, these tumors demonstrate classic microcysts, lined by bland, uniform glycogen-rich mucin-negative cells (PAS+). The aspirate is clear and watery, some are a cellular, while others contain a sparse exfoliate of monomorphic round cells with finely vacuolated, cytoplasm, glycogen-rich mucin-negative cells (PAS+)and centrally disposed nuclei containing fine chromatin. A PAS stain will highlight the glycogen-rich cytoplasm. Biochemical analysis of cyst fluid generally shows a low viscosity and low CEA and amylase levels. A recent study which combined imaging, biochemical and cytological data in reaching a diagnosis concluded that the preoperative diagnosis of serous cystadenomas remains a challenge [8-13] (Figure 26).

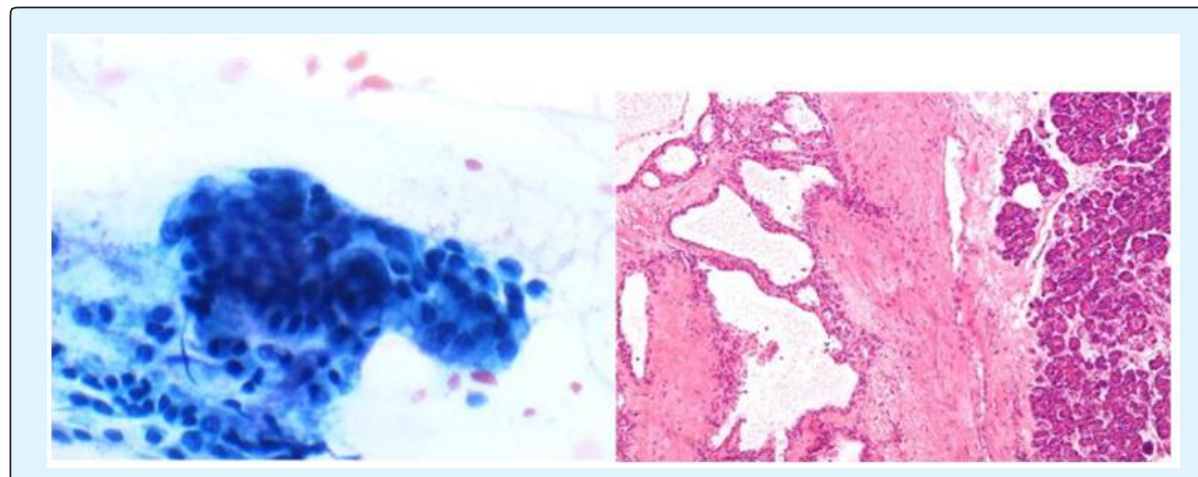

Figure 26: Serous cystadenoma cytology and corresponding histopathology.

\section{Solid-psedopapillary Neoplasm}

- Extremely cellular,

- Branching papillary fronds comprising central slender fibrovascular cores of myxoidstromalined by one or more layers of neoplastic cell which are exfoliating with dispersal,

- Acinar arrangements with central metachromatic material (pseudorosettes),

- Small epithelioid cells with bland round to oval nuclei, occasional longitudinal nuclear grooves, finely granular chromatin and inconspicuous nucleoli,
- Balls or globules of PAS-positive myxoidstroma and psammoma bodies,

- Background of foamy macrophages, multinucleated cells and necrosis.

Nuclei are round and even, with grooves but no major irregularities or significant pleomorphism. Chromatin is described as finely granular, without clumping or clearing. Small nucleoli may be appreciated and are occasionally multiple. In the background, foam cells, multinucleated giant cells, debris and laminated psammoma bodies reflect the cystic and papillary nature of the parent tumor [14] (Figure 27). 


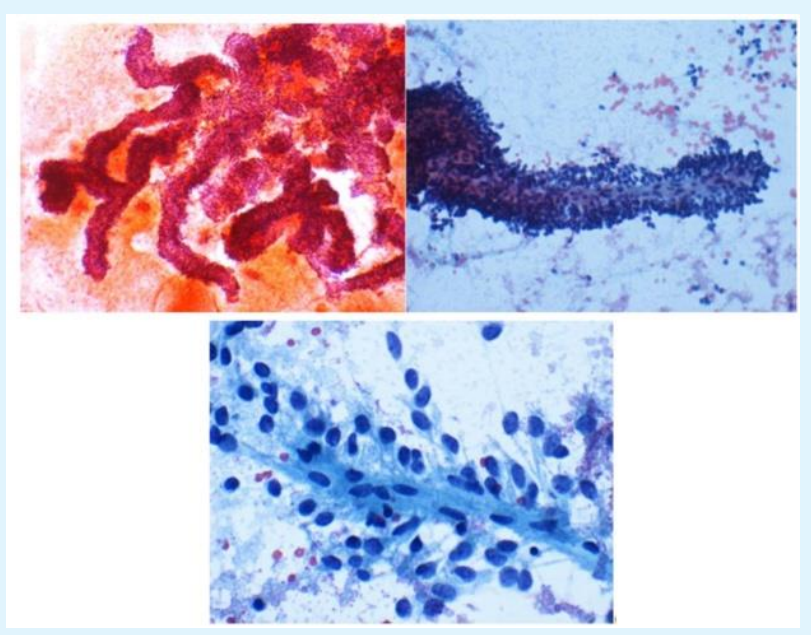

Figure 27: Note the pseudopapillary font without fibrovascular core.

\section{Ductal Adenocarcinoma}

- Disordered monolayer sheets, microglandular patterns, nuclear crowding; loss of cell cohesion [15-18],

- Nuclear criteria of malignancy with contour irregularity and fairly distinctive margination of chromatin,
- Moderate amount of cytoplasm, often mucin vacuoles, indistinct cell borders,

- Evidence of necrosis, mitoses, macronucleoli and hyperchromasia in poorly differentiated forms (Figures $28 \& 29)$.

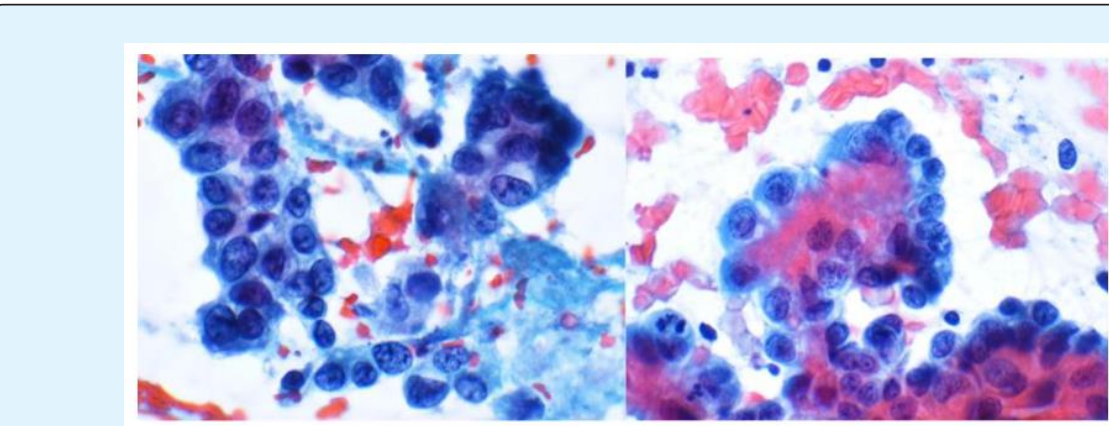

Figure 28: Malignant ductal epithelial cells of ductal adenocarcinoma of pancreas.

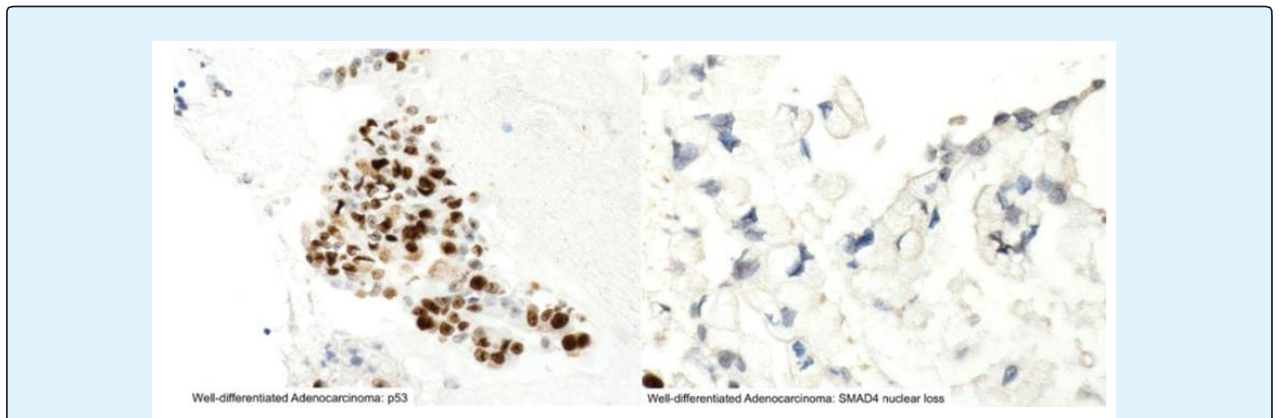

Figure 29: Cell blocks show p53 positivity and loss of nuclear SMAD4. 


\section{Mucinous Tumors of the Pancreas}

These tumors are best categorized into four subgroups [19]

- intraductal papillary-mucinous neoplasm (IPMN),
- mucinous cystic neoplasm (MCN),

- ductal adenocarcinoma of mucinous type, noncystic/colloid),

- Ductal adenocarcinoma of signet ring type (Figure 30).

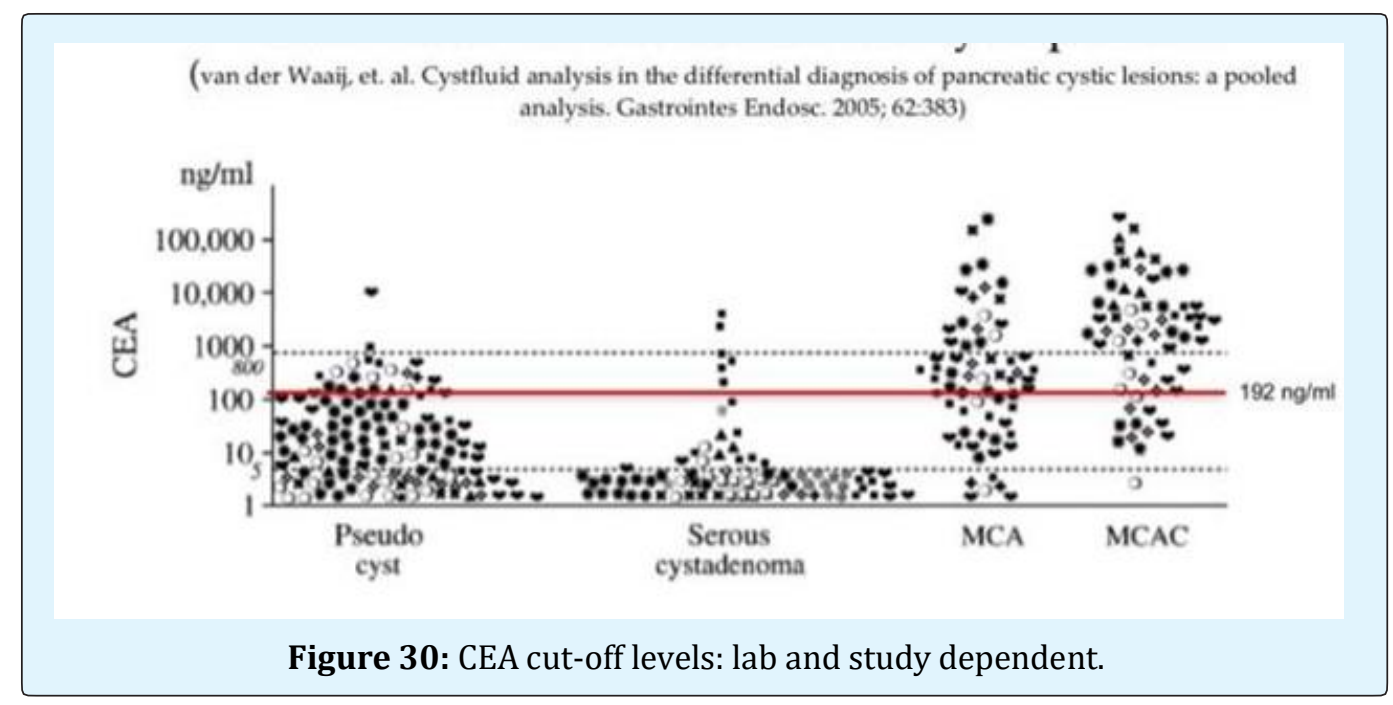

Mucinous adenocarcinoma/colloid carcinoma is a solid ductal carcinoma in which greater than $50 \%$ of the tumor is of mucinous type, revealing tall columnar morphology and demonstrable intracytoplasmic and extracellular mucus. Mucinous or colloid carcinomas occur mainly in the pancreatic head and have identical gender, age and prognostic implications as the usual adenocarcinoma. Signet ring carcinoma is exceptionally rare, and often difficult to distinguish histologically from chronic pancreatitis because of its diffuse infiltrative characteristics. It is cytologically recognizable by the presence of classic single lying signet ring cells, bloated with mucin, seen in pools of mucin.

\section{Intraductal Papillary Mucinous and Mucinous Cystic Neoplasms}

- Abundant background mucin,

- Cohesive sheets and papillary aggregates, in IPMN,

- Cuboidal to columnar, mucin-filled cells

- Spectrum of nuclear changes

Intraductal papillary-mucinous neoplasms (IPMN) were first described as a distinct entity in the 1980s. They are now well characterized as tumors of better prognosis as they have a long intraductal course but eventually will invade into periductal pancreatic parenchyma, and then go on to nodal and distant metastases. Both sexes can be affected, but elderly males predominate. IPMN usually involves the main duct in the head of the pancreas but can arise in side branches.

Mucinous cystic neoplasm (MCN) is an indolent tumor of middle-aged females, the majority occurring in the tail of the pancreas. These tumors show a spectrum of grade and behavior including benign cystadenomas, borderline forms, and malignant cystadenocarcinomas. The latter obviously has a poorer prognosis if invasion has occurred [20-24].

\section{- KRAS}

Mutation (s) support a neoplastic mucinous cyst

Does not distinguish IPMN and MCN

Does not correlate with grade

- GNAS

Mutation Supports IPMN over MCN

Doesnot correlate with grade

- RNF43

Mutation supports a mucinous cyst

Doenot distinguish IPMN and MCN

- 3p deletions

3p25, VHL gene, supports SCA

Other 39 deletions also noted SCA

- CTNNB1 (beta-catenin) deletion

Mutation(s) support SPN

- TP53, CDKN2A loss SMAD4 loss support a HR cyst 


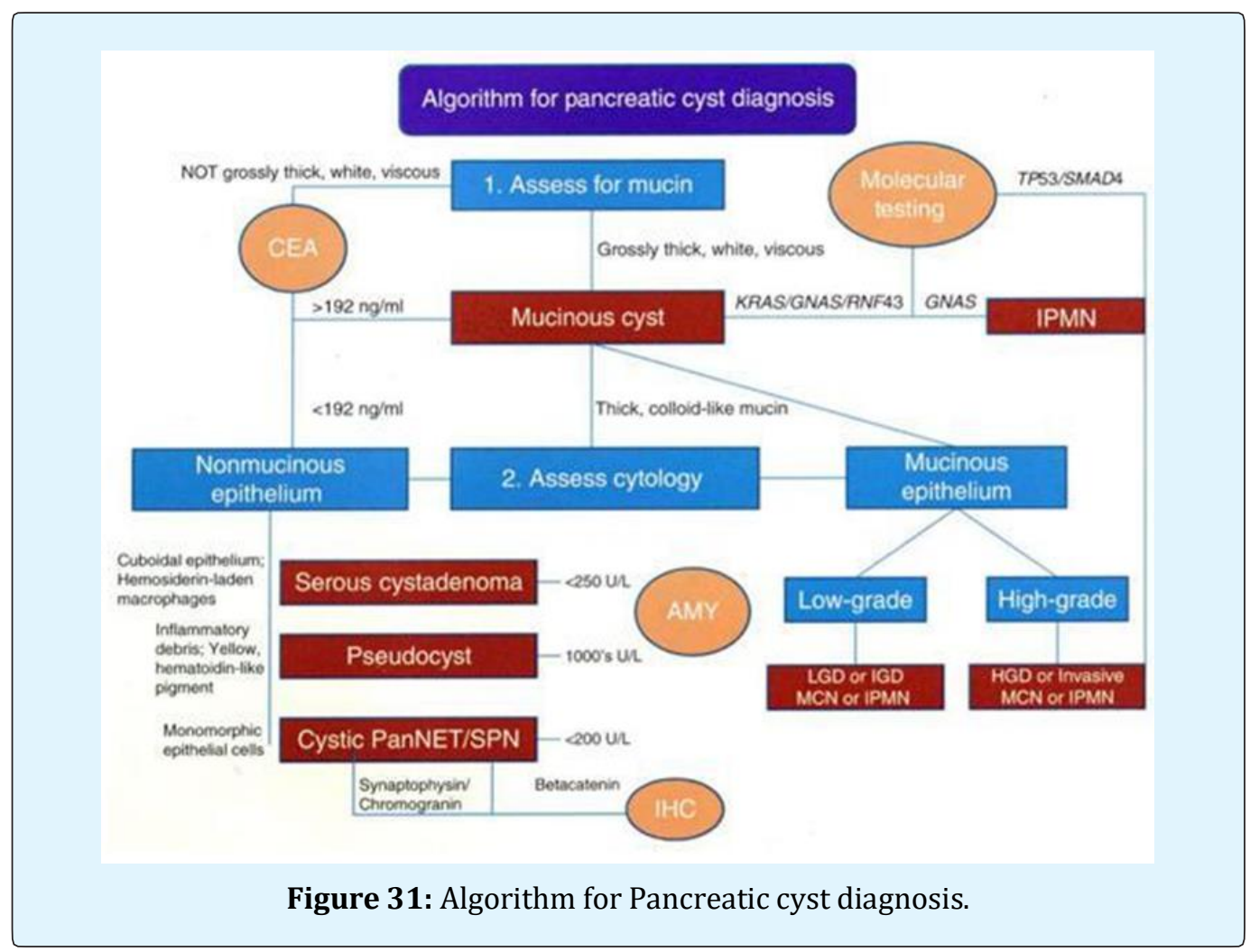

\section{Islet Cell Tumors}

- Many single and loosely grouped cells, pseudorosettes, - Rounded monotonous nuclei, mild to moderate anisokaryosis,

- Speckled chromatin and 1-3 small nucleoli,

- Poorly defined, finely granular cytoplasm, often dispersed in the background,

- Nuclei eccentric if cytoplasm intact.
General neuroendocrine markers will usually be positive, such as neuron-specific enolase(NSE), synaptophysin, chromogranin-A, PGP9.5 and CD56. Specific secretory products, e.g. insulin can be marked by appropriate antibodies but this does not necessarily correlate with raised serum levels [25-30] (Figures 3234).

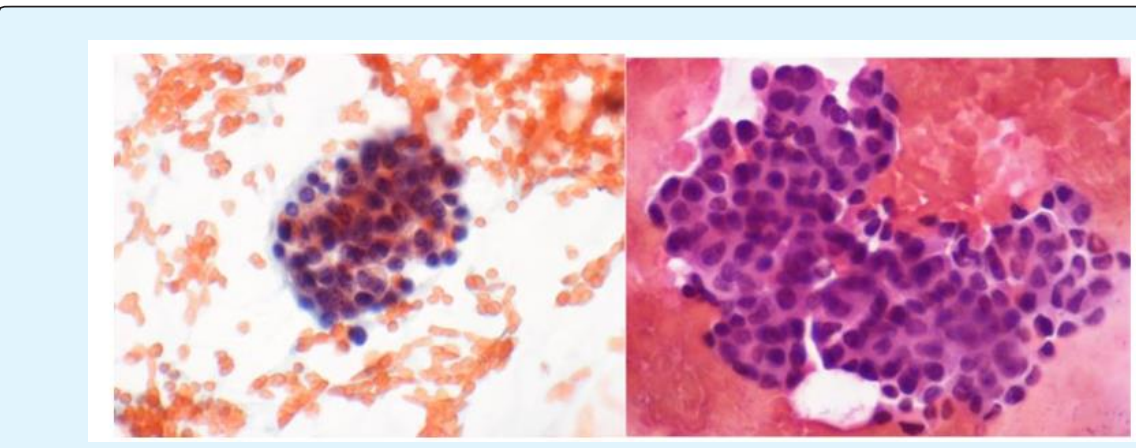

Figure 32: Features of powdery chromatin and small inconspicuous nucleoli. 


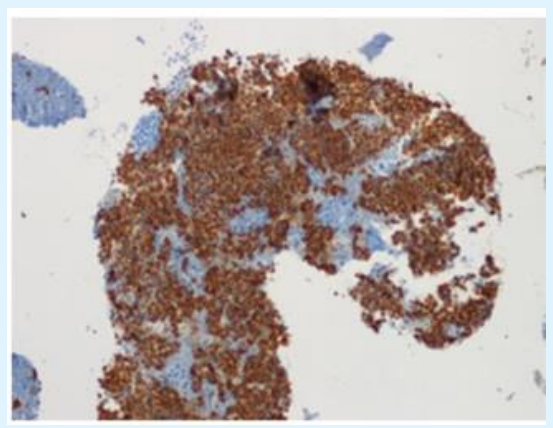

Figure 33: Chromogranin positive cells in cell block.

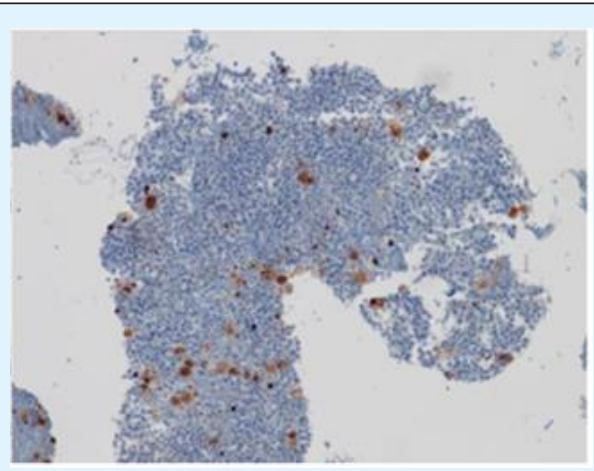

Figure 34: CD56 negativity in the same cell block.

\section{Pancreatoblastoma}

- cellular smears with solid and acinar architecture

- Interspersed squamous corpuscles and osseous/chondroid metaplasia.

- Detached small cells, primitive blastemal epithelial cells with even chromatin and delicate cytoplasm,

- The most obvious differential diagnosis in young women is solid-cystic papillary tumor particularly if mesenchyma is present and squamous differentiation absent [31-33].

Standardized Terminology and Nomenclature for
Pancreaticobiliary Cytopathology from the
Papanicolaou Society of Cytopathology
I. Nondiagnostic
II. Negative: Normal pancreatic tissue, splenule, LEC, pancreatitis (AIP)
III. Atypical: Suggestive but not diagnostic of NET or SPN;
indeterminate bile duct lesions
IV. Neoplastic
-Benign: SCA, NET microadenoma
-Other: IPMN, MCN, PanNET, SPN
V. Suspicious: Suggestive but not diagnostic of PDAC, Acinar Cell
Ca., PanNEC
VI. Positive/Malignant: PDAC, Acinar Cell Ca., PanNEC

\section{Other Intra-Abdominal Tumors}

- Gastrointestinal stromal tumors (GISTs)

- A gastrointestinal autonomic nerve tumor (GANT), is a spindle cell tumor of neural origin. It is a biologically aggressive neoplasm with metastatic potential. Neurosecretory granules are frequent, and staining with antibodies to synaptophysin, S-100, NSE and vimentin is observed, staining for desmin is negative [34-37].

- Intra-abdominal desmoplastic small cell round tumor (DSRBCT), a relatively new entity, is a rare, highly aggressive malignant neoplasm of the serosa of the abdominal cavity, seen mainly in young male patients.

\section{Lung}

\section{Granulomatous inflammation}

Epithelioid histiocytes in cohesive clusters, few nonpigmented multinucleate histiocytes, Granular, calcific, mucoid or acute inflammatory debris (corresponding to caseous necrosis in TB), Lymphocyte [38] (Figure 35).

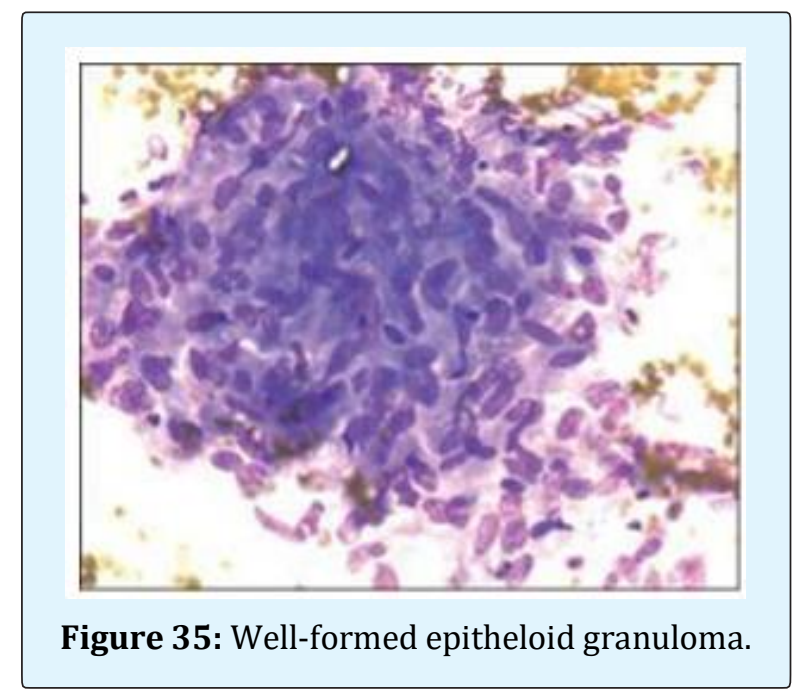

\section{Other Specific Infections}

In Aspergillus and phycomycete infections in the lung, fungal hyphae are easily visible in alcohol-fixed material [39]. The characteristic appearance of acute-angled branching, parallel cell walls and septa in Aspergillus. Oxalate crystals are produced by several species of Aspergillus and, if identified in cytological material, should lead to a search for organisms (Figures $36 \& 37$ ). 


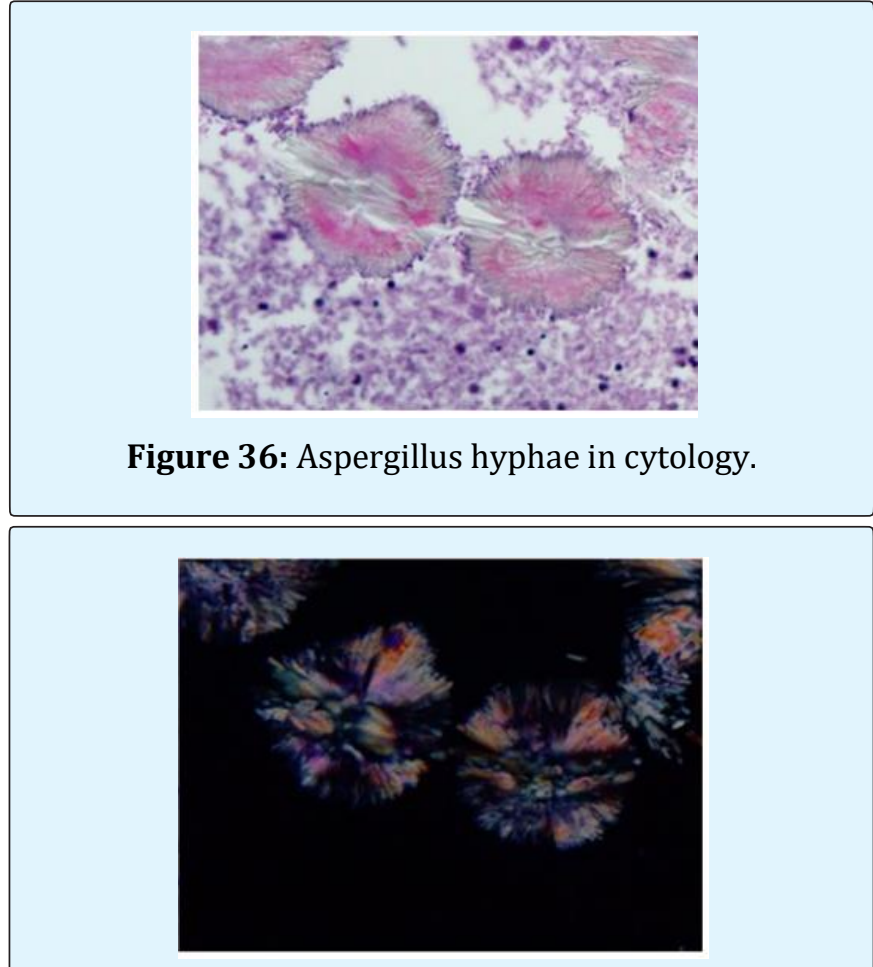

Figure 37: Birefringence crystals in polarized view.

\section{Pneumoconioses}

Birefringent silica and collagenous tissue or asbestos bodies may help confirm silicosis or exposure to asbestos. However, concomitant malignancy, tuberculosis or other infections may be the cause of the localized opacity in these patients [40] (Figures $38 \& 39$ ).

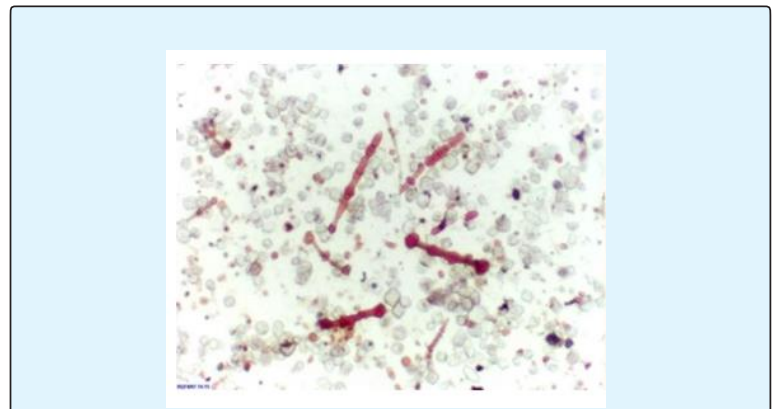

Figure 38: Asbestosis bodies.

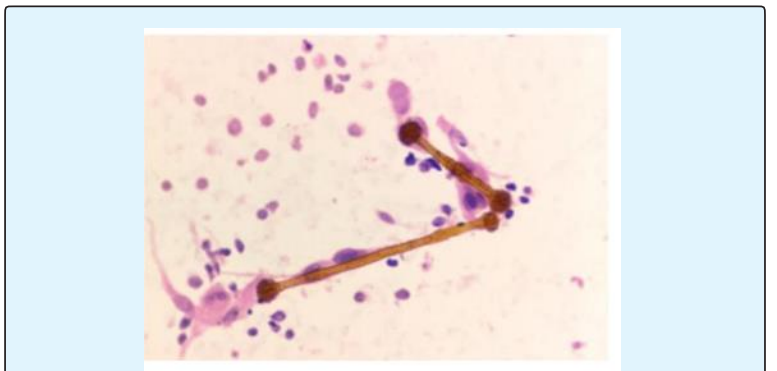

Figure 39: Ferruginous bodies in asbestosis.

\section{Squamous Cell Carcinoma}

\section{Keratinizing Type}

- Predominant single cell presentation,

- Keratinized malignant cells; cytoplasm refractile and eosinophilic (Pap, H\&E); dense, pure blue (MGG),

- Perinuclear halo,

- Bizarre cell shapes, spindle and caudate cells,

- Irregular angular, densely hyperchromatic nuclei, Necrosis (Figure 40).

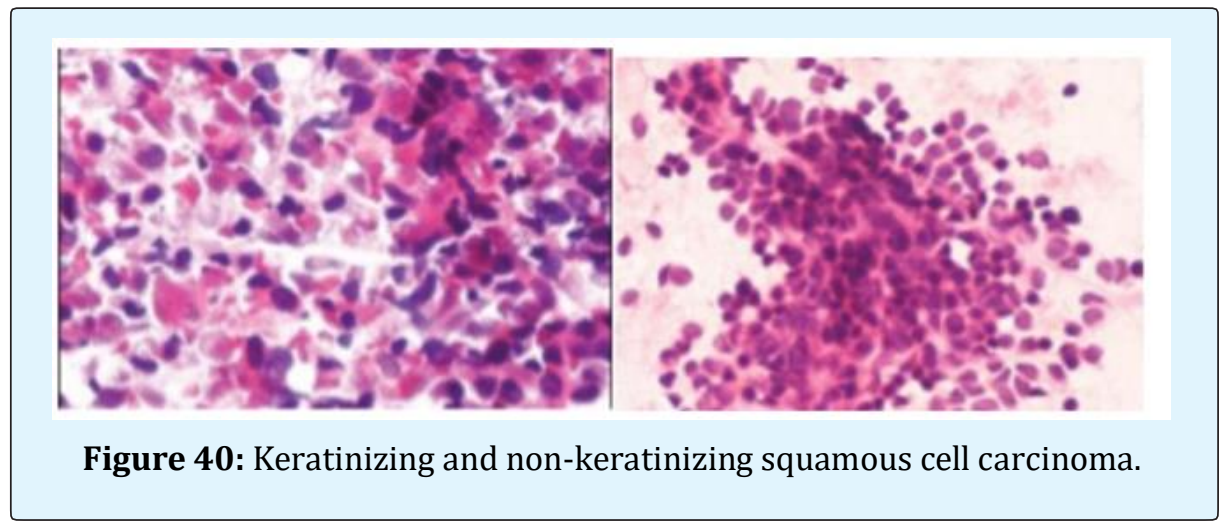

\section{Non-keratinizing type}

Irregular solid cohesive fragments variable chromatin density in adjacent cells. Small-celled forms of poorly differentiated squamous cell carcinoma, and those undergoing degeneration and necrosis, can be confused with small cell carcinoma. Attention to greater cohesion, larger cell size, presence of nucleoli, greater tendency to spindle at the periphery of clusters, denser cytoplasm and 
occasional keratinized cells should lead to the correct diagnosis. Strong positive p63 and CK 5/6 staining and absence of staining for TTF-1 would favor squamous rather than small cell carcinoma, although rare squamous carcinomas are TTF1 positive $[41,42]$.

\section{Adenocarcinoma, including broncho alveolar} carcinoma:

- Medium-sized to large cells with abundant delicate cytoplasm,

- flat sheets, rosettes, acinar structures or cell clusters/balls,

- Columnar cells, round to oval eccentric nuclei with large solitary nucleoli (Figure 41).

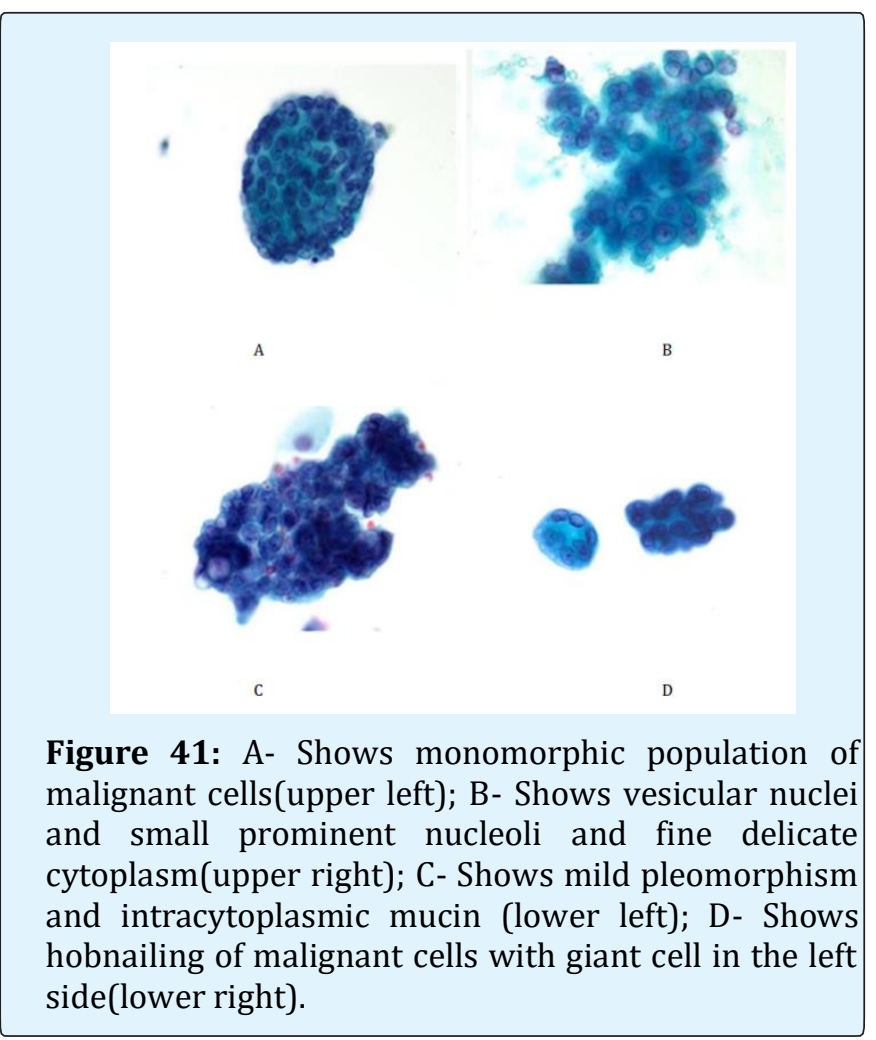

The differential diagnosis between a peripheral well differentiated adenocarcinoma and the epithelial form of malignant mesothelioma can usually be resolved by mucin and immunoperoxidase stains; occasionally, ultrastructural studies are required (Figure 42).

As the only difference between adenocarcinoma and BAC variant is basement membrane, stromal/ parenchymal invasion and less inflammatory reaction it's difficult to distinguish both in cytology.

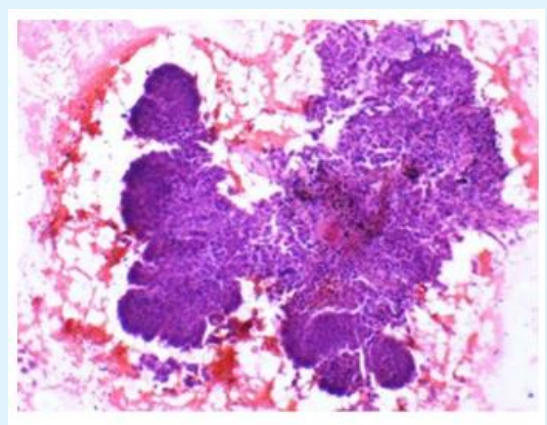

Figure 42: Adenocarcinoma showing clear papillary fonts in cytology.

\section{Small cell carcinoma [43]}

- Small or medium-sized cells with little or no cytoplasm (larger than in sputum),

- Dispersed cell presentation,

- Nuclear molding and engulfment; irregular nuclei,

- Uniform finely or coarsely granular nuclear chromatin; small nucleoli,

- Tear-drop cells, smeared cells and streaks of nuclear material,

- Engulfment of apoptotic bodies,

- Numerous mitotic figures (Figure 43).

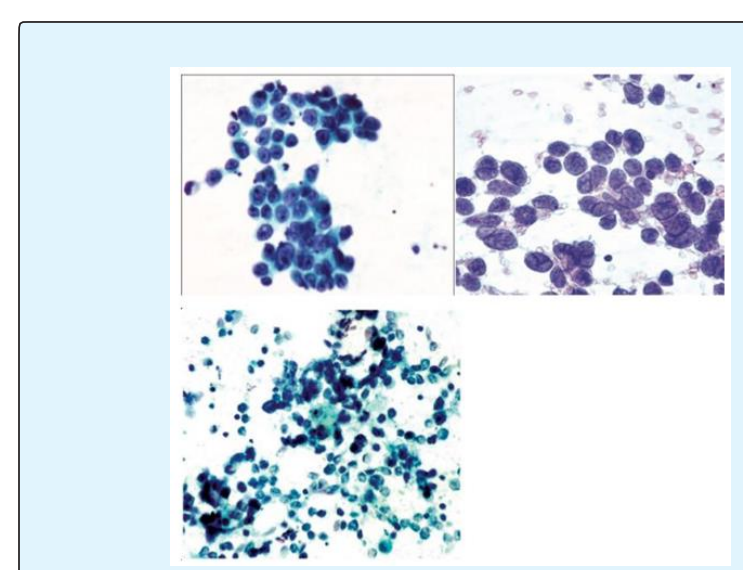

Figure 43: Above Images show powdery chromatin and small nuclei favoring small cell carcinoma.

\section{Large Cell Carcinoma}

- Large, highly pleomorphic cells with abundant cytoplasm,

- Large multilayered fragments of malignant tissue,

- Dispersed cells with a high N:C ratio,

- Tumor giant cells,

- Polymorph ingestion,

- Fragile cytoplasm (Figure 44). 


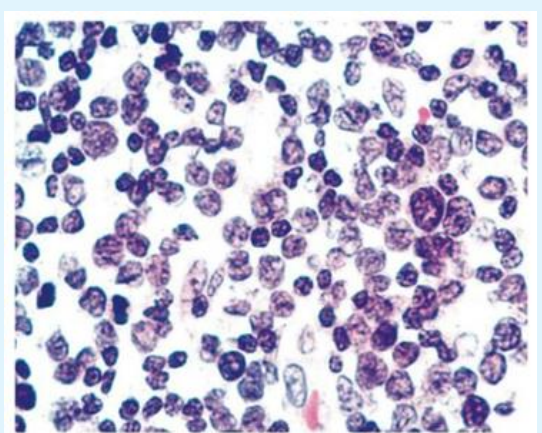

Figure 44: Large cells carcinoma showing neuro endocrine features.

\section{Carcinoid tumors}

Types includes,

- Typical carcinoid [44-48]

- Spindle cell carcinoid

- Atypical carcinoid

- Adenocarcinoid
- Large cell neuroendocrine carcinoma

- Diffuse idiopathic neuroendocrine cell hyperplasia (DIPNECH)

\section{Typical carcinoid $[49,50]$}

- Dispersed cell population with some trabeculae or palisades and small cell clusters,

- A monomorphous population of small neoplastic cells with small amounts of intact cytoplasm,

- Rounded or oval nuclei with stippled/granular nuclear chromatin and small nucleoli,

- Plexiform background of small blood vessels; adherence of cells to vascular cores.

In classic carcinoids, the 'neuroendocrine' round or oval nuclei with stippled nuclear chromatin and inconspicuous nucleoli are distinctive; the chromatin pattern may be rather similar to the 'clock face' chromatin of plasma cells (Figures $45 \& 46$ ).
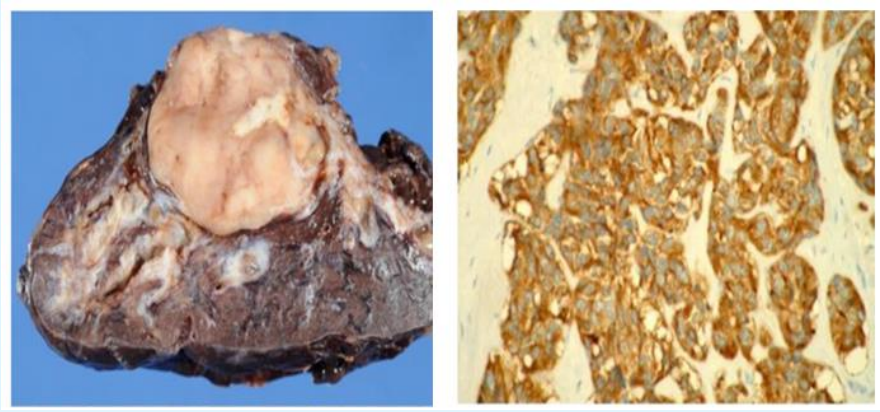

Figure 45: [CARCINOID, TYPICAL]-The cell differentiation of carcinoid tumor can be identified using immunohistochemistry. These tumors show positive immunohistochemical staining for pan-cytokeratin, Can 5.2 (CK 8). Chromogranin, synaptophysin, neuron-specific enolase (NSE), CD56, CD57, and Map-2 protein. Additional hormones may also be produced by any given tumor such as ACTH or calcitonin. This tumor shows positive reactivity for chromogranin-A.

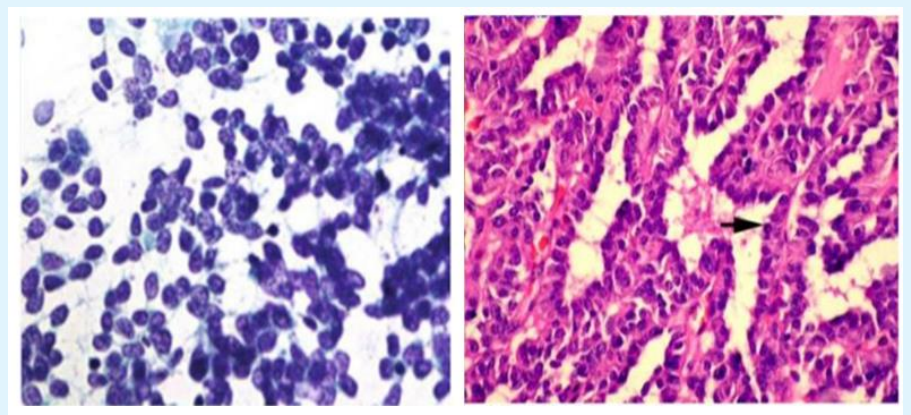

Figure 46: [CARCINOID, TYPICAL]-Except for the solid growth pattern other architectural arrangements are so characteristic that a correct diagnosis is not difficult at low magnification without additional studies. The two-cell thick plate arrangement (arrow) on a fibrovascular core gives this tumor a unique appearance readily identifying it as a carcinoid tumor. However, immunohistochemistry may be needed in some cases to confirm the diagnosis. 


\section{Spindle Cell Carcinoid}

Peripheral location of a spindle or small cell tumor raises this possibility. Uniformity of cells with absence of nuclear smearing and background debris. Small cell anaplastic carcinoma is the close differential. TTF-1 positivity is helpful to differentiate it from SCAC $[51,52]$.

\section{Atypical Carcinoid}

Some shows features in common with classic carcinoids such as a combination of cohesive aggregates and dissociation, small to moderate amounts of cytoplasm, neuroendocrine nuclei, trabecular arrangement of cells, palisades, rosettes and plexiform vascularity. Features favoring atypical carcinoid included necrosis, mitotic activity and more marked pleomorphism.

The absence of widespread molding, smeared fragile nuclei, abundant single-cell necrosis or abundant mitoses and cohesive acinar rosette-like or sheet-like groupings with palisading helps exclude small cell carcinoma. Low levels of staining for MIB-1(ki-67) would also be helpful (Figure 47).

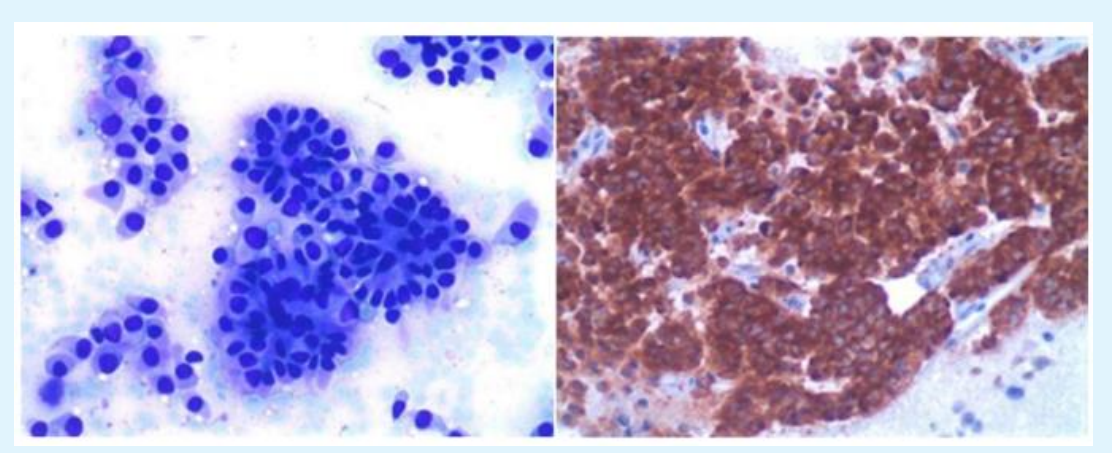

Figure 47: Thyroid FNAC shows same morphology of renal mass consistent with carcinoid with chromogranin A +.

Adenocarcinoid: Tumors with prominent glandular differentiation but showing ultrastructural neuroendocrine features are well described and may not be recognizable as being neuroendocrine cytologically [53].

Metastatic Malignancy: Specific immunohistochemical stains such as thyroid transcription factor (TTF-1), differential cytokeratins (high and low molecular weight cytokeratins and CK7 versus CK20), CEA, hormone receptors (ER and PR), mammoglobin and gross cystic disease protein (GCDFP-15) may be useful markers in differentiating primary from metastatic carcinoma. Other immunohistochemical stains which are fairly specific for certain malignancies may also be of value, e.g. prostatespecific antigen (PSA), thyroglobulin and S-100, HMB-45 and Melanin A.

\section{Metastatic colorectal adenocarcinoma: Features} includes,

- Necrosis,

- Palisading of nuclei; elongated nuclei,

- Large, elongated columnar cells.

-Well-formed gland structures
The demonstration of a clear apical space and a brush border in the tumor cells is another characteristic [54]. A CK7/ TTF-1 negative CK20/CDX2-positive immunophenotype is generally confirmatory. EM demonstration of junctional complex and cell surface features of hindgut type in colonic cancer. Prostatic carcinoma may show rosette-like structures with central cytoplasmic mass or monolayered sheets similar to BAC; positivity for PSA can be used to confirm the diagnosis. Transistional cell carcinoma distinctive features were the presence of spindled, pyramidal, and/or racquet-shaped malignant cells with eccentric nuclei and cytoplasmic features of both squamous and glandular differentiation including endoplasmic/ectoplasmic interfaces and intracytoplasmic vacuoles, and some glandular features. 'Cercariform' cells, which are non-keratinized cells with a globular body and a cytoplasmic process with a bulbous or fishtail end, can be appreciated cercariform cells (Figure 48).

Metastatic melanoma may have a different immunohistochemical staining profile from the primary melanoma; most commonly, the metastasis will lose Melan A or HMB- 45 but occasionally there is loss of S-100 expression [55]. 


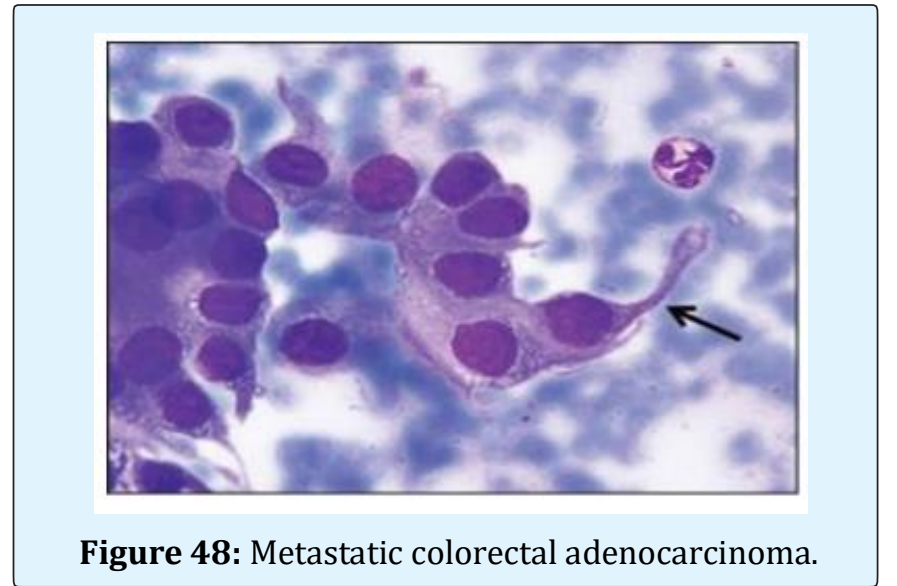

Inflammatory myofibroblastic tumor (IMFT): Loose collection of large mesenchymal cells with rounded nuclei, binucleation, prominent nucleoli and dense cytoplasm. Background of lymphocytes and plasma cells.

Other primary lesion of lung

Pulmonary hamartoma [56-59]: Most common benign tumor like condition of lung,

- Mature cartilage,

- Myxoid connective tissue/'immature cartilage',

- Sheets of entrapped bronchiolar/alveolar epithelium and fat. All the above favors the diagnosis.

Mature cartilage has a homogeneous waxy, purplegray appearance in $\mathrm{H} \& \mathrm{E}$-stained material. It is sparsely cellular; chondrocytes may be seen in lacunae. In contrast, the immature cartilage or myxoid connective tissue has a fibrillar texture (Figure 49).

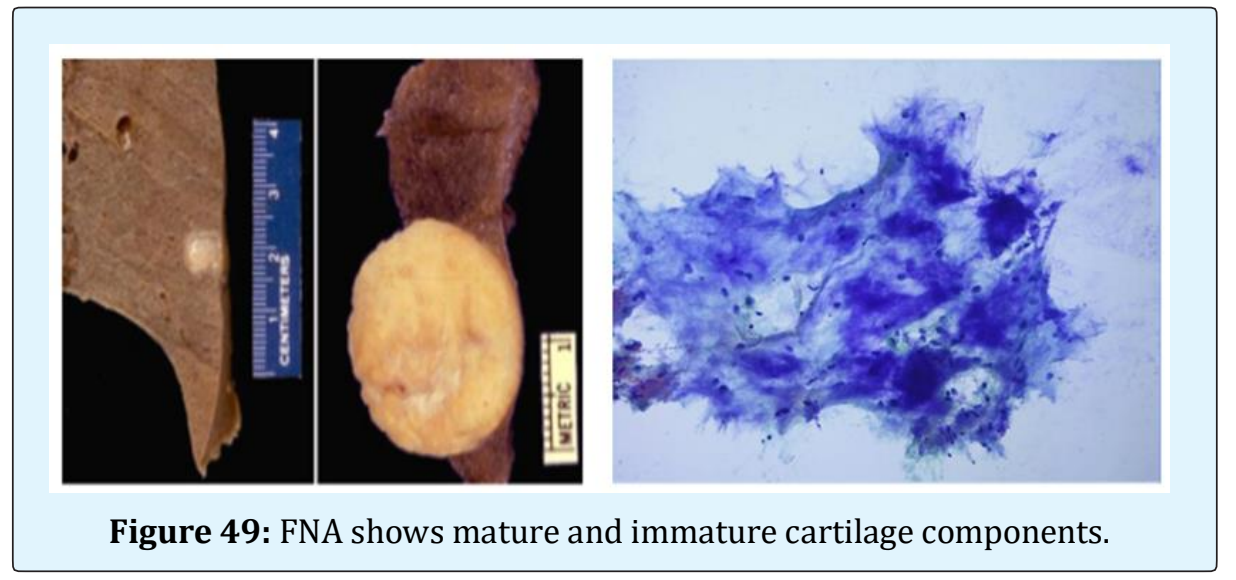

\section{Rare primary Malignancies:}

Pulmonary blastoma: These rare malignant tumors present most commonly in young adult males as peripheral lesions. They resemble fetal lung and show varying mixtures of epithelial tubules with glycogen-rich columnar cells, stromal elements composed of small compact tumor cells and cartilage or smooth or skeletal muscle. FNAC diagnosis is reported, although differentiation from carcinoma or other malignancies is difficult.

So-called pleuropulmonaryblastoma is a different neoplasm seen in childhood, which lacks an epithelial element, is commonly associated with cystic malformations and has the potential for transformation to multiple sarcomatous types [60] (Figure 50).

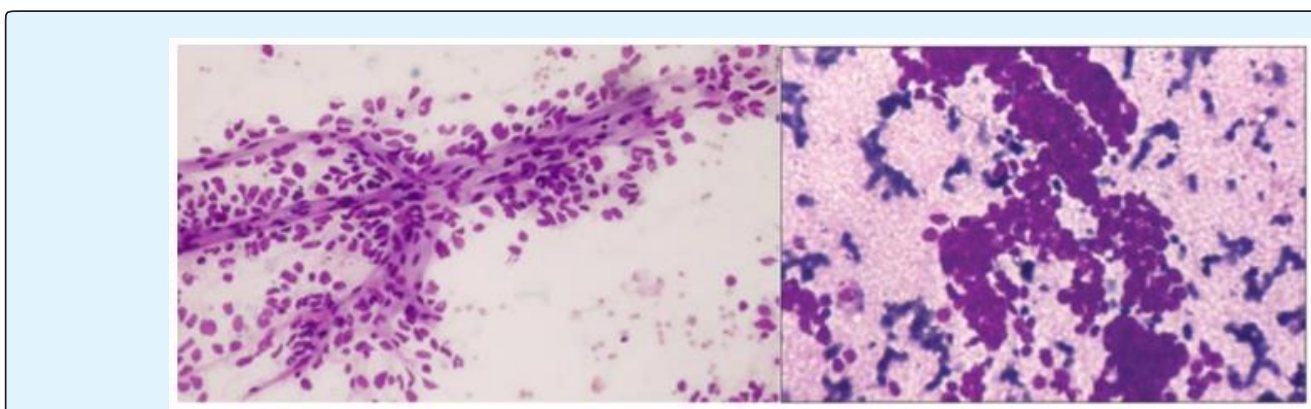

Figure 50: Cords and trabecular arrangement of blastemal components in pulmonary blastema. 
Pulmonary carcinosarcoma [61]: These lesions are rare tumors of later decades of life, sometimes presenting as pedunculated lesions of bronchi and composed of poorly differentiated epithelial and mesenchymal tissue. There is debate over whether they represent sarcomatoid carcinomas or a distinct entity.

Chest wall and pleura: Lesions include,

- Malignant mesothelioma

- Solitary fibrous tumors (benign; malignant; pleural fibroma)

- Peripheral primitive neuroectodermal tumor/ Ewing's sarcoma

- Pleural thymoma

\section{Malignant mesothelioma}

- Papillary processes; cell balls or cell clusters (tubulopapillary tumors) [62-65],

- Flat sheets of epithelial cells with abundant dense cytoplasm and some cell separation (epithelial or biphasic tumors),

- Cytoplasmic vacuolation; intracytoplasmic hyaluronic acid,

- Polygonal cells, dispersed, with binucleation and multinucleation,

- Spindled epithelial cells,

- Spindle cells with a fibroblastic appearance (biphasic or sarcomatous tumors),

- Pleomorphic malignant cells with a multi-nucleated cell component (anaplastic tumors) (Figures 51-54).

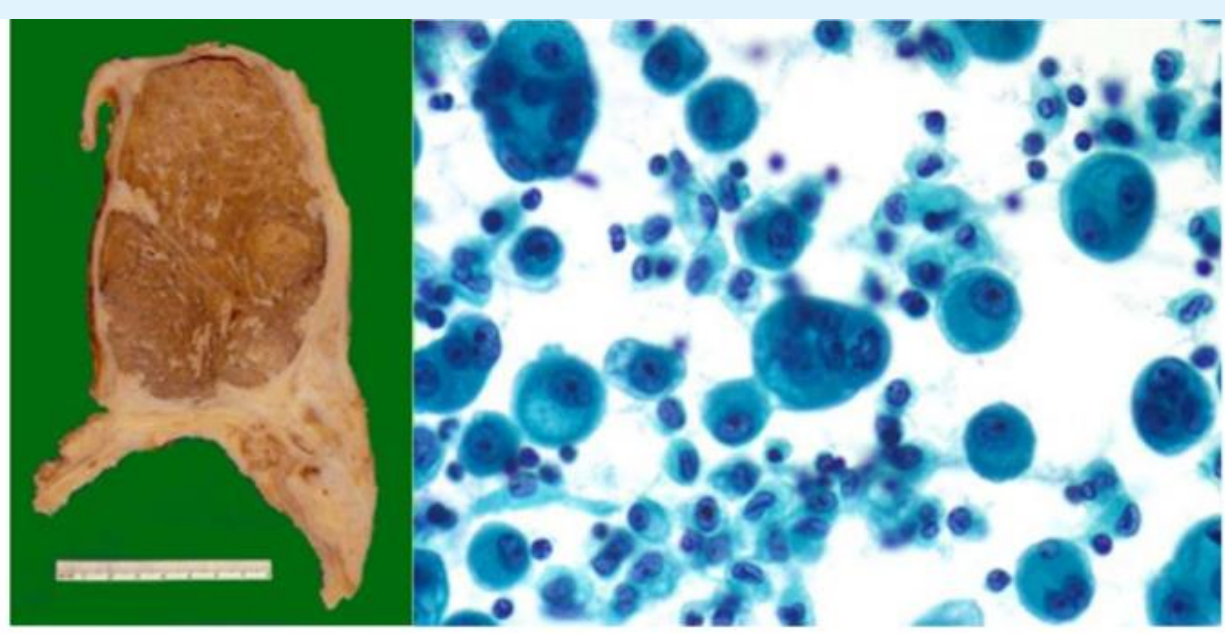

Figure 51: Mesothelioma covering entire pleural surface) (typical bi and multi nucleation in cytology smear.

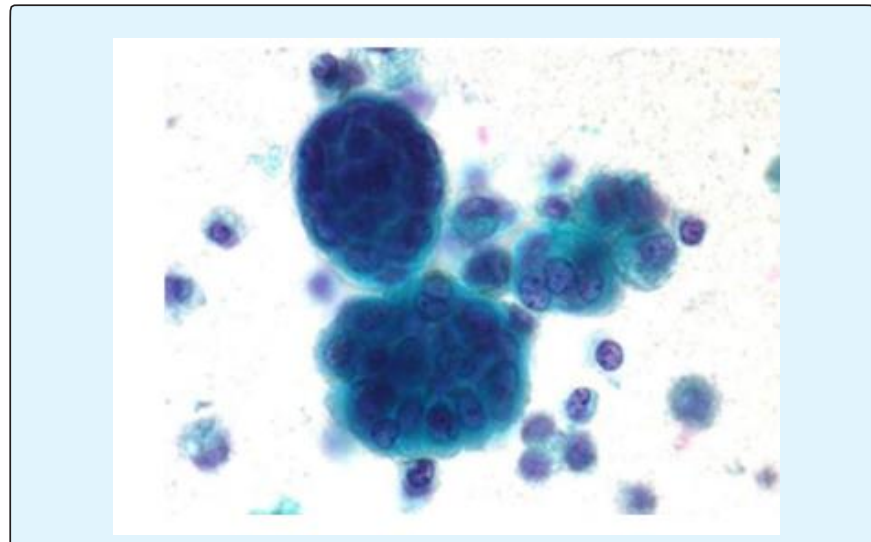

Figure 52: Irregular knobby border of 3D cell clustertypical.

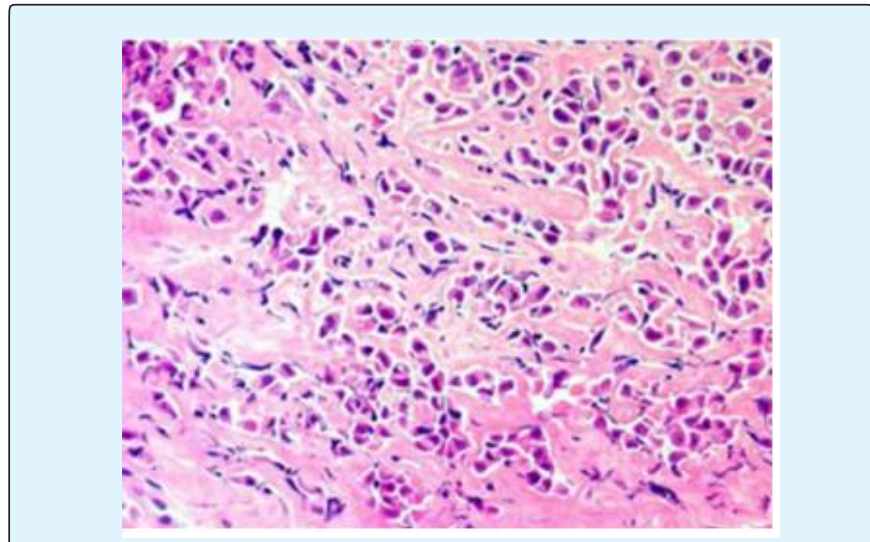

Figure 53: Immunocytochemistry of corresponding smear. 


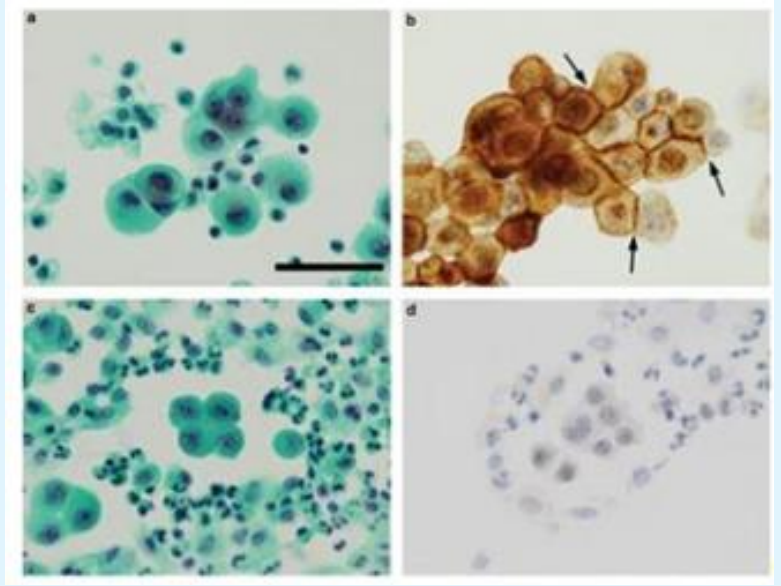

Figure 54: CD146 positivity in mesothelioma cells against reactive cells.

Solitary fibrous tumors (benign; malignant; pleural fibroma): Many spindle-shaped fibroblastic cells were present; nuclei were moderately pleomorphic and some chromatin clumping was seen, leading to a suspicion of low-grade malignancy in a benign case. Cell blocks or core biopsies showing CD34, CD99 and bcl-2 positivity and negative staining for keratins, CEA, EMA and other epithelial markers [66,67] (Figures 55-57).

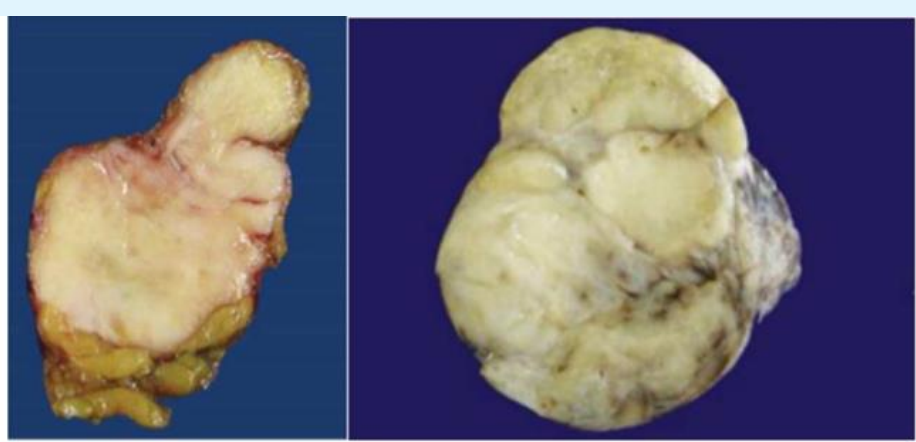

Figure 55: Benign and malignant SFT respectively)(note the heterogenous appearance of image 2.

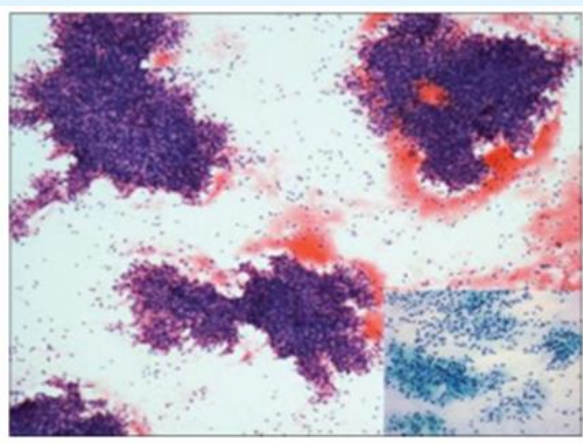

Figure 56: Monomorphic spindle cells with collagenous stroma.

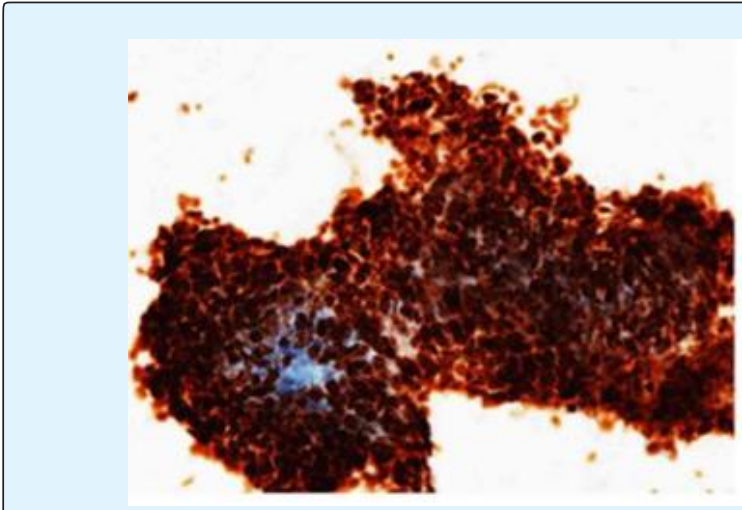

Figure 57: STAT6 positive cells in SFT. 


\section{Ewing's Sarcoma/Primitive Neuroectodermal Tumor (EWS/PNET)}

Ewing's sarcoma/primitive neuroectodermal tumor is the second most frequent malignant pediatric primary bone tumor. Both PNET and Ewing's sarcoma stain positively with monoclonal antibodies FLI-1 and CD99 (MIC-2 oncogene) and share a common chromosomal abnormality (11; 22 translocation). Smears are cellular, composed of small cohesive groups of undifferentiated small round cells without nuclear molding. In the DiffQuik smear, peripheral cytoplasmic vacuolization and membranous cytoplasmic blebs can be noted in occasional cases and considered as characteristic features (Figure 58) [64-66].

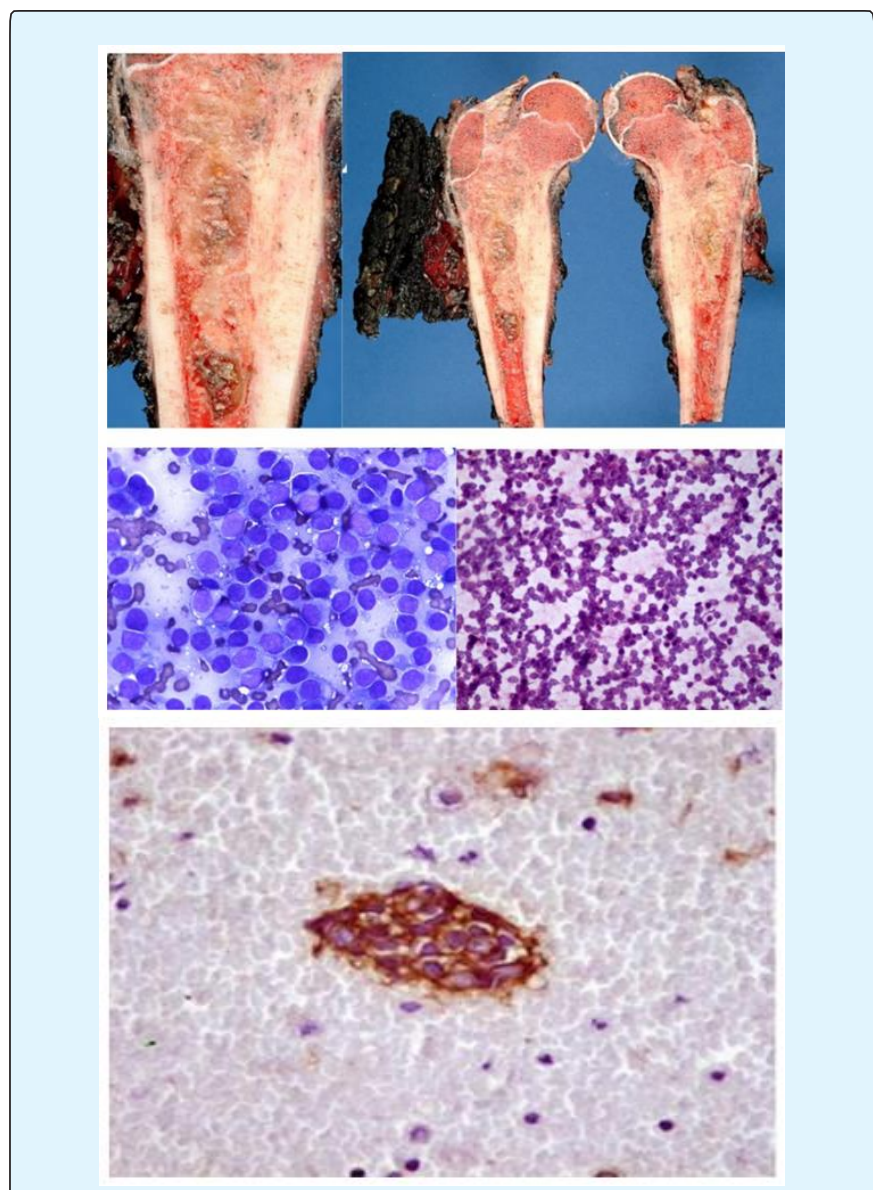

Figure 58: CD99 positivity in immunocytochemistry.

\section{Mediastinum}

Metastatic malignancy: The mediastinum is a common site of metastasis for neoplasms from all sites. In FNA samples, small cell carcinoma of lung is the most frequent metastasis, with lesser numbers of non-small cell tumors of lung, followed by breast carcinoma.

\section{Thymic Neoplasms}

\section{Thymoma [68]:}

- Cohesive tissue fragments with bland polygonal, oval, or spindled 'epithelial' cells (rarely, Hassall's corpuscles),

- Lymphoid cells (mixed thymoma) intermingled with the epithelial component (Figure 59).

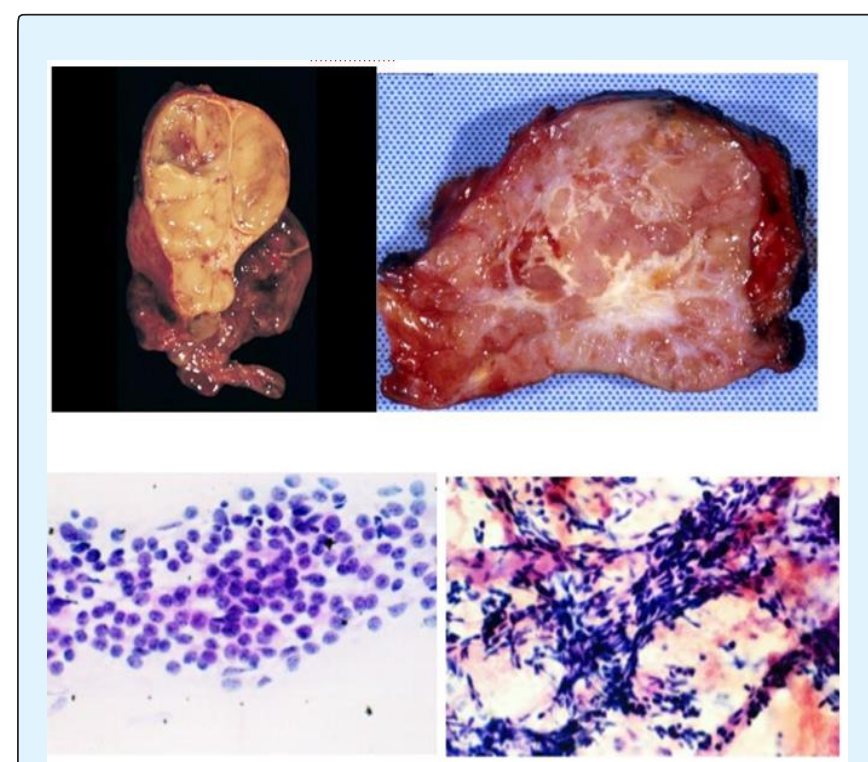

Figure 59: Thymic Neoplasms.

\section{Malignant Thymoma}

Thymic carcinomas are very uncommon cytologically malignant tumors with a wide variety of morphological appearances including keratinizing and nonkeratinizing squamous, sarcomatoid, anaplastic large cell, basaloid, mucoepidermoid, clear cell and small cell types. A cytological diagnosis of carcinoma may be made by FNB. Smears are variably cellular and usually dominated by loosely cohesive large malignant cells diagnostic of carcinoma. Most are composed of large tumor cells with solitary clearly malignant nuclei, with or without prominent nucleoli. Dorfman, et al. found CD5 positivity in tumor cells to be characteristic of primary carcinomas, in contradistinction to benign thymomas and carcinomas from other sites. Newer markers such as Foxn1 and CD205 may also prove useful [69-73] (Figures 60 \& 61). 

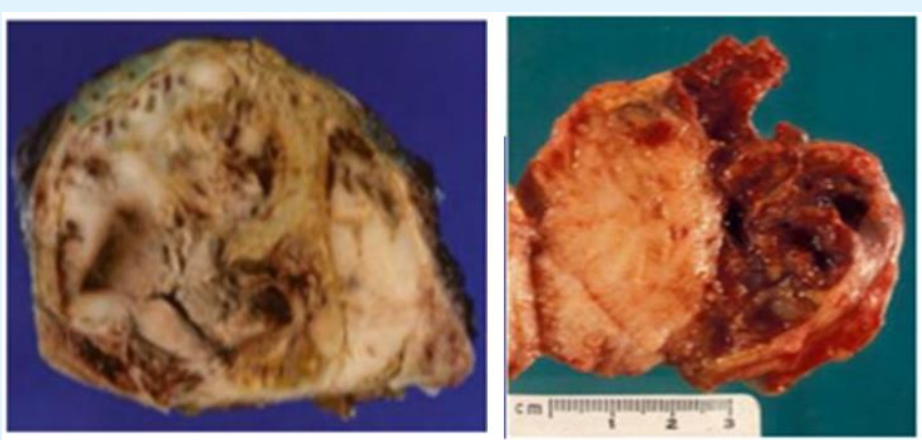

Figure 60: Squamous cell carcinoma and adenoid cystic carcinoma of thymus.

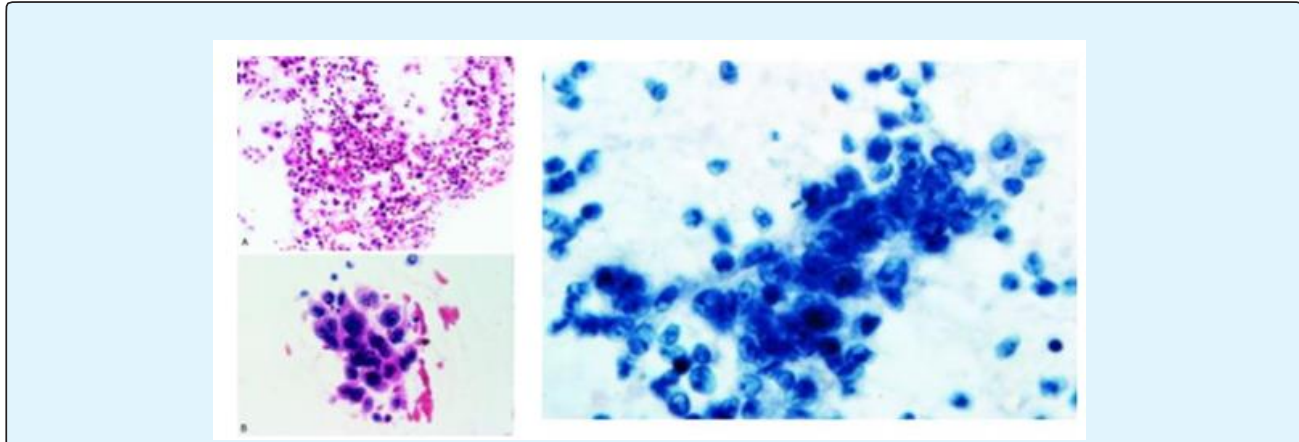

Figure 61: A typical epithelial cells in thymic carcinoma with admixed lymphocytes.

\section{Neural Neoplasms}

Ganglioneuroblatomas: There was a mixture of polyhedral cells including binucleate forms with abundant eosinophilic cytoplasm and smaller oval or spindle cells. Elevated VMA levels in serum helped to confirm the diagnosis.

Pure neuroblastoma: They occur mainly in children and present as small round cell tumors, with a background neuropil.

Ganglioneuroma: They may arise in the mediastinum. Smears are usually highly cellular, but the major tumor cell contour is variable, not only from neoplasm to neoplasm, but also within a given tumor. Cell shapes include round, plamacytoid and spindled. Nuclei are usually single but bi- and multi-nucleation may occur, at times frequently. Nuclei tend to be round with distinctly granular chromatin which stains with different intensities; nucleoli are generally inconspicuous. Cytoplasm is moderate in volume with MGG stain, is characteristically basophilic with minute red granules (Table 9, Figures 62\&63).

\begin{tabular}{|c|c|c|c|}
\hline Neuroblastoma & Ganglioneuroblastoma & Ganglioneuroma & $\begin{array}{c}\text { Paraganglioma(both } \\
\text { sympathetic and } \\
\text { parasympathetic) }\end{array}$ \\
\hline $\begin{array}{c}\text { Predominantly } \\
\text { neuroblasts with less } \\
\text { shwanonian stroma }\end{array}$ & $\begin{array}{c}\text { Both ganglionic and neuroblast } \\
\text { components seen along with rich } \\
\text { shwanonian stroma }\end{array}$ & $\begin{array}{c}\text { Predominantly of ganglion } \\
\text { cells with shwanonian } \\
\text { background. }\end{array}$ & $\begin{array}{c}\text { Tumor cells with zellballen } \\
\text { pattern along with } \\
\text { sustentacular stroma }\end{array}$ \\
\hline $\begin{array}{c}\text { ALK-1, NSE, GFAP, Synap } \\
\text { tophysin, chromogranin } \\
\text { positive }\end{array}$ & $\begin{array}{c}\text { Increased urine catecholamines } \\
\text { includes VMA, HVA, Dopamine }\end{array}$ & $\begin{array}{c}\text { S100, chromogranin, G FAP, } \\
\text { VIP Positivity }\end{array}$ & $\begin{array}{c}\text { S100 positive, elevated } \\
\text { VMA,HVA }\end{array}$ \\
\hline $\begin{array}{c}\text { S100; EMA, CK, CD99, } \\
\text { Desmin negative }\end{array}$ & $\begin{array}{c}\text { ALK1, S100, NF positive EMA, CD99, } \\
\text { HMB45,CK Negative }\end{array}$ & $\begin{array}{c}\text { EMA, CD99, HMB45, CK } \\
\text { Negative }\end{array}$ & $\begin{array}{c}\text { EMA, CD99, HMB45, } \\
\text { CKNegative }\end{array}$ \\
\hline
\end{tabular}

Table 9: Neural Neoplasms. 


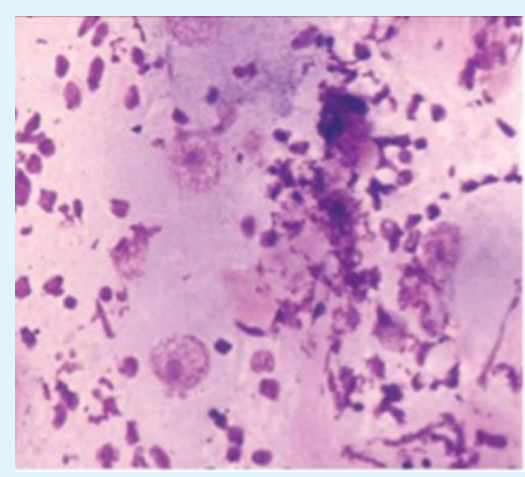

Figure 62: Ganglion cells with Schwann cell admix in ganglioneuroma.

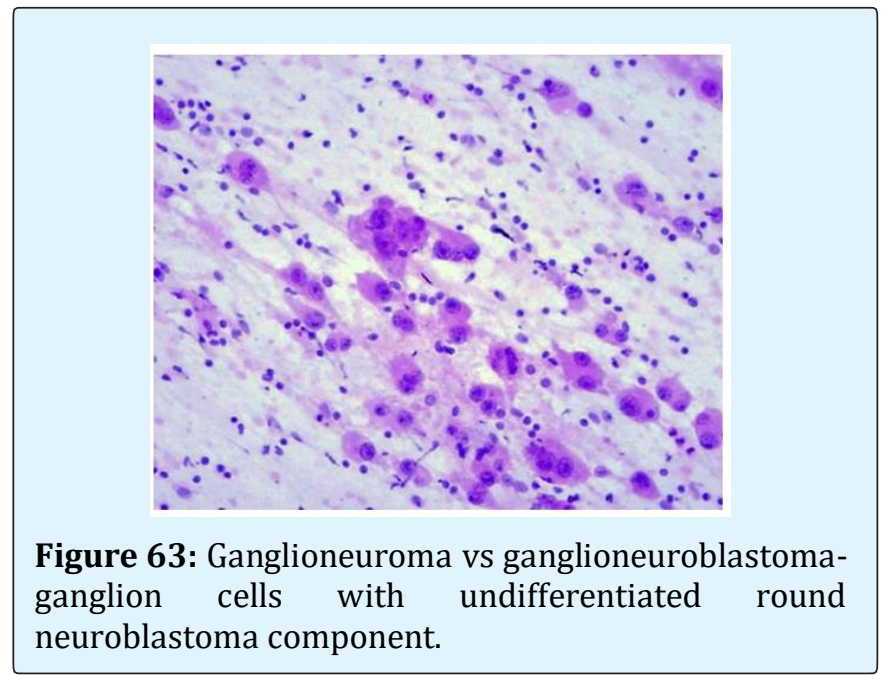

\section{Lymphoma and lymphoid lesions in the Mediastinum}

Hodgkin lymphoma [74,75]: Reed-Sternberg cells and mononuclear variants,

Mixed population of lymphoid cells with a predominance of small mature lymphocytes, Consistent immunocytochemical profile (CD15, 30/20, 45) (Figure $64)$.

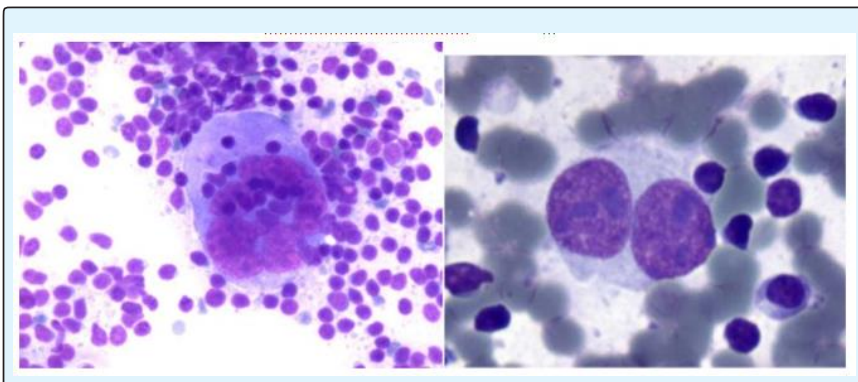

Figure 64: Multi-nucleated and classical RS cells in HL.

\section{Lymphoblastic lymphoma}

- High smear cellularity [76-78],

- Monotonous population of small to medium-sized lymphoid cells with very high $\mathrm{N}: \mathrm{C}$ ratios,

- High mitotic rate; tingible body macrophages,

- Delicate nuclear membranes with well-developed irregularities, especially convolutions,

- Finely granular 'dusty' chromatin pattern,

- Minute nucleoli,

- Consistent immunocytochemical profile (Figure 65).

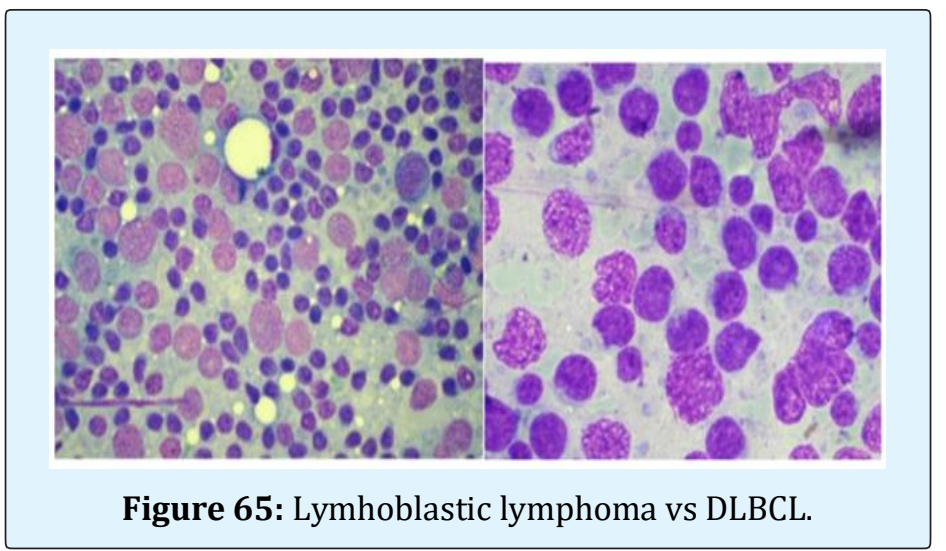

\section{Large cell lymphoma [79]}

- Dispersed monomorphic population of large lymphocytes with round or cleaved cells nuclei (centroblasts or immunoblasts),
- Relative absence of small lymphocytes,

- Background of lymphoglandular bodies [80],

- Consistent immunophenotype (Tables 10-12; Figures 66 \& 67). 
The below tables will be helpful in differentiating lymphomas based on size of cells and cytochemistry markers.
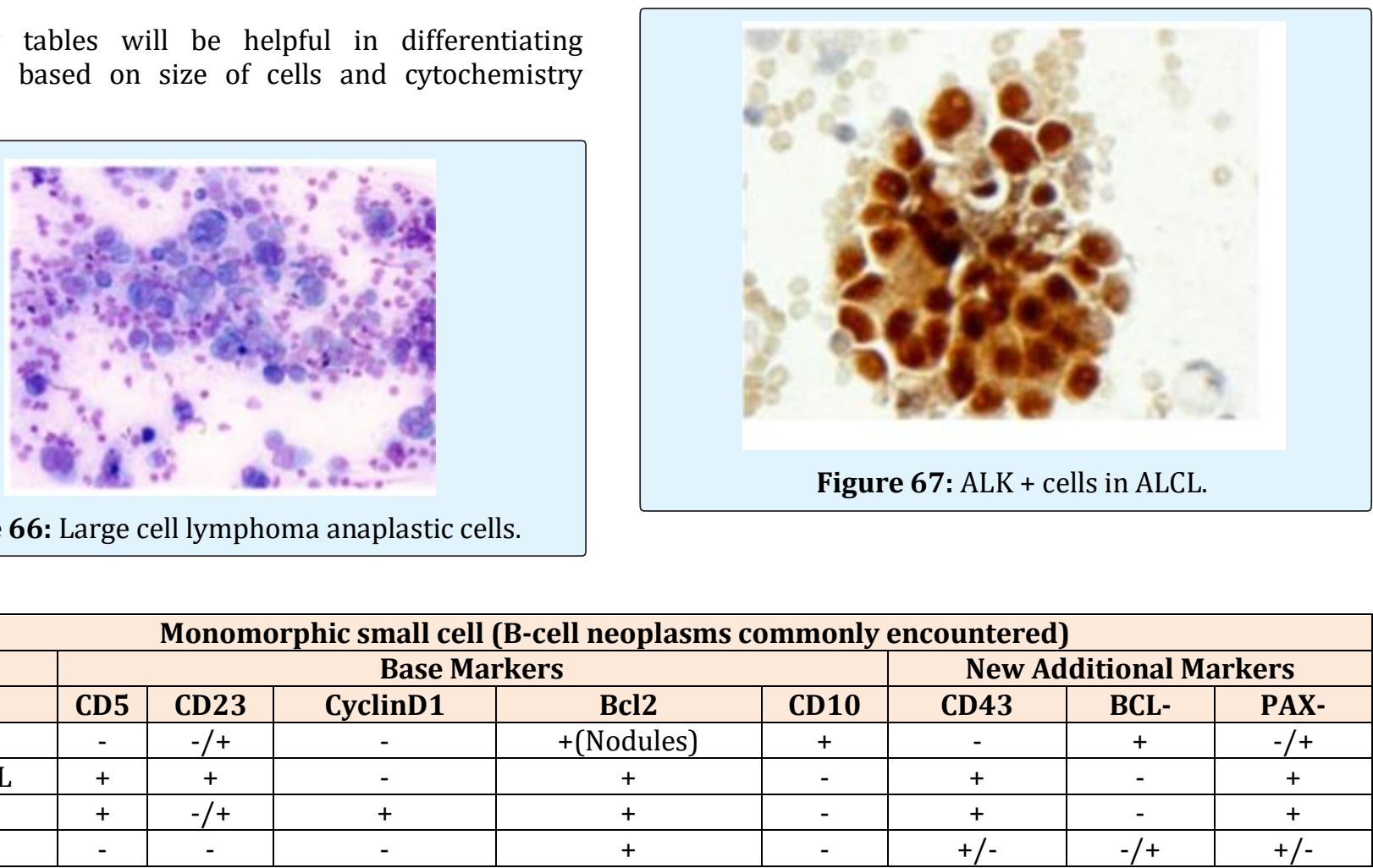

Figure 66: Large cell lymphoma anaplastic cells.

\begin{tabular}{|c|c|c|c|c|c|c|c|c|}
\hline \multicolumn{8}{|c|}{ Monomorphic small cell (B-cell neoplasms commonly encountered) } \\
\hline & \multicolumn{9}{|c|}{ Base Markers } & \multicolumn{3}{c|}{ New Additional Markers } \\
\hline & CD5 & CD23 & CyclinD1 & Bcl2 & CD10 & CD43 & BCL- & PAX- \\
\hline FL & - & $-/+$ & - & $+($ Nodules) & + & - & + & $-/+$ \\
\hline CLL/SLL & + & + & - & + & - & + & - & + \\
\hline MCL & + & $-/+$ & + & + & - & + & - & + \\
\hline MZL & - & - & - & + & - & $+/-$ & $-/+$ & $+/-$ \\
\hline
\end{tabular}

+, >50\%; -, >5\%; -/+, 5-25\%; +/-, 25-50\%; FL- Follicular Lymphoma; CLL/SLL- Chronic lymphocytic leukemia/small lymphocyte lymphoma; MCL- Mantle cell lymphoma; MZL- Marginal zone lymphoma.

Table 10: Monomorphic small cell.

\begin{tabular}{|c|c|c|c|c|c|}
\hline \multicolumn{7}{|c|}{ Monomorphic intermediate sized cells with diffuse pattern } \\
\hline CD20 & CD10 & Tdt & CD99 & mib-1 \\
\hline Lymphoblastic & $-/+$ (Btype) & + & + & + & $60-70 \%$ \\
\hline Burkitts & + & + & - & - & $100 \%$ \\
\hline
\end{tabular}

,$+>50 \% ;-,>5 \% ;-/+, 5-25 \% ;+/-, 25-50 \%$.

Table 11: Monomorphic intermediate sized cells.

\begin{tabular}{|c|c|c|c|c|c|c|c|c|}
\hline & CD15 & CD30 & CD20 & CD45 & ALK-1 & Clusterin & MUM1 & Fascin \\
\hline CHD & + & + & $-/+$ & $-/+$ & - & $+/-(M)$ & + & + Strong (C) \\
\hline NLPHD & - & - & + & + & - & - & $-/+$ or - & - \\
\hline ALCL & - & + & - & + & + & $+\operatorname{dot}$ like (C) & + & + Weak (C) \\
\hline T/HRBCL & - & $-/+$ & + & + & - & $-/+$ & UK & UK \\
\hline MLBCL & - & $-/+$ & + & + & - & UK & Uk & - \\
\hline
\end{tabular}

+, >50\%; -, <5\%; -/+, 5-25\%; +/-, 25-50\%; (M)- Membrance; (C)- Cytoplasmic; UK- unknown; CHD- Classical Hodgkin's Disease; NLPHD- Nodular lymphocyte predominance Hodgkin's disease; ALCL- Anaplastic large cell lymphoma; T/HRBCL- T-cell/histiocyte rich B-cell lymphoma; MLBCL- Mediastinal large B-cell lymphoma; Important caveats to remember; CD15- 30\% of CHD can be negative; CD30- C can be expressed in embryonal carcinoma melanoma and pancreatic cancer (Figure 68).

Table 12: Lymphomas based on size of cells. 


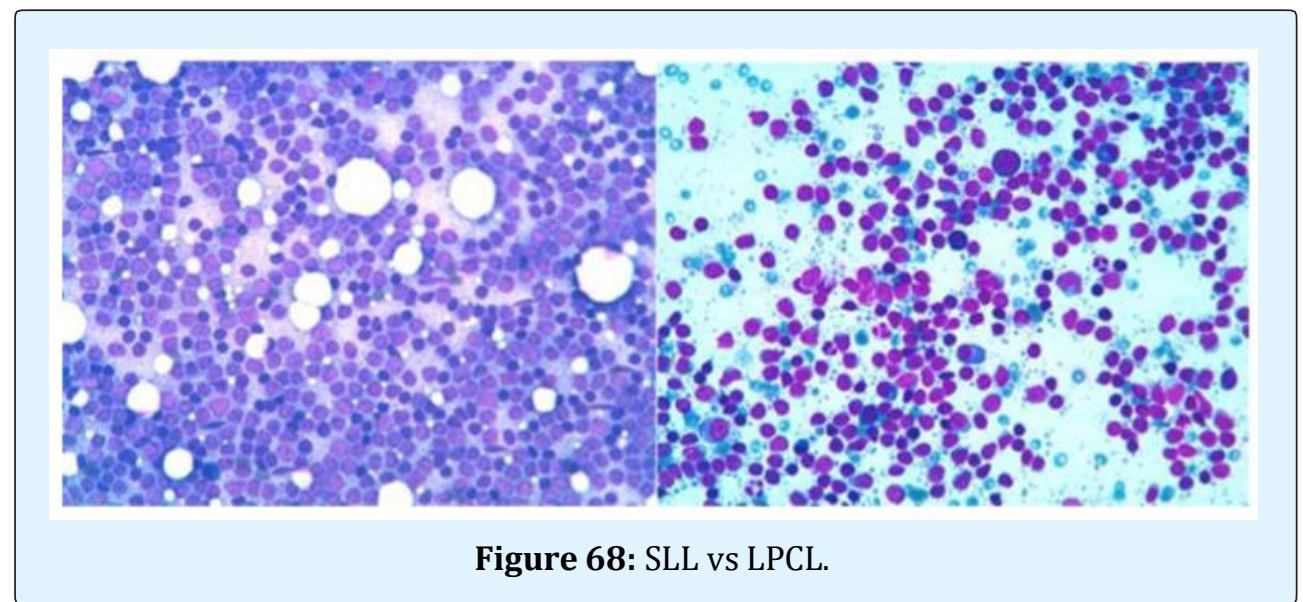

\section{Angiofollicular lymphoid hyperplasia (Castleman disease)}

- Cellular smear show mixed population of small and large lymphoid cells including follicular centre cells and tingible-body macrophages. Prominent vascularity with hyalinized capillaries [81,82].

- Germinal centre cells had eosinophilic material within the cell aggregates.

- There were no epitheloid cells, giant cells or necrosis (Figure 69).

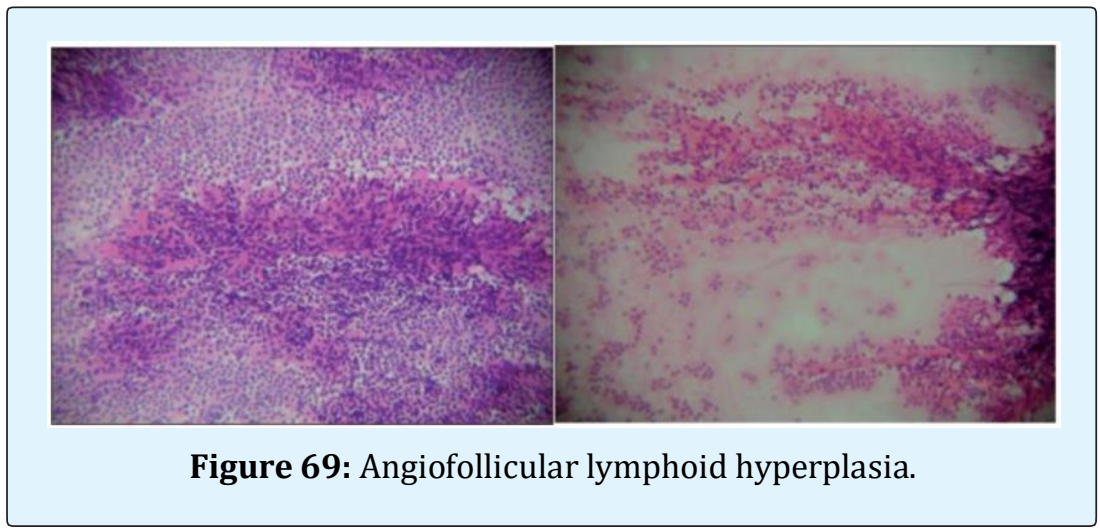

\section{Germ cell neoplasms}

Germ cell neoplasms of all types occur in the mediastinum and constitute about $20 \%$ of primary mediastinal masses. A strong association between germ cell tumors and Klinefelter's syndrome and with hematological neoplasia is recorded. Elevated serum levels of human chorionic gonadotrophin (beta-HCG) and alpha fetoprotein, together with clinical findings, may virtually establish the diagnosis in non-seminomatous tumors [83].

\section{Teratoma (mature cystic)}

Mature cystic teratomas of the mediastinum occur mainly in young women, have similar appearances to the counterpart in the ovary and are benign [84].

- Keratinous debris, anucleate squamous cells, hair shaft material,

- Mature squamous and/or glandular epithelium.

- Granulomatous reaction to tumor, sampling, welldifferentiated squamous cell carcinoma can arise from mature teratomas (Figure 70). 


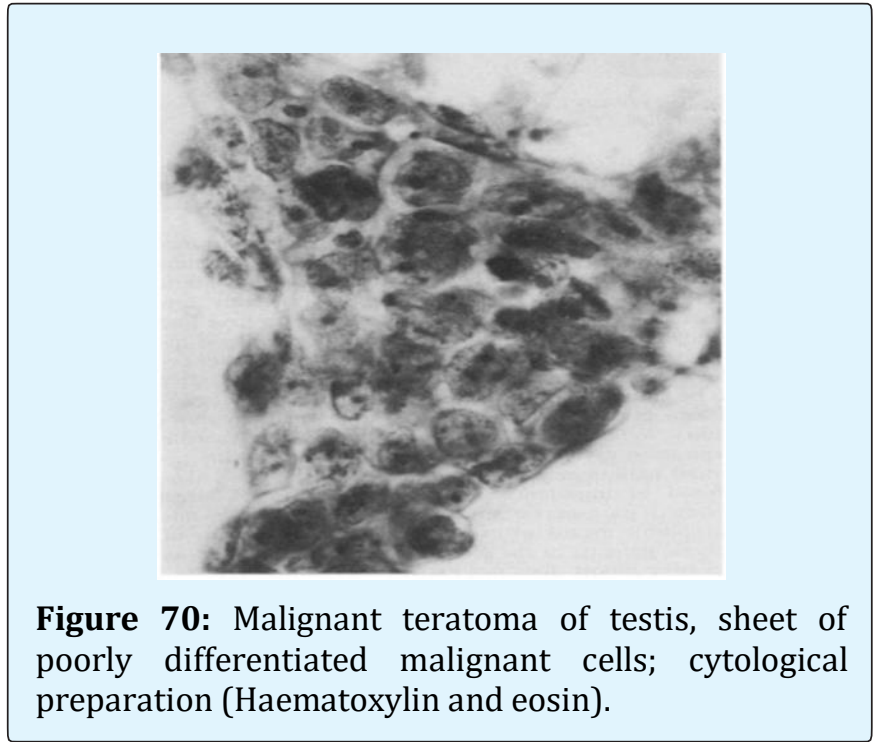

\section{Teratoma (immature, malignant)}

Immature elements may occur in some tumors. Immature neuroepithelial elements often predominate; resembling neuroblastoma. Other tumors such as carcinosarcoma, blastoma, synovial sarcoma, Wilms tumor or malignant mesothelioma will enter the differential diagnosis when biphasic lesions are encountered.

\section{Germinoma}

- High cellularity and mitotic activity $[85,86]$,

- Dispersed large cells; small loose groups,

- Rounded nuclei, prominent single or multiple nucleoli,

- Abundant fragile cytoplasm; vacuolation (glycogen),

- 'Tigroid' or streaked cytoplasmic/glycogenic background,

- Lymphocytes; granulomas (Figure 71)
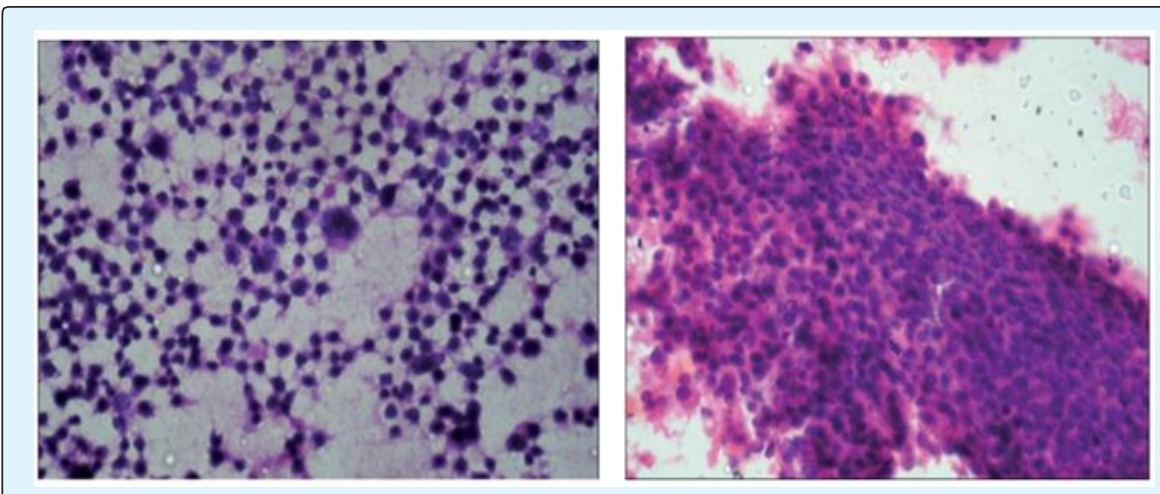

Figure 71: Cytology and cell block preparation from seminoma.

\section{Yolk sac tumor/Endodermal sinus tumor}

- Cellular smears [87],

- Aggregates and dispersed cells with solitary nuclei and large nucleoli,
- Adenocarcinoma-like groups; sheets called Schiller duval bodies,

- Spindle/mesenchymal cells (Figure 72).

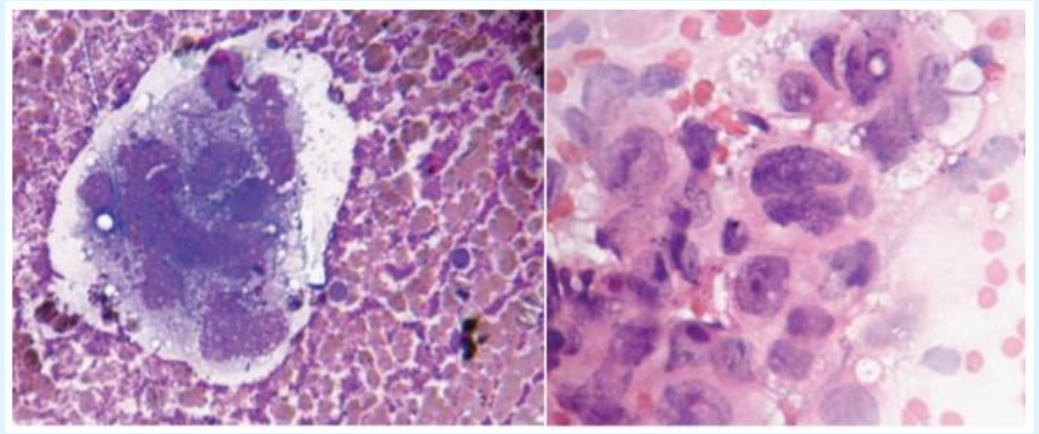

Figure 72: Tumor cells in loose cluster with open chromatin, prominent nucleoli and finely vacuolated cytoplasm. 


\section{Retro peritoneal lesions - Kidney and Retroperitoneal Lymph Nodes}

The kidney:

\section{Benign and inflammatory conditions:}

Renal cysts: The diagnosis of simple renal cyst is usually made by US examination alone and cytological confirmation is not often necessary. But the aspirated fluid is often routinely submitted for cytological examination. The fluid is typically thin, clear, containing small numbers of degenerate epithelial cells and macrophages, but the number of cells can occasionally be surprisingly large. If the radiological features are typical of a cyst and if the aspirated fluid is clear, there is no cause for concern. On the other hand, if the aspirate contains old blood and/or necrotic debris, a cystic neoplasm has to be excluded by further investigations, even if no tumor cells are found in the smears (Figure 73).

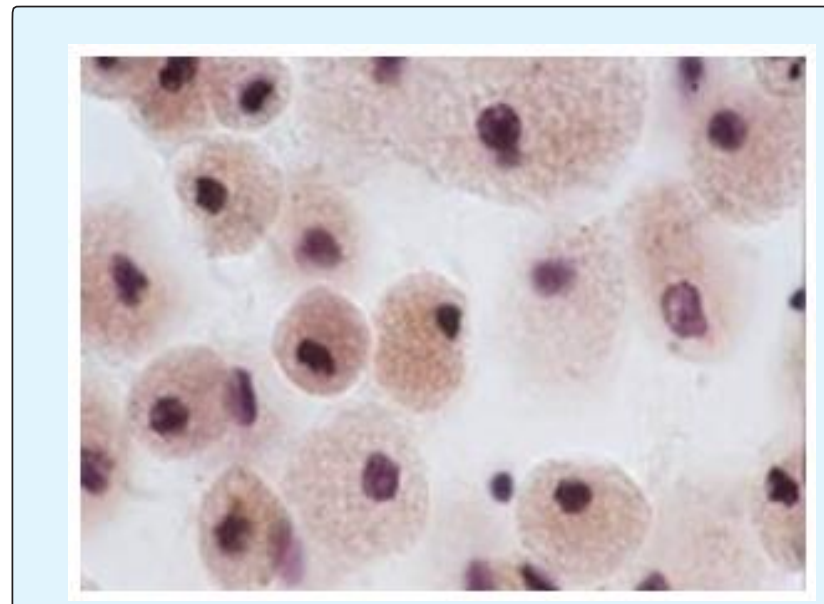

Figure 73: Simple renal cyst cytology shows only macrophages.

\section{Cystic Nephroma (Multilocular Renal Cyst)}

Aspiration yields mainly cyst fluid. The cell content of the fluid is fairly low, but the cells often appear atypical and may be mistaken for cystic renal cell carcinoma. The atypical cells, which are both clustered and single, represent the hobnail type of epithelial cells lining the cystic spaces smears contained highly cellular tissue fragments of spindle cells in addition to epithelial cells of hobnail type (Figures 74-76).

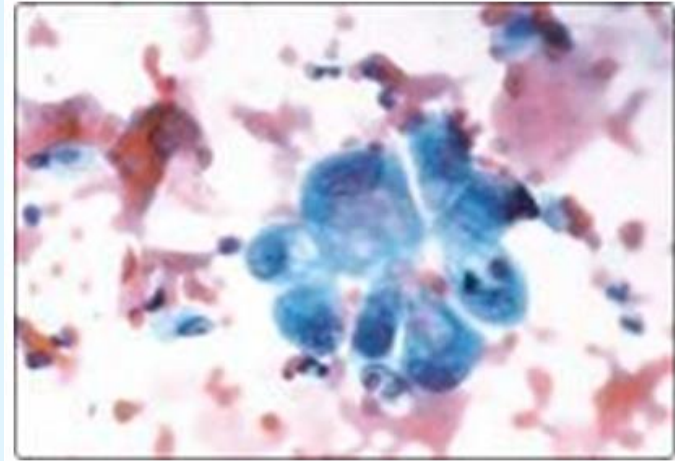

Figure 74: Nuclear hobnailing in cystic nephroma.
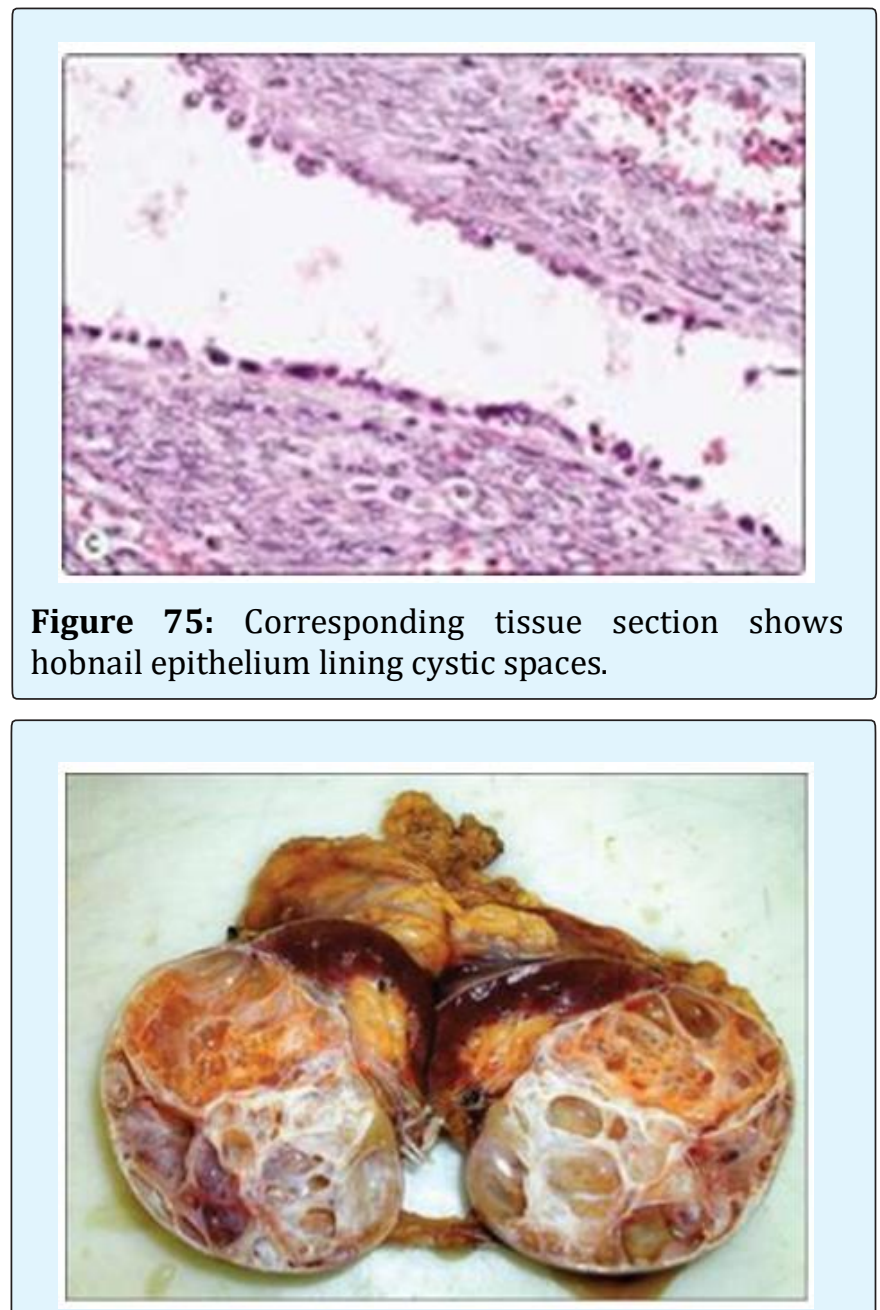

Figure 76: Gross picture of cystic nephroma. 


\section{Abscess}

- The aspirate is purulent and smears show mainly degenerating polymorphs and macrophages.

- A few normal or degenerating tubular epithelial cells may be present. Part of the aspirate should be submitted for culture.

\section{Xanthogranulomatous Pyelonephritis}

- Macrophages look quite atypical smears, can be mistaken for malignancy [88,89].

- They have a vacuolated cytoplasm and the nuclei appear enlarged and irregular, particularly in air-dried smears.

- The clinical and radiological findings, the generally inflammatory character of the smear, and the recognition of the 'atypical' cells as histiocytes (easier in alcohol-fixed smears) point to the correct diagnosis (Figure 77).

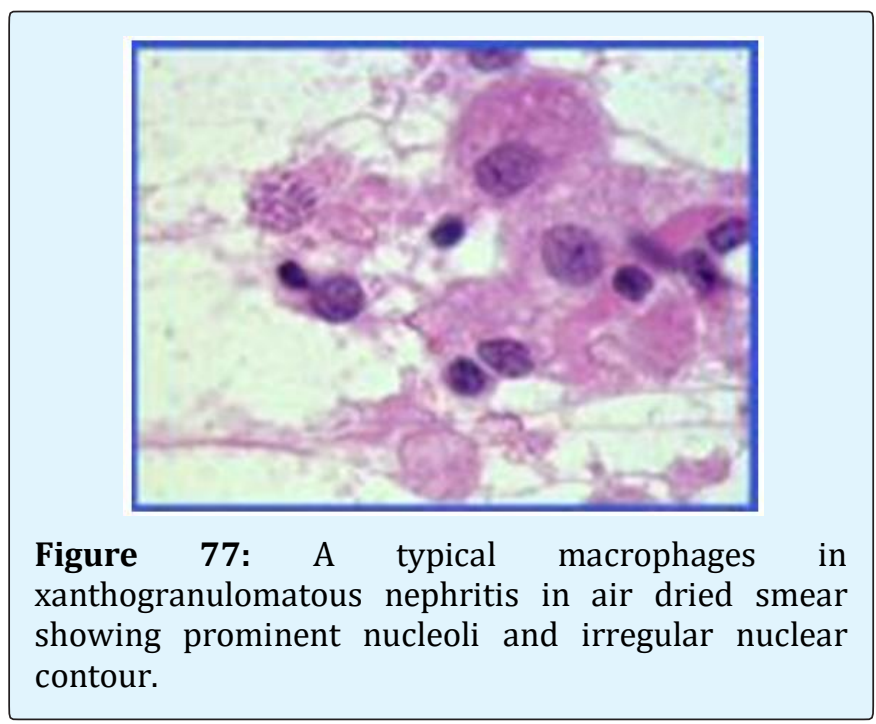

\section{Angiomyolipoma of kidney}

- spindle cells with features of smooth muscle cells [9093],

- cohesive syncytial tissue fragments and some single cells, a background of blood, prominent fat droplets and often Adipocytes,

- segments of small blood vessels (variable),

- positive immunostaining for smooth muscle actin and HMB-45,

- EMA negative.

- Nuclear chromatin is bland and mitoses are rare.

- Large fat vacuoles and some adipocytes are intimately associated with the spindle cells.
- Strands of endothelial cells and short segments of small vessels are often, but not always present in smears.

A background of fat droplets and adipocytes is usually seen in angiomyolipoma, whereas strands of basement membrane material with adhering tumor cells are characteristic of renal cell tumors. Prominent nuclear atypia and pleomorphism can occur also in angiomyolipoma of the usual spindle cell type raising a suspicion of malignancy. Correlation with clinical and radiological findings and immunostaining (EMA, SMA, HMB-45) is helpful in atypical cases (Figure 78).

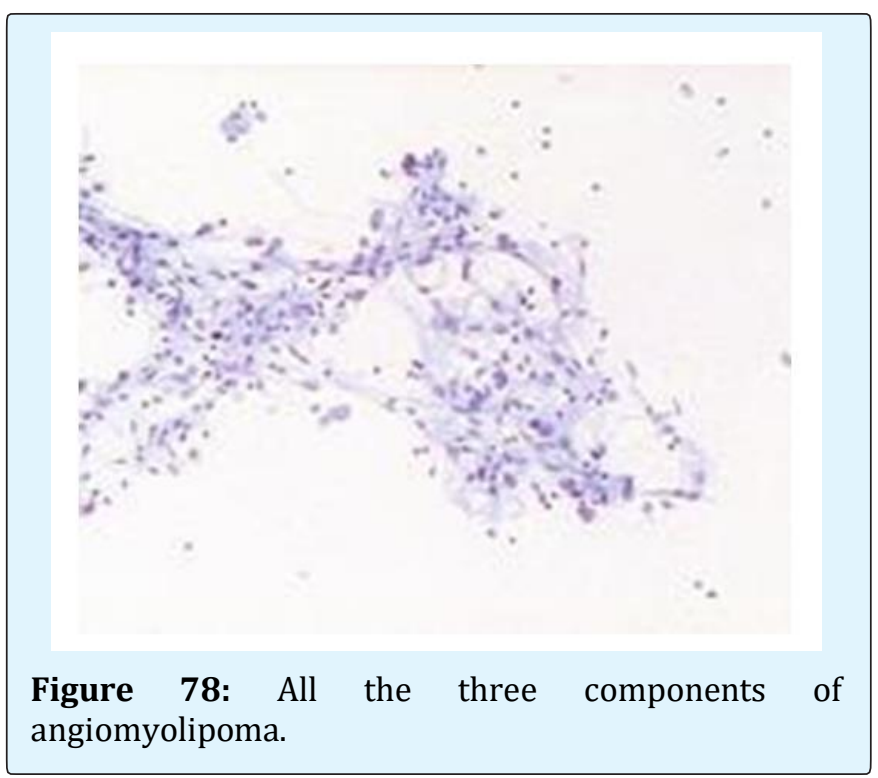

\section{Renal Cell Carcinoma}

\section{Clear cell renal cell carcinoma}

- Variable cellularity, background of fresh and altered blood and necrotic debris,

- Cells mainly in loosely cohesive tissue fragments; some single cells,

- Abundant fragile pale eosinophilic cytoplasm, vacuolated or granular but not truly clear; visible cell borders,

- Rounded nuclei, variable anisokaryosis; pleomorphic in high grade tumors,

- Nuclear size, chromatin and nucleoli vary with tumor grade,

- Intranuclear cytoplasmic inclusions common,

- Tumor cells adhering to endothelial cells and strands of stromal (basement membrane) material,

- Co-expression of vimentin and L.M.W. cytokeratin; EMA, RCC antigen and CD10 positive (Figure 79). 

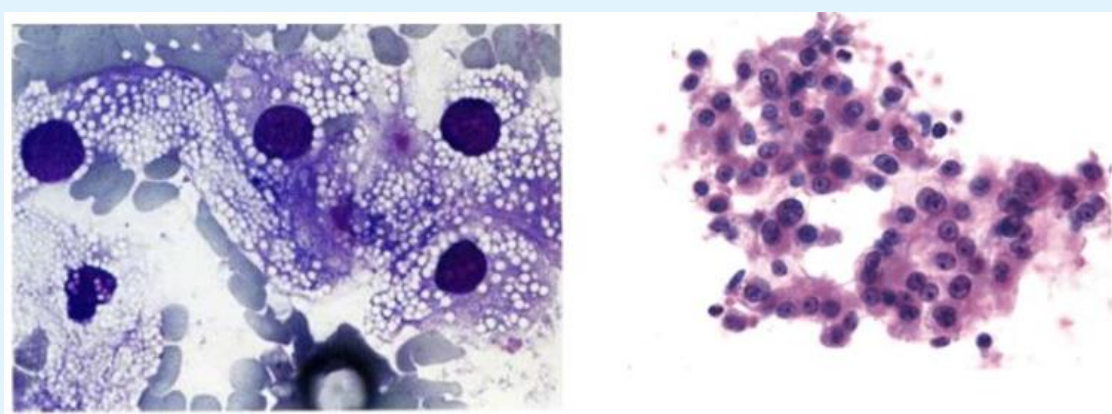

Figure 79: Left -A cluster of cells in FNAB, Smear from clear cell carcinoma showing fine cytoplasmic vacuolation mostly due to lipid.

\section{Papillary Renal Cell Carcinoma}

- Cell-rich smears,

- Cells forming papillary fragments/clusters with fibrovascular cores, and dispersed single cells,

- Small epithelial cells, mainly basophilic, with low-grade uniformly small nuclei, some grooved (type 1), or larger, acidophilic cells with larger nuclei of intermediate grade (type 2),

- Abundant foamy macrophages and hemosiderin pigment (type 1); background of blood and necrotic debris,

- Psammoma bodies commonly present,

- Immunoprofile similar to clear cell carcinoma, but vimentin is variable.

Numerous vacuolated macrophages are a characteristic component when present and intracytoplasmic hemosiderin is often seen [94,95] (Figure 80 \&Table 13).

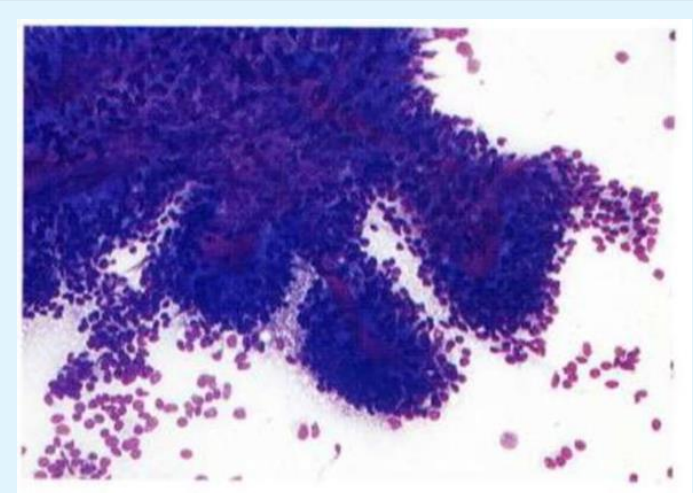

Figure 80: Left-Aspiration smear from a papillary renal cell carcinoma showing a papillary structure composed of fibrovascular cores covered by tumor cells.

\begin{tabular}{|c|c|}
\hline Type 1 papillary RCC & Type 2 papillary RCC \\
\hline $\begin{array}{c}\text { Basophilic cytoplasm and } \\
\text { bland nuclei }\end{array}$ & $\begin{array}{c}\text { Acidophilic cytoplasm and } \\
\text { atypical nuclei }\end{array}$ \\
\hline CK7+ & CK7- \\
\hline EMA+ & EMA- \\
\hline Good prognosis & Poor prognosis \\
\hline
\end{tabular}

Table 13: Papillary Renal Cell Carcinoma.

\section{Chromophobe Renal Cell Carcinoma}

- Moderately to highly cellular smears,

- Small, loosely cohesive monolayered sheets and single cells with intact cytoplasm,

- Mixture of large cells with abundant, pale, flocculent cytoplasm and smaller cells with dense cytoplasm, flocculent,

- Thick cell membrane, cytoplasm dense peripherally, pale centrally (halo),

- Nuclear grade usually 2, anisokaryosis, binucleation common, small nucleoli,

- No stromal material, no-necrosis,-

- CK7+, CD117+, vimentin, CD10, RCC antigen variable (Figure 81).

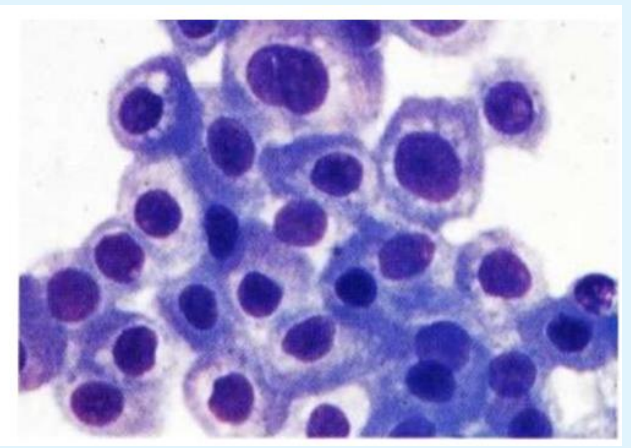

Figure 81: Chromophobe RCC showing perinuclear halos and bland monomorphic nuclei. 


\section{Five Percent of RCCs are of the Chromophobe Type}

Renal oncocytoma: Renal oncocytoma is the main differential diagnosis in FNB smears. Cells of oncocytoma have dense granular eosinophilic cytoplasm and small bland nuclei of uniform size. Immune markers are helpful in this distinction (Figure 82).

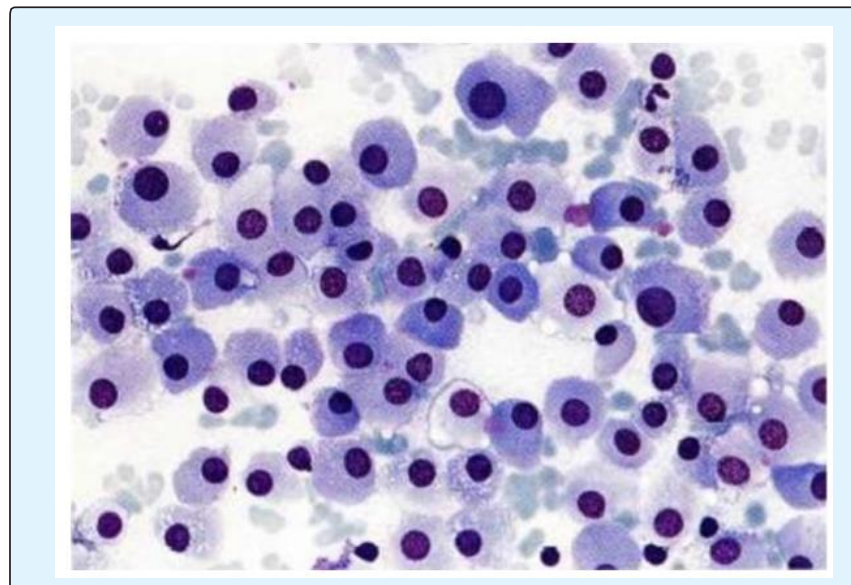

Figure 82: Loosly arranged clusters of oncocytic cells having bland monomorphic nuclei and fine granular eosinophilic cytoplasm.

Collecting duct type of RCC: Single cells of glandular or intermediate type with malignant nuclear features. A tubular or papillary arrangement may be present (Figure 83).

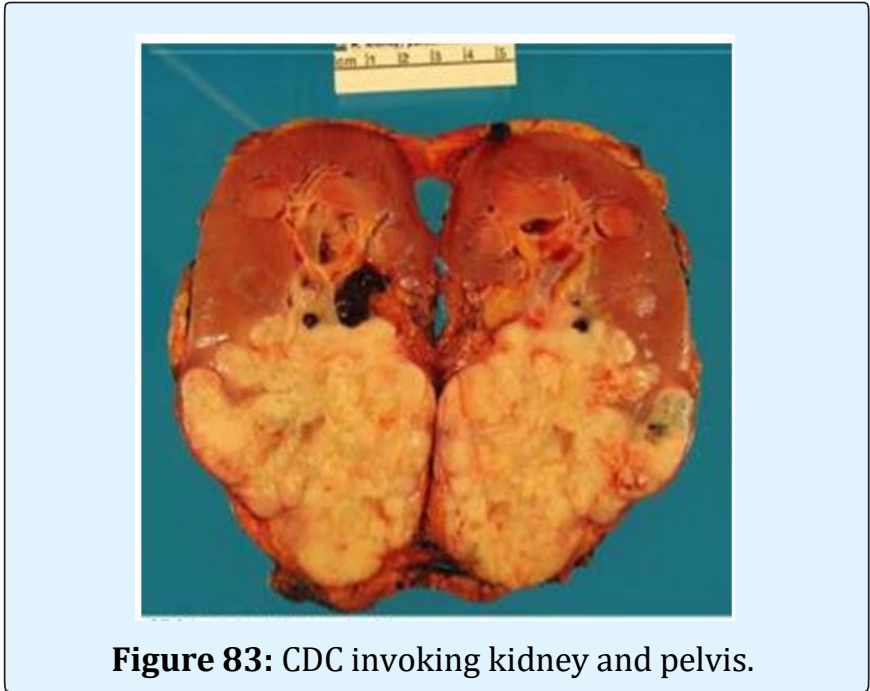

Xp11.2 Translocation Carcinoma: Xp11.2 translocation carcinoma has recently been separated from clear cell RCC on the basis of cytogenetic findings. It is most common in children but also occurs in adult patients and has a very aggressive behavior [96]. The histological features are a mixed pattern of clear cell and papillary components, prominent vascularity and in some cases hyaline globules and psammoma bodies. Positive nuclear staining for TFE3 and melanotic variants also reported (Figure 84).

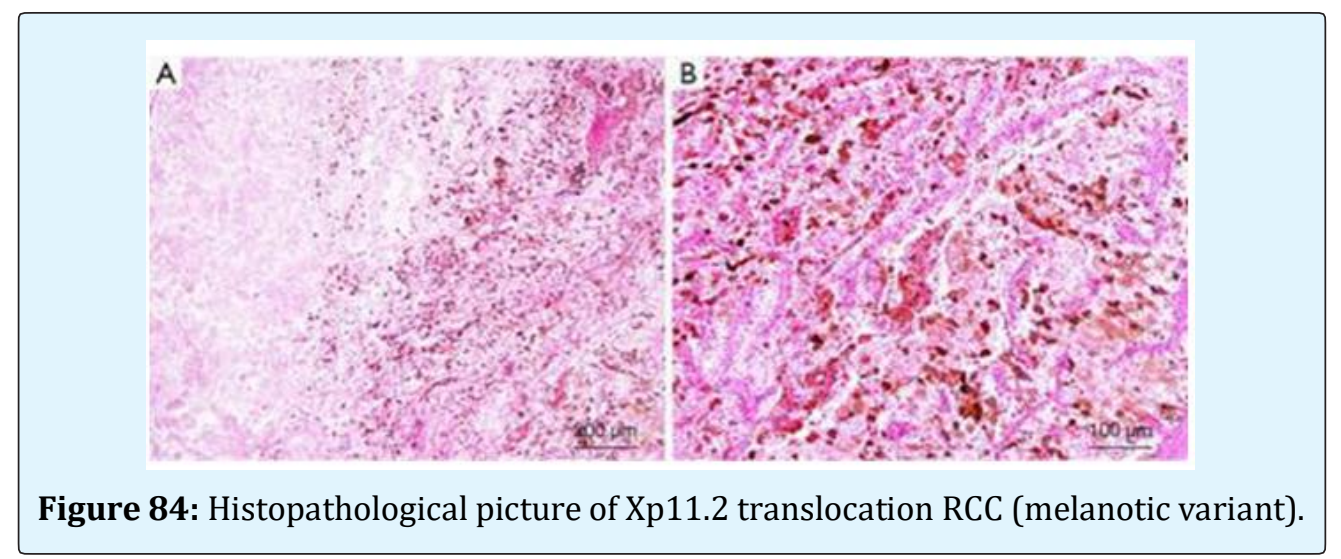

\section{Metanephric adenoma [97-100]}

- Rare benign renal tumor arising from metanephricblastema, most often seen in middle-aged women.

- Smears are relatively cellular of monomorphous cells with small oval overlapping nuclei, bland chromatin and scanty cytoplasm.
- The cells are arranged in micropapillary/trabecular clusters and rosette-like, small tubular/microfollicular groups.

- The cell groups are associated with scanty stromal, basement membrane-like material sometimes forming a thin central core in small rounded clusters. 
- The cytology in conjunction with the metanephric adenoma (Figures 85-87). clinical/radiological findings is needed for diagnosis

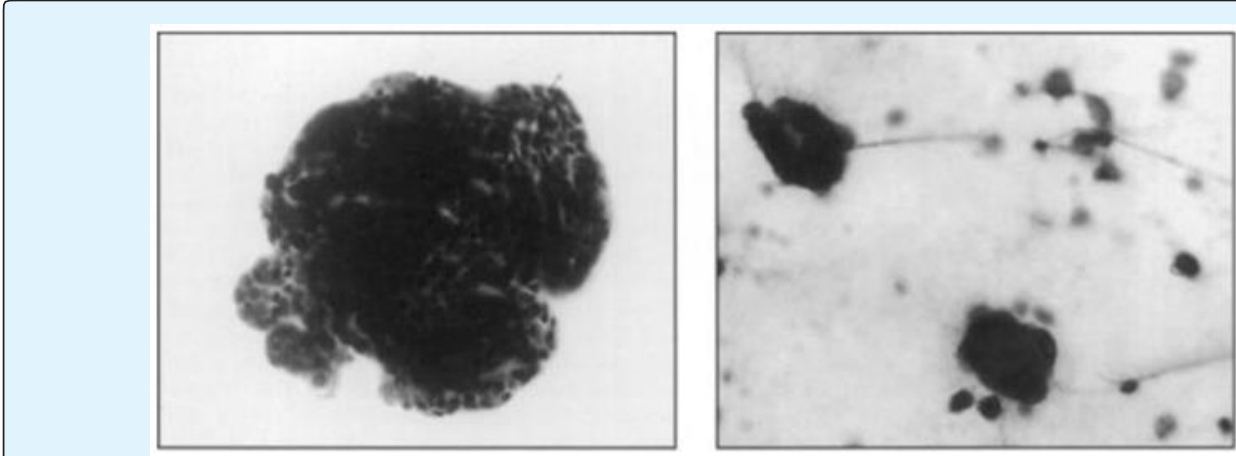

Figure 85: Glomeruloid like structure in metanephric adenoma \& resettes like appearance.

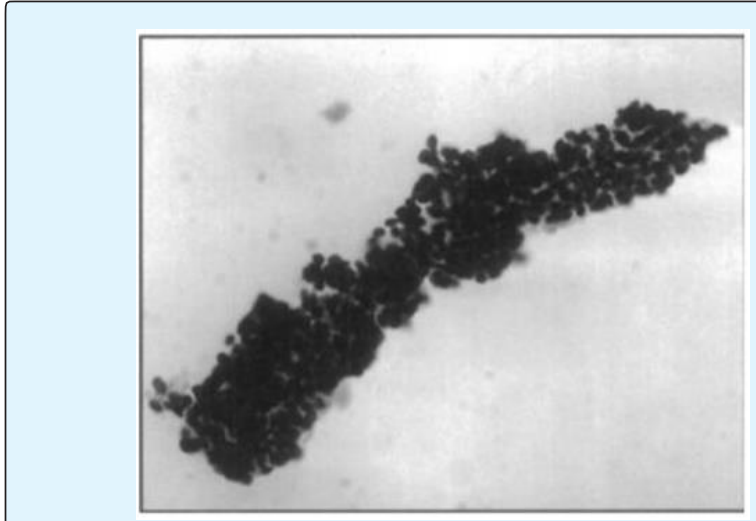

Figure 86: Tubules like feature which also support the diagnosis.

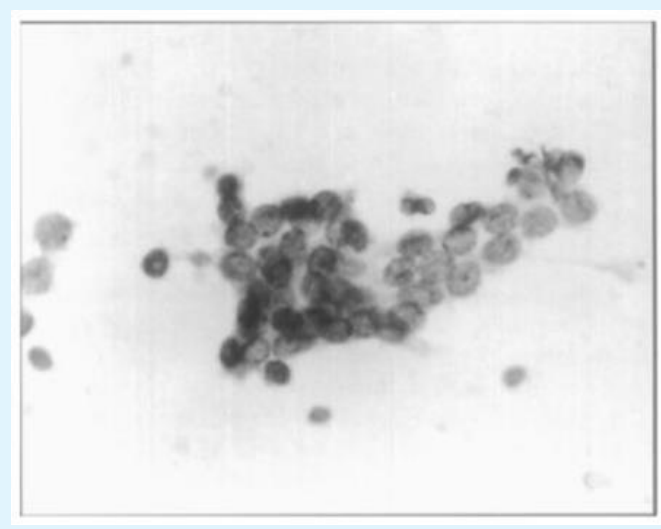

Figure 87: A feature of metanephricadenoma, optical clearing and grooving of nuclei.

\section{Wilms Tumor}

- Numerous undifferentiated small cells, single and in tight clusters (blastema) [101-103],

- Small, round or ovoid, hyperchromatic nuclei; multiple small Nucleoli,

- Scanty cytoplasm,

- Epithelial differentiation: rosettes, tubular structures or cords (commonly present),

- Mesenchymal differentiation: spindle cells (sometimes present).

Smears are usually predominated by small, undifferentiated malignant cells representing blastema. A specific diagnosis requires in addition evidence of epithelial and mesenchymal differentiation, but this may only be obvious in the better-differentiated tumors. Useful markers are vimentin, LMWCK, EMA and WT1 (Figures 88 \& 89).

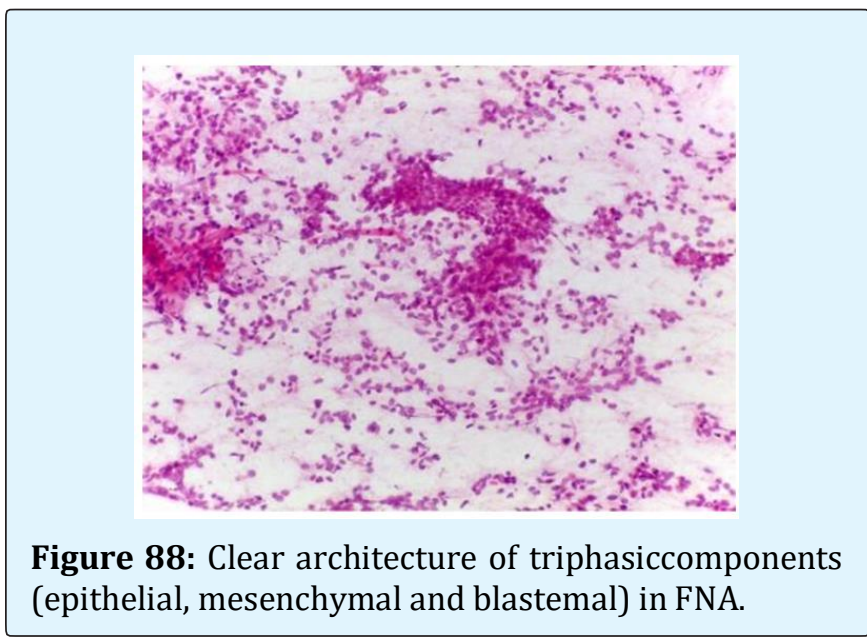




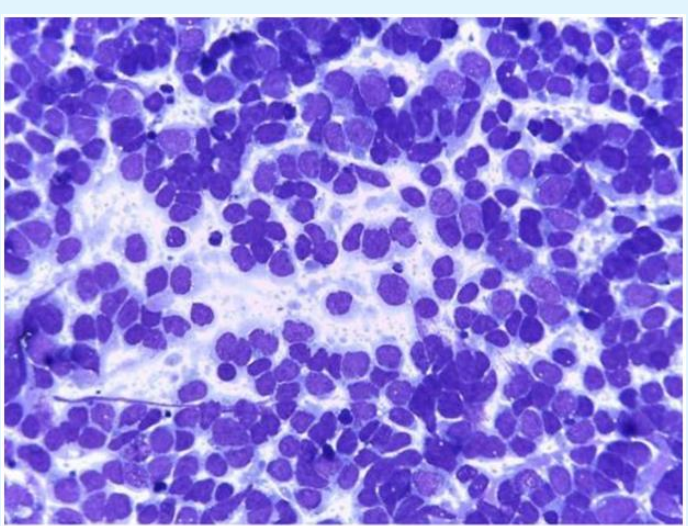

Figure 89: Monomorphic blastemal cells in geimsa with clear nuclear moulding and cytoplasmic remnant.

\section{Transitional cell carcinoma}

- High cellularity; cells single and in syncytial clusters; rarely papillary structures [104,105],

- Large pleomorphic nuclei; variable hyperchromasia; coarse chromatin,
- Eccentric nuclei within a dense cytoplasm,

- Prominent nucleoli,

- Cercariform cells often present (Figures 90 \& 91).

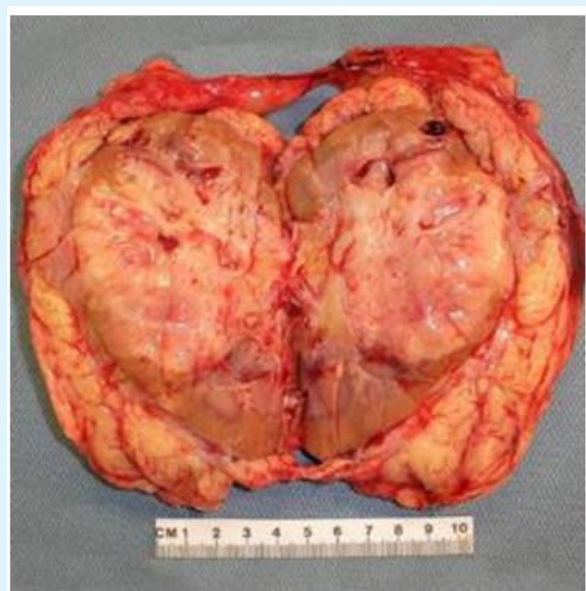

Figure 90: Gross picture of transitional cell ca. of renal pelvis.
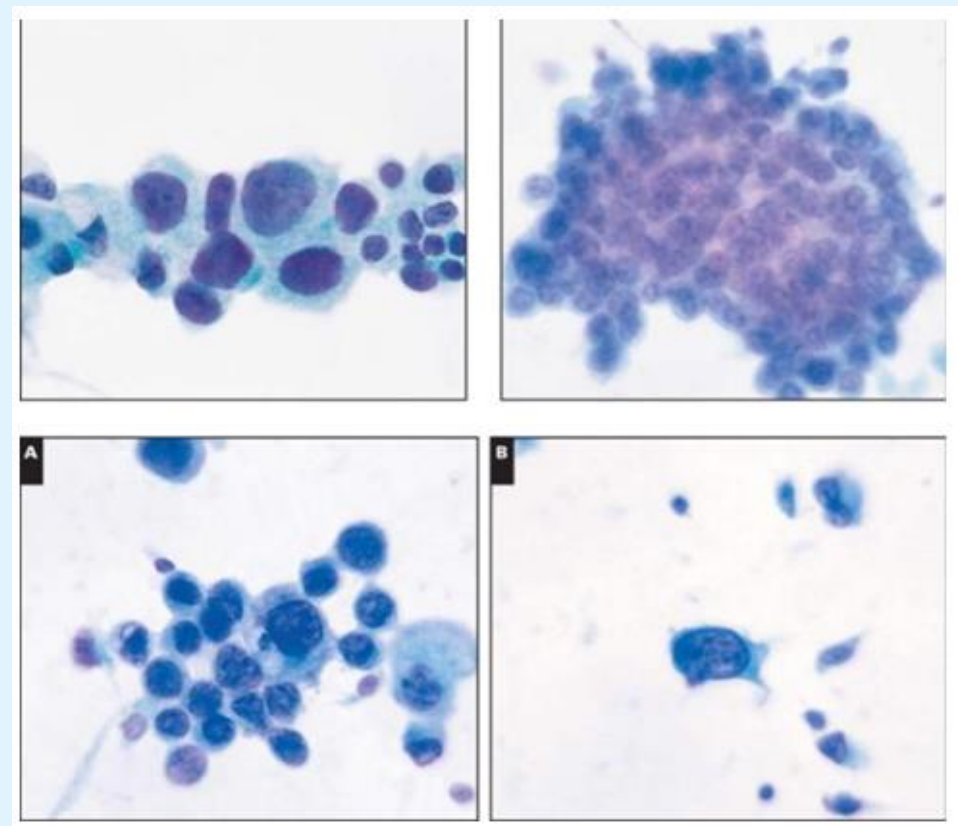

Figure 91: Morphology of all 4 smear clearly shows crowding, overlapping, high N:C ratio, pleomorphism and cercariform cells, and papillae.

So-called 'cercariform' cells, which have long unipolar cytoplasmic processes with a thickening at the tail, are regarded as a clue to the recognition of TCC in smears.
Tumor cells are positive for CK7, usually also for CK20, high molecular weight cytokeratin and thrombomodulin, negative for RCC antigen and CD10. 
Retroperitoneum proper: Malignant tumors includes,

- Liposarcoma,

- Malignant fibrous histiocytoma and

- Leiomyosarcomaare the most frequent malignant soft tissue tumors encountered in the retroperitoneum. Rhabdomyosarcoma is mainly seen in children and is most often of the embryonal type.

Benign soft tissue tumors includes,

- Fibromatoses,

- Xanthogranuloma,

- Lipoma (much less common than liposarcoma),

- Leiomyoma (rare),

- Schwannoma
- Neurofibroma and

- Angiomatous tumors.

\section{Fibromatosis}

- Cellular smears and show scattered spindle to fusiform cell clusters, stromal fragments and collagen matrix material.

- Spindle cells embedded in or are in proximity to the densely eosinophilic collagen matrix material.

- Spindle cells are oval to spindle shaped with tapering ends, bipolar nuclei, bland nuclear chromatin and inconspicuous nucleoli (Figure 92).

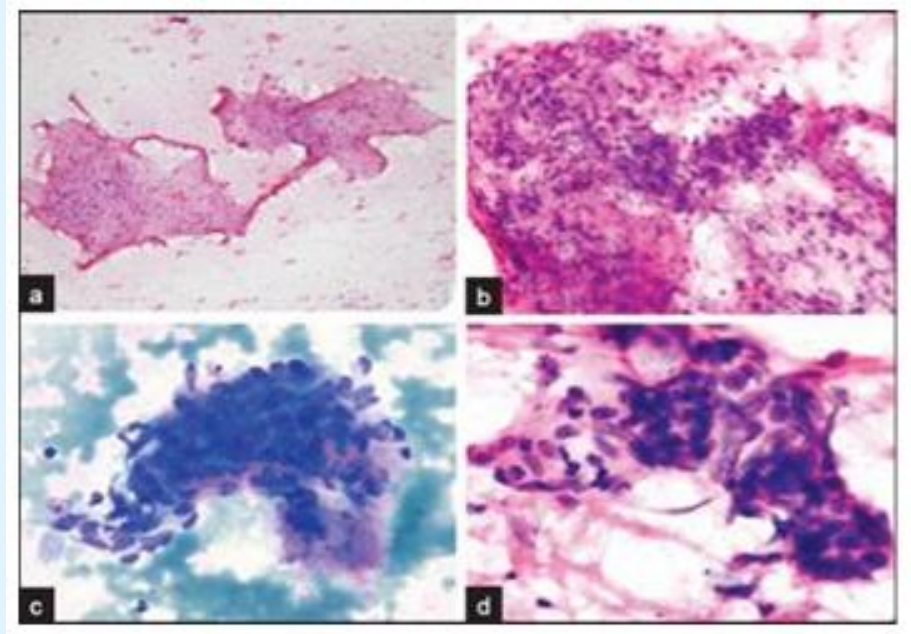

Figure 92: All the above 4 pictures clearly elicit the cytomorphology of fibromatosis (spindle cells, stromal fragment, and collagen).

\section{Hemangiopericytoma}

This tumor is usually found in the soft tissues of the extremities (usually distal).Tends to have amultinodular pattern of growth [106] (Figure 93).

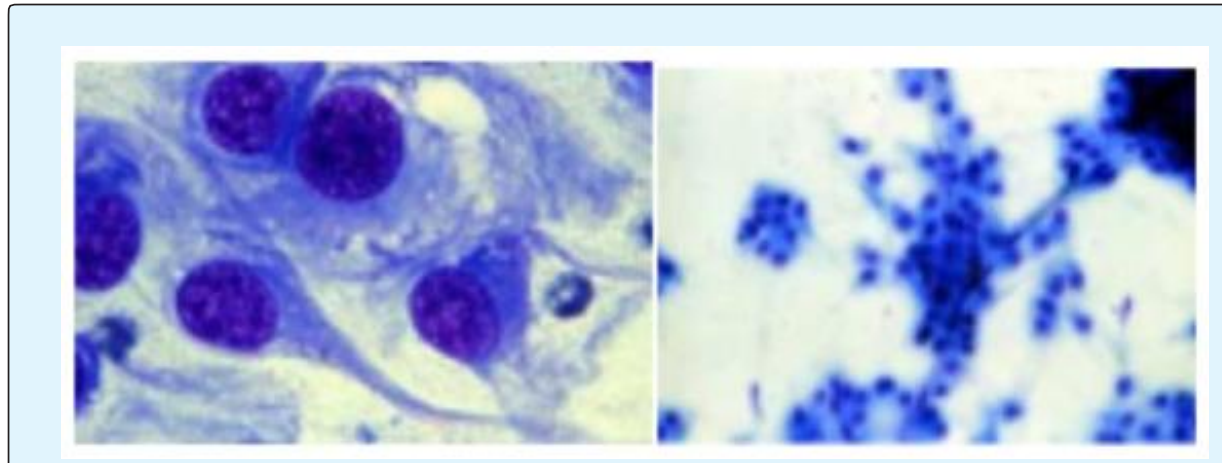

Figure 93: Pericytes which are malignant in nature and also intervening vessels. 


\section{Cystic lymphangioma}

Smears of fluid aspirated from a cystic lymphangioma contain only lymphoid cells, mainly small lymphocytes, in variable numbers [107] (Figures $94 \&$ 95).

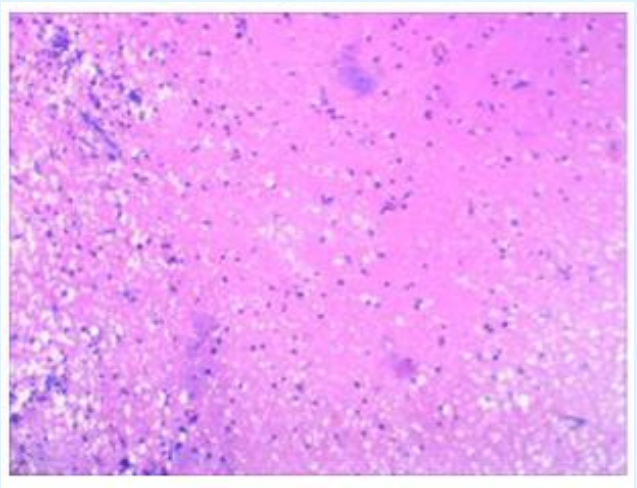

Figure 94: Contents of lymphangioma (both lymph and blood) in FNA.

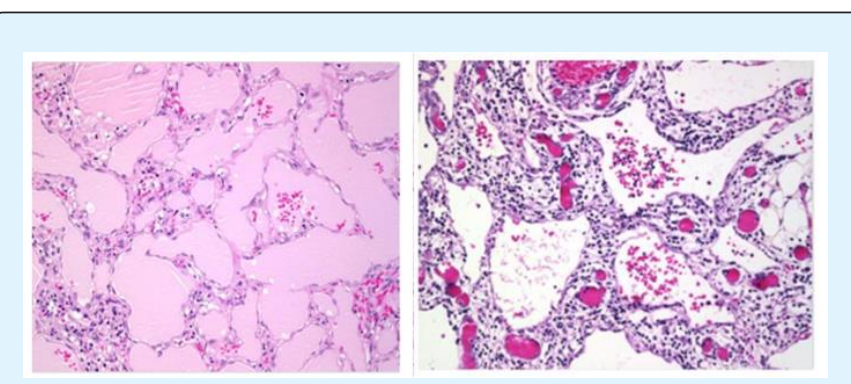

Figure 95: Cystic lymphangioma in deep thoracic region shows clear lymphatic and angiomatous vessels.

\section{Idiopathic retroperitoneal fibrosis}

- Occurs mainly in patients with a history of surgery and/or radiotherapy for urogenital cancer.

- Idiopathic fibrosis or metastases from other sites or lymphoma may also enter the differential diagnosis.

- Smears from idiopathic or post radiation fibrosis are likely to be hypo cellular and only a positive finding of neoplastic cells is diagnostic.

\section{Retroperitoneal Lymph Nodes}

Cancers of the Urogenital tract, Large bowel and Pancreas are the main sources of metastases to retroperitoneal nodes. Germ cell tumor, primary or metastatic, should be considered in cases without a known primary [108-110]. Germ cell tumors have a fairly characteristic cytological pattern and the diagnosis can be supported by immunostaining. The most common germ cell tumors in the pediatric age group are teratoma, embryonal carcinoma and yolk sac tumor; in the adult, all types can occur in this site. The tendency to fibrosis shown by some malignant lymphomas of retroperitoneal nodes can make it difficult to obtain sufficient numbers of cells by FNB, or can mimic a chronic inflammatory process. Core needle biopsy may be necessary to obtain diagnostic material and tissue for immune marker studies.

\section{Conclusion}

We studied 130 cases of image guided FNAC of deep seated lesions. Whose detailed history, clinical examination and USG/CT guided FNAC was done and the findings were as follows:

- In the present study, the age range of the patient varied from as young as 2 to 80 years. Majority of the patients were in the age group of 51-60 yrs (25.38\%) closely followed by 41-50 yrs (22.3\%).

- A male predominance was observed in present study with a male to female ratio of 2.82:1

- In this present study out of 130 lesions, 113 were aspirated under ultrasonographical guidance and 17 were aspirated under computed tomographic guidance.

- This present study suggested that lung (69.23\%) is the most common organ involved in deep seated lesions .This may be due to some epidemic reasons like smoking, infections and genetic association. This present study suggested the second most common organ of involvement is liver (6.15\%).

- In the present study, it was observed that a majority were malignant lesions which comprised $74.62 \%$ lesions and the remaining $15.48 \%$ were benign and non-neoplastic lesions.

\section{References}

1. Logrono R, Rampy BA, Adegboyega PA (2002) Fine needle aspiration cytology of hepatobiliary cystadenoma with mesenchymal stroma. Cancer 96(1): 37-42.

2. Nguyen GK (1986) Fine-needle aspiration biopsy cytology of hepatic tumors in adults. Pathol Annu 21(1): 321-349.

3. Jain M, Ahluwalia C, Agarwal K, Pathania OP (2004) Cytological diagnosis ofcholangiocarcinoma with rib 
metastasis in a young female-a case report. J Pathol Microbiol 47(3): 417-420.

4. Parikh B, Jojo A, Shah B, Bansal R, Trivedi P, et al. (2005) Fine needle aspiration cytology of hepatoblastoma: a study of 20 cases. Indian J Pathol Microbiol 48(3): 331-336.

5. Ramdall RB, Cai G, Alasio TM, Levine P (2006) Fineneedle aspiration biopsy for the primary diagnosis of lymphoproliferative disorders involving the spleen: one institution's experience and review of the literature. Diagn Cytopathol 34(12): 812-817.

6. Hollerbach S, Klamann A, Topalidis T, Schmiegel WH (2001) Endoscopic ultrasonography (EUS) and fineneedle aspiration (FNA) cytology for diagnosis of chronic pancreatitis. Endoscopy 33(10): 824-831.

7. Brugge WR (2001) Role of endoscopic ultrasound in the diagnosis of cystic lesions of the pancreas. Pancreatology 1(6): 637-640.

8. Centeno BA, Lewandrowski KB, Warshaw AL, Compton CC, Southern JF (1994) Cyst fluid cytologic analysis in the differential diagnosis of pancreatic cystic lesions. Am J Clin Pathol 101(4): 483-487.

9. Alpert LC, Truong LD, Bossart MI, Spjut HJ (1988) Microcystic adenoma (serous cystadenoma) of the pancreas. A study of 14 cases with immunohistochemical and electron-microscopic correlation. Am J Surg Pathol 12(4): 251-263.

10. Laucirica R, Schwartz MR, Ramzy I (1992) Fine needle aspiration of pancreatic cystic epithelial neoplasms. Acta Cytol 36(6): 881-886.

11. Nguyen GK, Suen KC, Villanueva RR (1997) Needle aspiration cytology of pancreatic cysticlesions. Diagn Cytopathol 17(3): 177-182.

12. van der Waaij LA, van Dullemen HM, Porte RJ (2005) Cyst fluid analysis in the differential diagnosis of pancreatic cystic lesions: a pooled analysis. Gastrointest Endosc 62(3): 383-389.

13. Belsley NA, Pitman MB, Lauwers GY, Brugge WR, Deshpande V (2008) Serous cystadenoma of the pancreas: limitations and pitfalls of endoscopic ultrasound-guided fine-needle aspiration biopsy. Cancer 114(2): 102-110.
14. Pettinato G, Di Vizio D, Manivel JC, Pambuccian SE, Somma P, et al. (2002) Solid-pseudopapillary tumor of the pancreas: a neoplasm with distinct and highly characteristic cytological features. Diagn Cytopathol 27(6): 325-334.

15. Cohen MB, Egerter DP, Holly EA, Ahn DK, Miller TR (1997) Pancreatic regression analysis to identify improved cytologic criteria. Diagn Cytopathol 7(4): 341-345.

16. Francillon YJ, Bagby J, Abreo F (1996) Criteria for predicting malignancy in fine needle aspiration biopsies (FNAB) of the pancreas and biliary tree. Acta Cytol 40: 1084.

17. Hejka AG, Baernacki EG (1990) Cytopathology of well-differentiated columnar adenocarcinoma of the pancreas diagnosed by fine needle aspiration. Acta Cytol 34: 716.

18. Lin F, Staerkel G (2003) Cytologic criteria for well differentiated adenocarcinoma of the pancreas in fine-needle aspiration biopsy specimens. Cancer 99(1): 44-50.

19. Fukushima N, Mukai K (1999) Pancreatic neoplasms with abundant mucus production: emphasis on intraductal papillary-mucinous tumors and mucinous cystic tumors. Adv Anat Pathol 6(2): 65-77.

20. Adsay NV, Conlon KC, Zee SY, Brennan MF, Klimstra DS (2002) Intraductal papillary-mucinousneoplasms of the pancreas: an analysis of in situ and invasive carcinomas in 28 patients. Cancer 94(1): 62-77.

21. Emerson RE, Randolph ML, Cramer HM (2006) Endoscopic ultrasound-guided fine-needle aspiration cytologydiagnosis of intraductal papillary mucinous neoplasm of the pancreas is highly predictive of pancreatic neoplasia. Diagn Cytopathol 34(7): 457462.

22. Stelow EB, Stanley MW, Bardales RH, Mallery S, Lai R, et al. (2003) Intraductal papillary-mucinous neoplasm of the pancreas. The findings and limitations of cytologic samples obtained by endoscopic ultrasound-guided fine-needle aspiration. Am J Clin Pathol 120(3): 398-404.

23. Fernandez-Esparrach G, Pellise M, Sole M, Soria MT, Miquel R, et al. (2007) EUS FNA in intraductal papillary mucinous tumors of the pancreas. Hepatogastroenterology 54(73): 260-264. 
24. Compagno J, Oertel JE (1978) Mucinous cystic neoplasms of the pancreas with overt and latent malignancy (cystadenocarcinoma andcystadenoma). A clinicopathologic study of 41 cases. Am J Clin Pathol 69(6): 573-580.

25. Gines A, Vazquez-Sequeiros E, Soria MT, Clain JE, Wiersema M (2002) Usefulness of EUS-guided fine needle aspiration (EUS-FNA) in the diagnosis of functioning neuroendocrine tumors. Gastrointest Endosc 56(2): 291-296.

26. Jhala D, Eloubeidi M, Chhieng DC, Frost A, Eltoum IA, et al. (2002) Fine needle aspiration biopsy of the islet cell tumor of pancreas: a comparison between computerized axial tomography and endoscopic ultrasound-guided fine needle aspiration biopsy. Ann Diagn Pathol 6(2): 106-112.

27. Chang F, Vu C, Chandra A, Meenan J, Herbert A (2006) Endoscopic ultrasound-guided fine needle aspiration cytology of pancreatic neuroendocrine tumours: cytomorphological and immunocytochemical evaluation. Cytopathology 17(1): 10-17.

28. Chatzipantelis P, Salla C, Konstantinou P, Karoumpalis I, Sakellariou S, et al. (2008) Endoscopic ultrasoundguided fine-needle aspiration cytology of pancreatic neuroendocrine tumors: a study of 48 cases. Cancer 114(4): 255-262.

29. Collins BT, Cramer HM (1996) Fine-needle aspiration cytology of islet cell tumors. Diagn Cytopathol 15(1): $37-45$.

30. Figueiredo FA, Giovannini M, Monges G, Charfi S, Bories E, et al. (2009) Pancreatic endocrine tumors: a large single-center experience. Pancreas 38(8): 936940.

31. Hasegawa Y, Ishida Y, Kato K, Ijiri R, Miyake T, et al. (2003) Pancreatoblastoma. A case report with special emphasis on squamoid corpuscles with optically clear nuclei rich in biotin. Acta Cytol 47(4): 679-684.

32. Henke AC, Kelley CM, Jensen CS, Timmerman TG (2001) Fine-needle aspiration cytology of pancreatoblastoma. Diagn Cytopathol 25(2): 118-121.

33. Silverman JF, Holbrook CT, Pories WJ, Kodroff MB, Joshi VV (1990) Fine needle aspiration cytology of pancreatoblastoma with immunocytochemical and ultrastructural studies. Acta Cytol 34(5): 632-640.
34. Akhtar M, Iqbal MA, Mourad W, Ali MA (1999) Fineneedle aspiration biopsy diagnosis of small round cell tumors of childhood: A comprehensive approach. Diagn Cytopathol 21(2): 81-91.

35. Caraway NP, Fanning CV, Amato RJ, Ordóñez NG, Katz RL (1993) Fine-needle aspiration of intra-abdominal desmoplastic small cell tumor. Diagn Cytopathol 9(4): 465-470.

36. Ferlicot S, Coue O, Gilbert E, Beuzeboc P, Servois V, et al. (2001) Intraabdominal desmoplastic small round cell tumor: report of a case with fine needle aspiration, cytologic diagnosis and molecular confirmation. Acta Cytol 45(4): 617-621.

37. Insabato L, Di Vizio D, Lambertini M, Bucci L, Pettinato G (1999) Fine needle aspiration cytology of desmoplastic small round cell tumor. A case report. Acta Cytol 43(4): 641-646.

38. Kaneishi NK, Howell LP, Russell LA, Vogt PJ, Lie JT (1995) Fine needle aspiration cytology of pulmonary Wegener's granulomatosis with biopsy correlation. A report of three cases. Acta Cytol 39(6): 1094-1100.

39. McCalmont TH, Silverman JF, Geisinger KR (1991) Cytologic diagnosis of aspergillosis in cardiac transplantation. Arch Surg 126(3): 394-396.

40. Roggli VL, Johnston WW, Kaminsky DB (1984) Asbestos bodies in fine needle aspirates of the lung. Acta Cytol 28(4): 493-498.

41. Khayyata S, Yun S, Pasha T, Jian B, McGrath C, et al. (2009) Value of P63 and CK5/6 in distinguishing squamous cell carcinoma from adenocarcinoma in lung fine-needle aspiration specimens. Diagn Cytopathol 37(3): 178-183.

42. Wu M, Wang B, Gil J, Sabo E, Miller L, et al. (2003) p63 and TTF-1 immunostaining. A useful marker panel for distinguishing small cell carcinoma of lung from poorly differentiated squamous cell carcinoma of lung. Am J Clin Pathol 119(5): 696-702.

43. Weisbrod L, Cunningham I, Tao LC, Chamberlain DW (1987) Small cell anaplastic carcinoma: cytologicalhistological correlations from percutaneous fineneedle aspiration biopsy. Can Assoc Radiol J 38(3): 204-208.

44. Nguyen GK, Gray JA, Wong EY, Crocket JA, McNamee C (2000) Cytodiagnosis of bronchogenic carcinoma and 
neuroendocrine tumor of the lung by transthoracic fine-needle aspiration. Diagn Cytopathol 23(6): 431434.

45. Collins BT, Cramer HM (1996) Fine needle aspiration cytology of carcinoid tumors. Acta Cytol 40(4): 695707.

46. Frierson HF, Covell JL, Mills SE (1987) Fine needle aspiration cytology of atypical carcinoid of the lung. Acta Cytol 31(4): 471-475.

47. Szyfelbein WM, Ross JS (1988) Carcinoids, atypical carcinoids, and small-cell carcinomas of the lung: differential diagnosis of fine needle aspiration biopsy specimens. Diagn Cytopathol 4(1): 1-8.

48. Nicholson SA, Ryan MR (2000) A review of cytologic findings in neuroendocrine carcinomas including carcinoid tumors with histologic correlation. Cancer 90(3): 148-161.

49. Mitchell ML, Parker FP (1991) Capillaries. A cytologic feature of pulmonary carcinoid tumours. Acta Cytol 35(2): 183-185.

50. Anderson C, Ludwig ME, O'Donnell M, Garcia N (1990) Fine needle aspiration cytology of pulmonary carcinoid tumours. Acta Cytol 34(4): 505-510.

51. Craig ID, Finley RJ (1982) Spindle-cell carcinoid tumour of lung. Cytologic, histopathologic and ultrastructural features. Acta Cytol 26(4): 495-498.

52. Fekete PS, Cohen C, DeRose PB (1990) Pulmonary spindle cell carcinoid. Needle aspiration biopsy, histologic and immunohistochemical findings. Acta Cytol 34(1): 50-56.

53. Pilotti S, Rilke F, Lombardi L (1983) Pulmonary carcinoid with glandular features. Report of two cases with positive fine needle aspiration biopsy cytology. Acta Cytol 27(5): 511-514.

54. Flint A, Lloyd R (1992) Pulmonary metastases of colonic carcinoma. Acta Cytol 36: 230-235.

55. Gomez-Fernandez C, Mejias A, Walker G, Nadji M (2010) Immunohistochemical expression of estrogen receptor in adenocarcinomas of the lung: the antibody factor. Appl Immunohistochem Mol Morphol 18(2): 137-141.
56. Zubovits J, Buzney E, Yu L, Duncan LM (2004) HMB45, S-100, NK1/C3, and MART-1 in metastatic melanoma. Hum Pathol 35(2): 217-223.

57. Wiatrowska BA, Yazdi HM, Matzinger FR, MacDonald LL (1995) Fine needle aspiration biopsy of pulmonary hamartomas. Radiologic, cytologic and immunocytochemical study of 15 cases. Acta Cytol 39(6): 1167-1174.

58. Wood B, Swarbrick N, Frost F (2008) Diagnosis of pulmonary hamartoma by fine needle biopsy. Acta Cytol 52(4): 412-417.

59. Cosgrove MM, Chandrasoma PT, Martin SE (1991) Diagnosis of pulmonary blastoma by fine-needle aspiration biopsy: cytologic and immunocytochemical findings. Diagn Cytopathol 7(1): 83-87.

60. Finley JL, Silverman JF, Dabbs DJ (1988) Fine needle aspiration cytology of pulmonary carcinosarcoma with immunocytochemical and ultrastructural observations. Diagn Cytopathol 4(3): 239-243.

61. Whitaker D, Shilkin KB, Sterrett GF (1992) Cytological appearances of malignant mesothelioma. Malignant mesothelioma, New York: Hemisphere, pp: 167-182.

62. Whitaker D, Sterrett GF, Shilkin KB (2003) Mesotheliomas. In: Gray W (Eds.), Diagnostic cytopathology. $2^{\text {nd }}$ (Edn.), Edinburgh: Churchill Livingstone.

63. Nguyen GK, Akin MR, Villanueva RR, Slatnik J (1999) Cytopathology of malignant mesothelioma of the pleura in fine-needle aspiration biopsy. Diagn Cytopathol 21(4): 253-259.

64. Yu GH, Soma L, Hahn S, Friedberg JS (2001) Changing clinical course of patients with malignant mesothelioma: implications for FNA cytology and utility of immunocytochemical staining. Diagn Cytopathol 24(5): 322-327.

65. Apple SK, Nieberg RK, Hirschowitz SL (1997) Fine needle aspiration biopsy of solitary fibrous tumor of the pleura. A report of two cases with a discussion of diagnostic pitfalls. Acta Cytol 41(5): 1528-1533.

66. Clayton AC, Salomao DR, Keeney GL, Nascimento AG (2001) Solitary fibrous tumor: a study of cytologic features of six cases diagnosed by fine-needle aspiration. Diagn Cytopathol 25(3): 172-176. 
67. Silverman JF, Berns LA, Holbrook CT, Neill JS, Joshi VV (1992) Fine needle aspiration cytology of primitive neuroectodermal tumors. A report of these cases. Acta Cytol 36(4): 541-550.

68. Folpe AL, Hill CE, Parham DM, O'Shea PA, Weiss SW (2000) Immunohistochemical detection of FLI-1 protein expression: A study of 132 round cell tumors with emphasis on CD99-positive mimics of Ewing's sarcoma/primitive neuroectodermal tumor. Am J Surg Pathol 24(12): 1657-1662.

69. Hummel P, Yang GC, Kumar A, Cohen JM, Winkler B, et al. (2001) PNET-like features of synovial sarcoma of the lung: a pitfall in the cytologic diagnosis of softtissue tumors. Diagn Cytopathol 24(4): 283-288.

70. Kim HS, Lee HJ, Cho SY, Koh JS, Ryoo BY, et al. (2007) Myasthenia gravis in ectopic thymoma presenting as pleural masses. Lung Cancer 57(1): 115-117.

71. Sterrett G, Whitaker D, Shilkin KB, Walters MN (1983) The Fine needle aspiration cytology of mediastinal lesions. Cancer 51(1): 127-135.

72. Finley JL, Silverman JF, Strausbauch PH, Dabbs DJ, West RL, et al. (1986) Malignant thymic neoplasms: diagnosis by fine-needle aspiration biopsy with histologic, immunocytochemical, and ultrastructural confirmation. Diagn Cytopathol 2(2): 118-125.

73. Kaw YT, Esparza AR (1993) Fine needle aspiration cytology of primary squamous cell carcinoma of the thymus. A case report. Acta Cytol 37(5): 735-739.

74. Posligua L, Ylagan L (2006) Fine-needle aspiration cytology of thymic basaloid carcinoma: case studies and review of the literature. Diagn Cytopathol 34(5): 358-366.

75. Kapila K, Pathan SK, Amir T, Joneja M, Hebbar S, et al. (2009) Mucoepidermoid thymic carcinoma: a challenging mediastinal aspirate. Diagn Cytopathol 37(6): 433-436.

76. Hoerl HD, Wojtowycz M, Gallagher HA, Kurtycz DF (2000) Cytologic diagnosis of true thymic hyperplasia by combined radiologic imaging and aspiration cytology: a case report including flow cytometric analysis. Diagn Cytopathol 23(6): 417-421.

77. Kardos TF, Vinson JH, Behm FG, Frable WJ, O'Dowd GJ (1986) Hodgkin's disease: diagnosis by fine-needle aspiration biopsy: analysis of cytologic criteria from a selected series. Am J Clin Pathol 869(3): 286-291.

78. Jacobs JC, Katz RL, Shabb N, el-Naggar A, Ordonez NG, et al. (1992) Fine needle aspiration of lymphoblastic lymphoma. A multiparameter diagnostic approach. Acta Cytol 36(6): 887-894.

79. Kardos TF, Sprague RI, Wakely PE Jr, Frable WJ (1987) Fine needle aspiration biopsy of lymphoblastic lymphoma and leukaemia. A clinical, cytologic and immunologic study. Cancer 60(10): 2448-2453.

80. Wakely PE Jr, Kornstein MJ (1996) Aspiration cytopathology of lymphoblastic lymphoma and leukemia: the MCV experience. Pediatr Pathol Lab Med 16(2): 243-252.

81. Silverman JF, Raab SS, Park HK (1993) Fine-needle aspiration cytology of primary large-cell lymphoma of the mediastinum: cytomorphologic findings with potential pitfalls in diagnosis. Diagn Cytopathol 9(2): 209-215.

82. Francis IM, Das DK, al-Rubah NA, Gupta SK (1994) Lymphoglandular bodies in lymphoid lesions and non-lymphoid round cell tumours: a quantitative assessment. Diagn Cytopathol 11(1): 23-27.

83. Meyer L, Gibbons D, Ashfaq R, Vuitch F, Saboorian MH (1999) Fine-needle aspiration findings in Castleman's disease. Diagn Cytopathol 21(1): 57-60.

84. Deschênes M, Michel RP, Tabah R, Auger M (2008) Fine-needle aspiration cytology of Castleman disease: case report with review of the literature. Diagn Cytopathol 36(12): 904-908.

85. Akhtar M, Al Dayel F (1997) Is it feasible to diagnose germ-cell tumours by fine-needle aspiration biopsy? Diagn Cytopathol 16(1): 72-77.

86. Harun MH, Yaacob I (1993) Congenital posterior mediastinal teratoma--a case report. Singapore Med J 34(6): 567-568.

87. Silverman JF, Olson PR, Dabbs DJ, Landreneau R (1999) Fine-needle aspiration cytology of a mediastinal seminoma associated with multilocular thymic cyst. Diagn Cytopathol 20(4): 224-228.

88. Dunsmore N, Sherman ME, ErozanYS (1991) Massive necrosis: a pitfall in the cytopathologic diagnosis of 
primary mediastinal seminoma. Diagn Cytopathol 7(3): 323-324.

89. Sangali G, Livraghi T, Giosano F, Tavani E, Schiaffino E (1986) Primary mediastinal embryonal carcinoma and choriocarcinoma. A case report. Acta Cytol 30(5): 543-546.

90. Sease WC, Elyanderani MK, Belis JA (1987) Ultrasonography and needle aspiration in diagnosis of xanthogranulomatous pyelonephritis. Urology 29(2): 231-235.

91. Bonzanini M, Pea M, Marignoni G, Zamboni G, Capelli $P$, et al. (1994) Preoperative diagnosis of renal angiomyolipoma: fine needle aspiration cytology and immunocytochemical characterization. Pathology 26(2): 170-175.

92. Tallada N, Martinez S, Raventos A (1994) Cytologic study of renal angiomyolipoma by fine-needle aspiration biopsy: report of four cases. Diagn Cytopathol 10(1): 37-40.

93. Wadih GE, Raab SS, Silverman JF (1995) Fine needle aspiration cytology of renal and retroperitoneal angiomyolipoma. Report of two cases with cytologic findings and clinicopathologic pitfalls in diagnosis. Acta Cytol 39(5): 945-950.

94. Crapanzano JP (2005) Fine-needle aspiration of renal angiomyolipoma: Cytological findings and diagnostic pitfalls in a series of five cases. Diagn Cytopathol 32(1): 53-57.

95. Granter SR, Perez-Atayde AR, Renshaw AA (1998) Cytologic analysis of papillary renal cell carcinoma. Cancer 84(5): 303-308.

96. Wang S, Filipowicz EA, Schnadig VJ (2001) Abundant intracytoplasmic hemosiderin in both histiocytes and neoplastic cells: a diagnostic pitfall in fine-needle aspiration of cystic papillary renal-cell carcinoma. Diagn Cytopathol 24(2): 82-85.

97. Assad L, Resetkova E, Oliveira VL, Wei S, John MS. et al. (2005) Cytologic features of renal medullary carcinoma. A Study of Three Cases. Cancer Cytopathol 105(1): 28-34.

98. Meyer PN, Clark JI, Flanigan RC, Picken MM (2007) Xp11.2 translocation renal cell carcinoma with very aggressive course in five adults. Am J Clin Pathol 128(1): 70-79.
99. Otani M, Shimizu T, Serizawa H, Nagashima Y (2006) Mucinous tubular and spindle cell carcinoma of the kidney. Report of a case with imprint cytology features. Acta Cytol 50(6): 680-682.

100. Hartwick RW, el-Naggar AK, Ro JY, Srigley JR, McLemore DD, et al. (1992) Renal oncocytoma and granular renal cell carcinoma. A comparative clinicopathologic and DNA flow cytometric study. Am J Clin Pathol 98(6): 587-593.

101. Nguyen GK, Amy RW, Tsang S (1985) Fine needle aspiration biopsy cytology of renal oncocytoma. Acta Cytol 29(1): 33-36.

102. Caputo V, Repetti ML, Bordoni U, Radice F (1996) Preoperative diagnosis of renal oncocytoma by fine needle aspiration (FNA). Cytopathology 7(5): 366371.

103. Hazarika D, Narasimhamurthy KN, Rao CR, Gopinath KS (1994) Fine needle aspiration cytology of Wilms' tumor. A study of 17 cases. Acta Cytol 38(3): 355-360.

104. Ellison DA, Silverman JF, Strausbauch PH, Wakely PE, Holbrook CT, et al. Role of immunocytochemistry, electron microscopy, and DNA analysis in fine-needle aspiration biopsy diagnosis of Wilms' tumor. Diagn Cytopathol 14(2): 101-107.

105. Li P, Perle MA, Scholes JV, Yang GC (2002) Wilm's tumor in adults: aspiration cytology and cytogenetics. Diagn Cytopathol 26(2): 99-103.

106. Nguyen GK, Schumann GB (1997) Needle aspiration cytology of low-grade transitional cell carcinoma of the renal pelvis. Diagn Cytopathol 16(5): 437-441.

107. Ho CC, Nguyen GK, Schumann GB (1998) Needle aspiration cytology of metastatic high-grade transitional-cell carcinomas of the urinary tract. Diagn

108. Geisinger KR, Silverman JF, Cappellari JO, Dabbs DJ (1990) Fine-needle aspiration cytology of malignant hemangiopericytomas with ultrastructural and flow

109. Barbaric ZL, MacIntosh PK (1981) Periureteral thinneedle aspiration biopsy. Urol Radiol 2(3): 181-185.

110. Collins KA, Geisinger KR, Wakely PE Jr, Silverman JF (1995) Extragonadal germ cell tumors: a fine-needle aspiration biopsy study. Diagn Cytopathol 12(3): 223229. 